\title{
Kähler Manifolds Positive Ricci Curvature
}

\author{
Boudjemaa Anchouche
}

\begin{abstract}
Department of Mathematics and Statistics, College of Science, Sultan Qaboos University,P.O.Box 36, PC 123, Al-Khodh, Muscat, Sultanate of Oman, Email: anchouch@squ,edu.om.
\end{abstract}

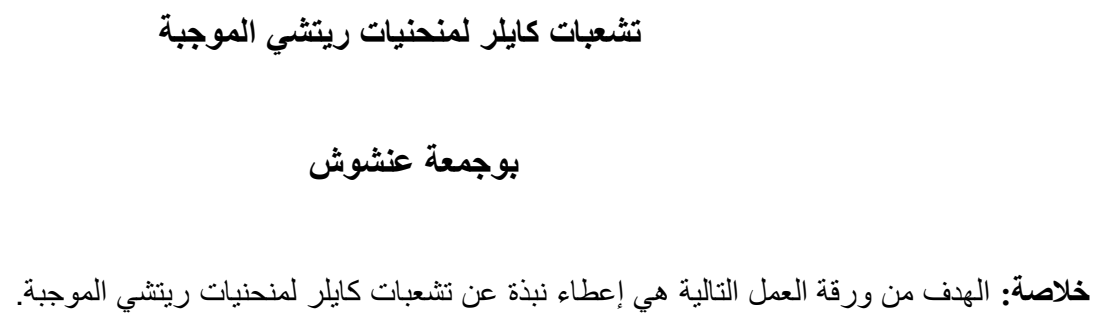

\begin{abstract}
The aim of this paper is to give an overview of some results obtained in the field of Kähler manifolds of positive Ricci curvature.
\end{abstract}

KEYWORDS: Kähler manifolds, positive Ricci curvature, kodaira dimension.

\section{Introduction}

D ifferential geometry is a cornerstone of modern mathematics. Besides the natural beauty of the subject, it has found many applications in various branches of mathematics such as number theory, analysis, topology, algebraic geometry and also in some areas of physics, ranging from general relativity to string theory.

Recently one of the most famous conjectures in topology, the Poincaré conjecture1, was solved by Perelman2, a Russian mathematician, using differential geometry, a work for which he was awarded the Fields medal at the International Congress of Mathematics in Spain, August 2006. An excellent account of Perelman's work is given by Morgan and Tian in 2007.

The aim of this paper is to give an overview of an active research area of differential geometry, namely Kähler manifolds of positive Ricci curvature.

Since most of the proofs are either omitted or sketched and since we have in mind a reader who is not necessarily an expert in the field, we made an effort to introduce most of the basic notions and definitions, and we included references whenever needed, so that he/she can fill the gaps and go through the details by himself/herself.

The paper is organized as follows. In Part 1 we collect some basic Riemannian geometry results mostly needed

1 The Poincaré conjecture states that every simply connected closed three dimensional manifold is homeomrphic to $S^{3}$, where $S^{3}$ is the three dimensional sphere.

2 Building on R. Hamilton's work on the Ricci flow. 


\section{BOUDJEMAA ANCHOUCHE}

in the following sections (readers with a background in Riemannian geometry can skip it). For the sake of completeness we included some results 3 in Riemannian geometry even though they are not needed in the following sections. The main reasons for doing that are; first we believe that they are fundamental results and therefore should be known, and secondly it makes a smooth transition to Kähler manifolds introduced in 2, since it gives a characterization of Kähler manifolds in terms of holonomy groups. Part 2 deals with Kähler manifolds. Part 3 deals with compact Kähler manifolds of positive Ricci curvature. Part 4 deals with Einstein-Kähler metrics on Fano manifolds. Part 5 deals with noncompact complete Kähler manifolds of positive Ricci curvature.

\subsection{Riemannian manifolds}

This part is a collection of some definitions and results from Riemannian geometry which will be needed in the following parts. The reason for including a section on holonomy groups, even though we don't need it in the following parts, is our belief that it is a fundamental concept in Riemannian geometry and therefore worth mentioning.

Some of the material covered in this part can be found in most differential geometry textbooks, such as Kobayashi and Nomizu, 1969, Aubin 2001 and Gallot and Hulin, 1990. For an account of the development of Riemannian geometry during the second half of the twentieth century, and its main contributors we suggest a book, recently published, by Marcel Berger(2000). We expect the reader to have some knowledge of general topology (Munkres, 1975) is an excellent reference). As we said in the introduction, readers with a background in Riemannian geometry can skip this part.

\subsection{Differentiable manifolds}

Definition 1. A locally Euclidean space $\mathrm{M}$ of dimension $n$ is a Hausdorff topological space that is locally Euclidean, i.e., each point of $\mathrm{M}$ has a neighborhood which is homeomorphic to an open subset of $\square^{n}$.

Definition 2. $A C^{\infty}$ (resp. real analytic) structure $\Psi$ on an $n$-dimensional locally Euclidean space $\mathrm{M}$ is a collection $\Psi=\left(U_{\alpha}, \varphi_{\alpha}\right)_{\alpha \in I}$ of pairs $\left(U_{\alpha}, \varphi_{\alpha}\right)$ such that

1. $\left(U_{\alpha}\right)_{\alpha \in I}$ are open sets of $M_{\text {satisfying }} \cup_{\alpha \in I} U_{\alpha}=M$.

2. $\varphi_{\alpha}: U_{\alpha} \longrightarrow V_{\alpha}$, are homeomorphisms, where $V_{\alpha}$ is an open subset of $R^{n}$.

3. $\varphi_{\alpha} \mathrm{o} \varphi_{\beta}^{-1}: \varphi_{\beta}\left(U_{\alpha} \cap U_{\beta}\right) \longrightarrow \varphi_{\alpha}\left(U_{\alpha} \cap U_{\beta}\right)$ is a $C^{\infty}-($ resp. real analytic) diffeomorphism.

4. The collection $\left(U_{\alpha}, \varphi_{\alpha}\right)_{\alpha \in I}$ is maximal with respect to 3 ., i.e., given any pair $(U, \varphi)$, where $U$ is an open subset of $M$ and $\varphi: U \longrightarrow V$ is a homeomorphism, where $V$ is some open subset of $R^{n}$, such that

$$
\varphi \circ \varphi_{\alpha}^{-1}: \varphi_{\alpha}\left(U \cap U_{\alpha}\right) \longrightarrow \varphi\left(U \cap U_{\alpha}\right),
$$

5. is a $C^{\infty}-$ (resp. real analytic) diffeomorphism for all $\alpha \in I$, then $(U, \varphi) \in \Psi$. The collection $\left(U_{i}, \varphi_{i}\right)_{i \in I}$ satisfying $1 ., 2$. and 3 . above is called a $C^{\infty}$-atlas.

Definition 3. $A C^{\infty}$ (resp. real analytic) manifold of dimension $n$ is a pair $(M, \Psi)$, where $M$ is a locally Euclidean space of dimension $n$ and $\Psi$ is a $C^{\infty}-$ (resp. real analytic) differentiable structure on $M$. The

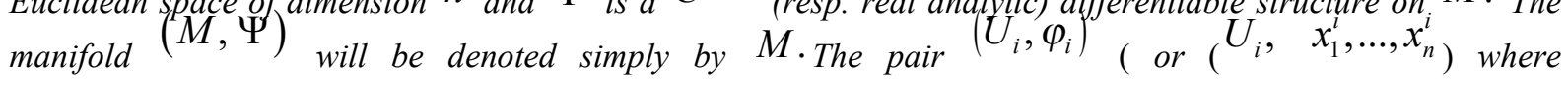




\section{KÄHLER MANIFOLDS POSITIVE RICCI CURVATURE}

$\left.\varphi_{i}=\left(x_{1}^{i}, \ldots, x_{n}^{i}\right)\right)$ is called a local chart and $\left(x_{1}^{i}, \ldots, x_{n}^{i}\right)$ is called a local coordinate system (defined in $U_{i}$ ) associated to $\varphi_{i}$. A manifold $M$ is said to be compact (resp. noncompact) if the underlying topological space is compact (resp. noncompact).

\section{Example 4.}

1. Every vector space has the structure of a $C^{\infty}$, noncompact manifold. In particular $\square^{n}$ has the structure of a $C^{\infty}$, noncompact manifold.

2. The unit sphere $S^{n}=\left\{\left(x_{1}, \ldots, x_{n+1}\right) \in R^{n+1} \mid \sum_{i=1}^{n+1} x_{i}^{2}=1\right\}$,

is a compact real analytic manifold.

3. The projective space ${ }^{\text {defined by }}$

$$
\mathrm{P}^{n}(\square):=\left(\square^{n+1},\{0\} \text { ù }\right) \sim,
$$

where

$$
\left(x_{0}, \ldots, x_{n}\right) \sim\left(y_{0}, \ldots, y_{n}\right) \Longleftrightarrow \exists \lambda \in \square^{*} \text { such that }\left(x_{0}, \ldots, x_{n}\right)=\lambda\left(y_{0}, \ldots, y_{n}\right),
$$

is a compact actually real analytic manifold.

4. An open subset of a $C^{\infty}-$ manifold is a $C^{\infty}-$ manifold.

5. The set of $\mathrm{p}^{\times \mathrm{q}}$ matrices with real entries $\mathrm{M}_{\mathrm{p}, \mathrm{q}}(\square)$ is a finite dimensional real vector space, hence $a$ $C^{\infty}-$ manifold.

6. If $\mathrm{M}_{1}$ and $\mathrm{M}_{2}$ are $C^{\infty}-$ manifolds, then $M_{1} \times M_{2}$ is a $C^{\infty}-{ }_{\text {manifold. }}$

\section{Notation 5.}

1. Let $U$ be an open subset of a manifold $\mathrm{M}$ and let $\mathrm{K}_{\text {be either }} \square$ or $\square$. In what follows we will denote by $C^{\infty}(U, \mathrm{~K})_{(\text {resp. }} C^{\infty}(U, \mathrm{~K})$ ) the set of infinitely differentiable (resp. $r$-times differentiable) functions on $U$ with values in $\mid$.

2. Sometimes we use the word "smooth" to mean of class $C^{\infty}$.

Definition 6. A Lie group $\mathrm{G}$ is a $C^{\infty}-$ manifold endowed with a group structure which is compatible with its differentiable structure, i.e. $\mathrm{G}$ is a group andithemap $\quad \mathrm{G}$

$$
(g, h) \quad \mapsto \quad v(g, h)=g h^{-1},
$$

is of class $C^{\infty}$.

Let $\mathrm{G}$ and $\mathrm{H}$ be two Lie groups. A map, or a $\underset{\varphi: \text { rphism }}{\longrightarrow} H$, is a differentiable map, which is a group homomorphism. 


\section{BOUDJEMAA ANCHOUCHE}

Example 7. The following are Lie groups.

1. Every finite dimensional real vector space with its underlying abelian group structure is a Lie group.

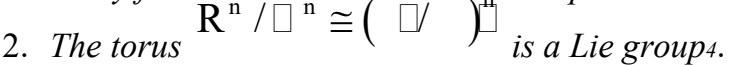

3. The linear group $\mathrm{GL}(\mathrm{n}, \square)$ is the set of all $n \times n$ invertible matrices with real entries.

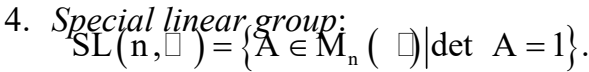

5. Orthogonal group: $\underset{\mathrm{n}, \square}{=}\left\{\mathrm{A} \in \mathrm{GL}(\mathrm{n}, \square) \mathrm{A}^{\top} \mathrm{A}=\mathrm{I}_{\mathrm{n}}\right\}$.

6. Special orthogonal group: $\operatorname{SO}(\mathrm{n}, \square)=\{\mathrm{A} \in \mathrm{O}(\mathrm{n}, \mathrm{det} \mathrm{A}=1\}$.

7. Unitary group:

$$
\mathrm{U}(\mathrm{n}) \stackrel{\text { notap: }}{=}\left\{\mathrm{A} \in \mathrm{GL}(\mathrm{n}, \square) \mathrm{A} * \mathrm{~A}=\mathrm{I}_{\mathrm{n}}\right\} \text {, }
$$

where $\mathrm{A}^{*}=\overline{\mathrm{A}}^{\top}$.

8. Special unitary group $\operatorname{SU}(\mathrm{n})=\{\mathrm{A} \in \mathrm{U}(\mathrm{n}) \mid \operatorname{det} \mathrm{A}=1\}$.

9. Simplectic group:

$$
\operatorname{Sp}(\mathrm{n}, \square) \underset{\mathrm{S}}{=}\left\{\mathrm{A} \in \mathrm{GL}(2 \mathrm{n}, \square) \mid \mathrm{A}^{\top} \mathrm{JA}=\mathrm{J}\right\}
$$

where

$$
J=\left(\begin{array}{cc}
O & I_{n} \\
-I_{n} & O
\end{array}\right)
$$

(10) If $\mathrm{G}$ and $\mathrm{H}$ are two Lie groups, then the direct product $\mathrm{G} \times \mathrm{H}$ has a structure of a Lie group.

(11) If $\mathrm{G}$ is a Lie group and $\mathrm{H}$ is a closed normal subgroup of $\mathrm{G}$, then $\mathrm{G} / \mathrm{H}$ has the structure of a Lie group.

Readers who want more examples and desire to know more about Lie groups, can consult (Warner,1983, Knapp, 2001, Brocker and Diek or Helgason, 1978).

Remark 8. In all that follows we will assume, without loss of generality, that manifolds are connected.

\section{Submanifolds}

Definition 9. Let $\mathrm{M}$ be a manifold of dimension $N$. A subset $N$ of $\mathrm{M}$ is a submanifold of dimension ${ }^{\mathrm{p}}$ if for every point $\mathrm{x} \in n$, there exists a local chart $(\mathrm{U}, \varphi)$, with $\mathrm{m} \in \mathrm{U}$ such that

(1) $\varphi(\mathrm{U}) \cong \mathrm{V}_{1} \times \mathrm{V}_{2}$, where $\mathrm{V}_{1}$ (resp. $\mathrm{V}_{2}$ ) is an open subset of $\square^{\mathrm{p}}$ (resp. $\square^{\mathrm{n}-\mathrm{p}}$ ).

(2) $\varphi(\mathrm{U} \cap \mathrm{N}) \cong \mathrm{V}_{1} \times\{0\}$.

The $\left.\left(\mathrm{x}_{1}, \ldots, \mathrm{x}_{n}\right)\right)$, above $\mathrm{x} \in \mathrm{U}$ be reformulated as follows: For each $\mathrm{x} \in n$, there exists a local chart $\varphi(U \cap N) \cong\left\{x \in U x_{j}(x)=0\right.$ for $\left.y=p+1, \ldots, n\right\}$.

4 The torus $\mathrm{R} / \mathrm{Z}^{n}$ is isomorphic to $\left(\mathrm{S}^{1}\right)^{n}$, where $\mathrm{S}^{1}=\{z \in \square\|\| z \|=1\}$. 


\section{KÄHLER MANIFOLDS POSITIVE RICCI CURVATURE}

Example 10. (1) $\mathrm{S}^{\mathrm{n}}=\left\{\left(\mathrm{x}_{1}, \ldots, \mathrm{x}_{\mathrm{n}+1}\right) \in \mathrm{R}^{\mathrm{n}+1} \mid \sum_{\mathrm{i}=1}^{\mathrm{n}+1} \mathrm{x}_{\mathrm{i}}^{2}=1\right\} \quad$ is a submani-fold of $\square^{\mathrm{n}+1}$.

(2) The set

$$
\mathrm{M}_{\mathrm{p}, \mathrm{q}}^{\mathrm{k}}(\square)=\left\{\mathrm{A} \in \mathrm{M}_{\mathrm{p} \cdot \mathrm{q}}(\square) \mid \text { rank } \mathrm{A}=\mathrm{k}\right\}
$$

is a submanifold of $\mathrm{M}_{\mathrm{p}, \mathrm{q}}(\square), \mathrm{U}_{\mathrm{I}<\mathrm{k}} \mathrm{M}_{\mathrm{p}, \mathrm{q}}^{\mathrm{I}}(\square)$.

(3) Let $\mathrm{G}$ be a Lie group and let $\mathrm{H}$ be an abstract subgroup of $\mathrm{G}$. It is well known that $\mathrm{H}$ is a submanifold of $\mathrm{G}$ (and hence a Lie group) $\Leftrightarrow \mathrm{H}$ is closed in $\mathrm{G}$.

\section{Tangent Bundle}

The aim of this section is to define the tangent bundle TM of a differentiable manifold $\mathrm{M}$. Let $\mathrm{m} \in \mathrm{M}$, and let $\mathrm{f}$ (resp. ${ }^{g}$ ) be a differentiable function defined in a neighborhood $\mathrm{U}$ (resp. $\mathrm{V}$ ) of $\mathrm{m}$. We say that $\mathrm{f}$ and $g$ are equivalent, and we write $\mathrm{f}<\mathrm{g}$, if there exists a neighborhood $\mathrm{W} \subset \mathrm{U} \cap \mathrm{V}, \mathrm{m} \in \mathrm{W}$, such that

$$
\mathrm{f} \equiv g \text { in } \mathrm{W}
$$

It is easy to see that $R$ is an equivalence relation. The equivalence class of a function $\mathrm{f}$ defined in a neighborhood of $\mathrm{m}$, called a germ of $\mathrm{f}$ at $\mathrm{m}$, will be denoted by $\mathrm{f}$. The set of germs at $\mathrm{m}$ will be denoted by $\mathrm{E}_{\mathrm{m}}$ It can be shown that $\mathrm{E}_{\mathrm{m}}$ is an $\square$ - algebra.

Definition 11. A tangent vector at $\mathrm{m} \in \mathrm{M}$ is linear map

$\mathrm{X}: \mathrm{E}_{\mathrm{m}}$,

satisfying

$$
X(\hat{f} . \hat{g})=\hat{f} X(\hat{g})+\hat{g} X(\hat{f})
$$

i.e., $\mathrm{X}$ is an $\square-$ derivation of the $\square-$ algebra $\mathrm{E}_{\mathrm{m}}$

Definition 12. (1) The set of tangent vectors to $\mathrm{M}$ at a point $\mathrm{m} \in \mathrm{M}$ is called the tangent space to $\mathrm{M}$ at $\mathrm{m}$ and is denoted by $\mathrm{T}_{\mathrm{m}} \mathrm{M}$.

(2) The dual of $\mathrm{T}_{\mathrm{m}} \mathrm{M}$, denoted by $\mathrm{T}_{\mathrm{m}}^{*} \mathrm{M}$, is called the cotangent space of $\mathrm{M}$ at $\mathrm{m}$.

(3) The disjoint union $\amalg_{\mathrm{m} \in \mathrm{M}} \mathrm{T}_{\mathrm{m}} \mathrm{M}$ (resp. $\amalg_{\mathrm{m} \in \mathrm{M}} \mathrm{T}_{\mathrm{m}}^{*} \mathrm{M}$ ), denoted $\mathrm{TM}$ (resp. $\mathrm{T}^{*} \mathrm{M}$ ), is called the tangent (resp. cotangent) bundle of $\mathrm{M}$.

\section{Vector bundles}

Definition 13. Let $\mathrm{M}$ be a $C^{\infty}$-differentiable manifold of dimension ${ }^{n}$. A vector bundLe of rank $\mathbf{r}$ is a differentiable manifold $\mathrm{E}$ together with:

(1) A surjective $C^{\infty}$-differentiable map $\pi: \mathrm{E} \rightarrow \mathrm{M}$, such that for every $\mathrm{x} \in \mathrm{M}, \mathrm{E}_{\mathrm{x}}=\pi^{-1}(\mathrm{X})$ has a structure of a real $\mathrm{r}$-dimensional vector space, where $\mathrm{r}$ is independent of $\mathrm{x}$.

(2) An open covering $\left(\mathrm{U}_{\alpha}\right)_{\alpha \in \mathrm{I}}$ of $\mathrm{M}$ and diffeomorphisms $\varphi_{\alpha}$ (called trivializations)

$$
\varphi_{\alpha}: \mathrm{E}_{\mathrm{U}_{\alpha}}=\pi^{-1}\left(\mathrm{U}_{\alpha}\right) \rightarrow \mathrm{U}_{\alpha} \times \square^{r}
$$

such that for each $\mathrm{x} \in \mathrm{U}_{\alpha}$, the map 


\section{BOUDJEMAA ANCHOUCHE}

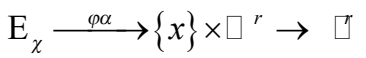

is $a \square$-linear isomorphism. The vector bundle is denoted by $(\mathrm{E}, \mathrm{M}, \pi)$ or simply by $\mathrm{E}$.

Let $\mathrm{U}_{\alpha}$ and $\mathrm{U}_{\beta}$ are two open subsets of $\mathrm{M}$ such that $\pi^{-1}\left(\mathrm{U}_{\mathrm{i}}\right) \stackrel{\cong}{\longrightarrow} \mathrm{U}_{\mathrm{i}} \times \square^{r}=\left\{\left(\mathrm{m}, \zeta_{1}^{i}, \ldots, \zeta_{1}^{i}\right) \mid \mathrm{m} \in \mathrm{U}_{i},\left(\zeta_{1}^{i}, \ldots, \zeta_{1}^{i}\right) \in \square\right\}, \mathrm{i}=\alpha, \beta$

For each couple $(\alpha, \beta)$, consideg the $\phi_{\beta}$ unctio $\bar{\alpha}_{\alpha} \mathrm{ns}_{\alpha} \cap \mathrm{U}_{\beta} \rightarrow \quad \mathrm{GL}(\mathrm{r})$

$$
x \mapsto g_{\alpha}^{\beta}(\mathrm{x})=\left(g_{\alpha, \mathrm{i}, \mathrm{k}}^{\beta}(\mathrm{x})\right)_{1 \leq \mathrm{i}, \mathrm{j} \leq r} .
$$

where $g_{\alpha, \mathrm{i}, \mathrm{k}}^{\beta} \in C^{\infty}\left(\mathrm{U}_{\alpha} \cap \mathrm{U}_{\beta}\right)$. For $\mathrm{m} \in \mathrm{U}_{\alpha} \cap \mathrm{U}_{\beta}$, the points $\left(\mathrm{m}_{1}, \zeta_{1}^{\alpha}, \ldots, \zeta_{r}^{\alpha}\right)$ and $\left(\mathrm{m}_{2}, \zeta_{1}^{\beta}, \ldots, \zeta_{r}^{\beta}\right)$ represent the same point on

$$
E_{\mid \pi^{-1}\left(\mathrm{U}_{\alpha} \cap \mathrm{U}_{\beta}\right)} \stackrel{\cong}{\longrightarrow}\left(\mathrm{U}_{\alpha} \cap \mathrm{U}_{\beta}\right) \times \square^{r},
$$

if and only if

$$
\mathrm{m}_{1}=\mathrm{m}_{2}=\mathrm{m} \text { and } \zeta_{\mathrm{i}}^{\beta}=\sum_{k=1}^{r} g_{\alpha}^{\beta}(\mathrm{m}) \zeta_{\mathrm{j}}^{\alpha}, \mathrm{i}=1, \ldots, \mathrm{r}
$$

Example 14. (1) If $\mathrm{M}$ is a differentiable manifold, then $\mathrm{M} \times \square^{r}$ is a vector bundle called the trivial bundle of rank $\mathbf{r}$.

(2) Let $\mathrm{M}$ be a differentiable manifold and consider the TpWbjextion gived by

$$
\mathrm{X} \mapsto \pi(\mathrm{x})=\mathrm{m} \text { if } \mathrm{X} \in \mathrm{T}_{\mathrm{m}} \mathrm{M}
$$

Then it can easily be seen that $(\mathrm{TM}, \mathrm{M}, \pi)$ is a vector bundle of rank $n=\operatorname{dim}_{\mathrm{R}} \mathrm{M}$. Similarly for $\mathrm{T} * \mathrm{M}$.

(3) A vector bundle of rank $r=1$ is called a line bundle.

(4) Since a vector bundle is a family of vector spaces of a given dimension parameterized by a $C^{\infty}$ - manifold $\mathrm{M}$, we can perform on vector bundles the same operations performed on vector spaces, such as the direct sum, the tensor product, the dualization, and so on.

Definition 15. A Lie aLgebra is vector space V[e]ndowed With Wbilinear map

$$
(\zeta, \eta) \mapsto[\zeta, \eta]
$$

called the Lie bracket, such that:

(1) $[\zeta, \eta]=-[\zeta, \eta]$ for all $\zeta, \eta \in \mathrm{V}$

(2) $[\zeta,[\eta, \gamma]]+[\gamma,[\zeta, \eta]]=0$ for all $\zeta, \eta \in \mathrm{V}$ (Jacobi Identity).

Let $\mathrm{G}$ be a Lie group. It can be shown that the tangent space $\mathrm{g}=\mathrm{T}_{\mathrm{e}} \mathrm{G}$ to $\mathrm{G}$ at the identity $\mathrm{e}$ has the structure of a Lie algebra and the tangent bundle $\mathrm{TG}_{\text {of }} \mathrm{G}$ is trivial, more precisely $\mathrm{TG} \cong \mathrm{G} \times \mathrm{g}$. 


\section{KÄHLER MANIFOLDS POSITIVE RICCI CURVATURE}

Definition 16. (1) A section s of the $C^{\infty}$-vector bundle $(\mathrm{E}, \mathrm{M}, \pi)$ over an (open) subset $\mathrm{U}$ of $\mathrm{M}$ is a $C^{\infty}{ }_{\text {-map }}$ $\mathrm{s}: \mathrm{U} \rightarrow \mathrm{E}$ such that $\pi \circ \mathrm{s}=\mathrm{id}_{\mathrm{U}}$.

The space of $C^{\infty}$-sections of $\mathrm{E}$ over $\mathrm{U}_{\text {is denoted by }} \Gamma(\mathrm{U}, \mathrm{E})$. If $\mathrm{U}=\mathrm{M}$, then we denote $\Gamma(\mathrm{U}, \mathrm{E})$ simply by $\Gamma(\mathrm{E})$

(2) A section of the vector bundle $\mathrm{TM}\left(\right.$ resp. $\left.\mathrm{T}^{*} \mathrm{M}\right)$ over an open set $\mathrm{U}$ of $\mathrm{M}$ is called a yector field (resp. a differential form) defined over $\mathrm{U}$. The space $C^{\infty}$-vector fields over $\mathrm{U}$ will be denoted by $\Gamma(\mathrm{U}, \mathrm{TM})$.

Let $\mathrm{M}$ be $C^{\infty}$ differentiable manifold of dimension $n, \mathrm{~m} \in \mathrm{M}$ and let $\left(\mathrm{x}_{1}, \ldots, \mathrm{x}_{\mathrm{n}}\right)$ be a local coordinate system defined in an open set $\mathrm{U}$, with $\mathrm{m} \in \mathrm{U}$. A $C^{\infty}$-vector field $\mathrm{X}$ over $\mathrm{U}$ may be written

$$
\mathrm{X}(\mathrm{x})=\sum_{\mathrm{i}=1}^{\mathrm{n}} \zeta_{\mathrm{i}}(\mathrm{x}) \frac{\partial}{\partial \mathrm{x}_{\mathrm{i}}}
$$

where $\zeta_{\mathrm{i}} \in C^{\infty}(\mathrm{U}, \square)$.

Definition 17. The differentiab $\mathrm{df}_{\mathrm{m}}$ of a function $\mathrm{f} \in C^{\mathrm{l}}(\mathrm{U}, \square)$ at $\mathrm{m} \in \mathrm{M}$ is a linear form on $\mathrm{T}_{\mathrm{m}} \mathrm{M}$ defined as follows: for each

$$
\mathrm{X}=\sum_{\mathrm{i}=1} \zeta_{\mathrm{i}} \frac{\partial}{\partial \mathrm{x}_{\mathrm{i}} \mid \mathrm{m}} \in \mathrm{T}_{\mathrm{m}} \mathrm{M}
$$

$$
\mathrm{df}_{\mathrm{m}}(\mathrm{X})=\mathrm{X}(\mathrm{f})(\mathrm{m})=\sum_{\mathrm{i}=1}^{n} \zeta_{\mathrm{i}} \frac{\partial \mathrm{f}}{\partial x_{\mathrm{i}}}(\mathrm{m})
$$

In particular, for $\mathrm{f}=\mathrm{x}_{\mathrm{i}}$, we have $\mathrm{d}\left(\mathrm{x}_{\mathrm{i}}\right)_{\mathrm{m}}(\mathrm{X})=\zeta_{\mathrm{i}}$. Hence we can write

$$
\mathrm{df}_{\mathrm{m}}=\sum_{\mathrm{i}=1}^{\mathrm{n}} \frac{\partial \mathrm{f}}{\partial \mathrm{x}_{\mathrm{i}}} \mathrm{dx}
$$

If $\left(\mathrm{x}_{1}, \ldots, \mathrm{x}_{\mathrm{n}}\right)$ is a local coordinate system defined in an open subset $\mathrm{U}$ of $\mathrm{M}$, with $\mathrm{m} \in \mathrm{U}$, then $\left(\frac{\partial}{\partial \mathrm{x}_{1}}, \ldots, \frac{\partial}{\partial \mathrm{x}_{\mathrm{n}}}\right)$ (resp. $\left(\frac{\left.\mathrm{dx}_{1}, \ldots, \mathrm{dx}_{\mathrm{n}}\right)}{\partial \mathrm{x}_{1}}, \ldots, \frac{\partial}{\partial \mathrm{x}_{\mathrm{n}}}\right)$ is a $C^{\infty}$-frame of $\mathrm{TM}\left(\right.$ resp. $\left.\mathrm{T}^{* \mathrm{M}}\right)$ over $\mathrm{U}$. The frame $\left(\mathrm{dx}_{1}, \ldots, \mathrm{dx}_{\mathrm{n}}\right)$ is the dual of the

$$
\mathrm{dx}_{\mathrm{i}}\left(\frac{\partial}{\partial \mathrm{x}_{\mathrm{j}}}\right)=\delta_{\mathrm{i}, \mathrm{j}}
$$

where $\delta_{\mathrm{i}, \mathrm{j}}$, is the Kronecker symbol.

Definition 18. Let $\mathrm{X}$ and $\mathrm{Y}$ be two vector fields defined in an open subset $\mathrm{U}$ of $\mathrm{M}$. The Lie bracket of $\mathrm{X}$ and $\mathrm{Y}$ is the vector field $[\mathrm{X}, \mathrm{Y}]$ defined by

$$
[X, Y](f)=X(Y(f))-Y(X(f))
$$

where $\mathrm{f} \in C^{2}(\mathrm{U}, \mathrm{TM})$. If $\left(\mathrm{U}, \mathrm{x}_{1}, \ldots, \mathrm{x}_{\mathrm{n}}\right)$ is a local chart with $\mathrm{m} \in \mathrm{U}$ and if 


\section{BOUDJEMAA ANCHOUCHE}

$$
\mathrm{X}=\sum_{\mathrm{i}=1}^{\mathrm{n}} \zeta_{\mathrm{i}} \frac{\partial}{\partial \mathrm{x}_{\mathrm{i}}} \text { and } Y=\sum_{\mathrm{i}=1}^{\mathrm{n}} \eta_{\mathrm{i}} \frac{\partial}{\partial \mathrm{x}_{\mathrm{i}}} \text { in } \mathrm{U}
$$

then

$$
[\mathrm{X}, \mathrm{Y}] \sum_{\mathrm{i}=1}^{\mathrm{n}}\left(\sum_{\mathrm{i}=1}^{\mathrm{n}} \zeta_{j} \frac{\partial \eta_{\mathrm{i}}}{\partial \mathrm{x}_{j}}-\eta_{j} \frac{\partial \zeta_{i}}{\partial \mathrm{x}_{j}}\right) \frac{\partial}{\partial \mathrm{x}_{i}}
$$

\section{Embeddings}

Definition 19. Let $\mathrm{M}$ and $\mathrm{N}$ be two $C^{\infty}$-manifolds. $A C^{\infty}$-map $\mathrm{f}: \mathrm{M} \rightarrow \mathrm{N}$ is a continuous map such that $\Psi_{\text {ofo } \varphi^{-}: \varphi(\dot{\mathrm{U}}) \rightarrow}^{\rightarrow} \Psi(\mathrm{V})$ is a $C^{\infty}-$ map for all charts $(U, \varphi)$ of $\mathrm{M}$ and $(\mathrm{V}, \Psi)$ of $N_{\text {such that }} \mathrm{U} \subset \varphi^{-1}(\mathrm{~V})$.

Definition 20. Let $\mathrm{M}$ and $N$ be two $C^{\infty}$-manifolds and $\mathrm{df}_{\mathrm{m}}: \mathrm{T}_{\mathrm{m}} \mathrm{M} \rightarrow \mathrm{T}_{\mathrm{f}(\mathrm{m})} \mathrm{N}, C^{\infty}{ }_{\text {-map. The differential is }}$ defined by

$$
\mathrm{df}_{\mathrm{m}}(\mathrm{X})(\hat{\mathrm{g}})=\mathrm{X}(\text { gof }),
$$

where $g$ is a function defined in a neighborhood of $\mathrm{f}(\mathrm{m})$ representing $\hat{g}$.

It can be proved that the definition is independent of the choice of a representative of ${ }^{\hat{g}}$. If we put $N=\square$ in Definition 20, then we get the differential of a function which was already defined in Definition 17.

Definition 21. Let $\mathrm{M}$ and $N$ be two $C^{\infty}$-manifolds and $\mathrm{f}: \mathrm{M} \rightarrow N_{a} C^{\infty}{ }_{-m a p}$.

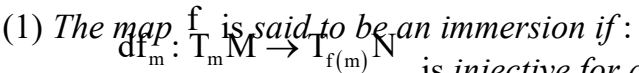

$$
\text { is injective for all } \mathrm{m} \in \mathrm{M} \text {. }
$$

(2) The map $\mathrm{f}$ is said to be an embedding if:

(a) $\mathrm{f}$ is an injective immersion,

and

(b) $\mathrm{f}$ is a homeomorphism between $\mathrm{M}$ and $\mathrm{f}(\mathrm{M})$, where $\mathrm{f}(\mathrm{M})$ is endowed with the induced topology of $N$.

\section{Isomorphism of Vector Bundles}

Definition 22. Let $\mathrm{E}$ and $\mathrm{F}$ be two vector bundles over a differentiable manifold $M$. A map between the vector bundles $\mathrm{E}$ and $\mathrm{F}$ is a $C^{\infty}$ map

$$
v: \mathrm{E} \rightarrow \mathrm{F},
$$

such that:
(1) $v\left(\mathrm{E}_{\mathrm{x}}\right) \subseteq \mathrm{F}_{\mathrm{x}}$, for all $\mathrm{x} \in \mathrm{M}$
and $v_{\mathrm{x}}=v_{\mid \mathrm{E}_{\mathrm{x}}}: \mathrm{E}_{\mathrm{x}} \rightarrow \mathrm{F}_{\mathrm{x}}$ is linear for all $\mathrm{x} \in \mathrm{M}$.

The vector bundles $\mathrm{E}$ and $\mathrm{F}$ are said to be isomorphic if there exists a map $v: \mathrm{E} \rightarrow \mathrm{F}$ such that $v_{\mathrm{x}}: \mathrm{E}_{\mathrm{x}} \rightarrow \mathrm{F}_{\mathrm{x}}$ is an ismorphism for all $\mathrm{x} \in \mathrm{M}$. We denote this by $\mathrm{E} \cong \mathrm{F}$.

A vector bundle (resp. a complex vector bundle) $\mathrm{E}$ over $\mathrm{M}$ is said to be a trivial bundle if 


\section{KÄHLER MANIFOLDS POSITIVE RICCI CURVATURE}

\section{Pull-Back of Vector Bundles}

Definition 23. Let be a $C^{\infty}$-map between two $C^{\infty}$ manifolds $\mathrm{M}$ and $\mathrm{N}$ and $\mathrm{E}$ a vector bundle over $\mathrm{N}$. The pull-back bundle $\mathrm{f*} \mathrm{E}$ is a vector bundle over $\mathrm{M}$ defined by

$$
(\mathrm{f} * \mathrm{E})_{\mathrm{m}}=\mathrm{E}_{\mathrm{f}(\mathrm{m})} \text { for all } \mathrm{m} \in \mathrm{M} \text {. }
$$

The transition functions of $f^{*} \mathrm{E}$ are given by the pull-back of the transition functions of $\mathrm{E}$. Hermitian Metrics on Vector Bundles

Definition 24. $A C^{\infty}$-frame over an open subset $\mathrm{U}$ of $\mathrm{M}$ is an $\mathrm{r}$-tuple $\left(\sigma_{1}, \ldots, \sigma_{r}\right)$, where such $\sigma_{i} \in \Gamma(\mathrm{U}, \mathrm{E})$, such that $\left(\sigma_{1}(\mathrm{x}), \ldots, \sigma_{r}(x)\right)$ is a basis for $\mathrm{E}_{\mathrm{x}}$ for all $\mathrm{x} \in \mathrm{U}$.

Let $\mathrm{U}$ be an open subset of $\mathrm{M}$ such that

$$
\varphi: \mathrm{E}_{\mid \mathrm{U}}=\pi^{-1}(\mathrm{U}) \stackrel{\sim}{\rightarrow} \mathrm{U} \times \varphi^{r},
$$

and let $\left(\mathrm{e}_{i}\right)_{1 \leq i \leq r}$ be the canonical basis of $\square^{r}$ To the trivialization $\varphi$, we associate the $C^{\infty}$-frame $\left(\tilde{\mathrm{e}}_{i}\right)_{1 \leq i \leq r}$ of $\mathrm{E}_{\mid \mathrm{U}}$, where $\tilde{\mathrm{e}}_{i}$ is defined by

$$
\tilde{\mathrm{e}}_{i}(\mathrm{x}):=\varphi^{-1}\left(\mathrm{x}, \mathrm{e}_{i}\right) \mathrm{x} \in \mathrm{U}
$$

Then any section $\mathrm{s} \in \Gamma(\mathrm{U}, \mathrm{E})$ can be written as

$$
\mathrm{s}(\mathrm{x})=\sum_{i=1}^{r} a_{i}(\mathrm{x}) \tilde{\mathrm{e}}_{i}(\mathrm{x})
$$

with $\mathrm{a}_{i} \in C^{\infty}(\mathrm{U}, \mathrm{R})$. Conversely, to $C^{\infty}-$ frame $\left(\sigma_{1}, \ldots, \sigma_{r}\right), \sigma_{i} \in \Gamma(\mathrm{U}, \mathrm{E})$ we can associate a trivialization of $\mathrm{E}$ over $\mathrm{U}$ as follows

$$
\begin{aligned}
\varphi: \mathrm{E}_{\mid \mathrm{U}} & \rightarrow \mathrm{U} \times \square^{r} \\
& \mapsto\left(\mathrm{x},\left(\mathrm{a}_{1}, \ldots ., \mathrm{a}_{r}\right)\right)
\end{aligned}
$$

where $\left(\mathrm{a}_{1}, \ldots, \mathrm{a}_{r}\right)$ are defined as follows:

$$
\sigma(\mathrm{x})=\sum_{i=1}^{r} \mathrm{a}_{i} \sigma_{i}(\mathrm{x})
$$

The definition of a $C^{\infty}-$ frame for a complex vector bundle is obvious and is left to the reader.

Definition 25. Let $\mathrm{E}$ be $C^{\infty}$ - complex vector bundle of rank $\mathrm{r}$ over a $C^{\infty}$ manifold $\mathrm{M}$ of dimension ${ }^{n}$. A Hermitian metric $\mathrm{h}$ on $\mathrm{E}$ is a family $\left(\mathrm{h}_{x}\right)_{\mathrm{x} \in \mathrm{M}}$, where $\mathrm{h}_{x}$, is a Hermitian inner product on $\mathrm{E}_{x}$, such that if $\left(\tilde{\mathrm{e}}_{i}\right)_{1 \leq i \leq \mathrm{r}} \in C^{\infty}(U, \mathrm{C})$ is a $C^{\infty}$-frame for the complex vector bundle $\mathrm{E}$ defined in an open set $\mathrm{U}$, then, the functions

$$
\begin{aligned}
\mathrm{h}_{\mathrm{i}, \mathrm{j}}: \mathrm{U} & \rightarrow \square \\
\mathrm{x} & \mapsto \mathrm{h}_{\mathrm{x}}\left(\tilde{\mathrm{e}}_{\mathrm{i}}(x), \tilde{\mathrm{e}}_{\mathrm{j}}(x)\right),
\end{aligned}
$$

are smooth, i.e., $\mathrm{h}_{\mathrm{i}, \mathrm{j}}: \in C^{\infty}(\mathrm{U}, \mathrm{C})$ for all $\mathrm{i}, \mathrm{j}=1, \ldots, \mathrm{r}$. 


\section{BOUDJEMAA ANCHOUCHE}

\section{Tensor and differential forms}

In this section we will assume some knowledge of the properties of tensor and exterior algebras. Let $\mathrm{M}$ be a differentiable manifold of dimension $n$ and consider the following vector bundles

$$
\begin{gathered}
\mathrm{T}_{\mathrm{p}, \mathrm{q}} \mathrm{M}:=\mathrm{t}_{\mathrm{m} \in \mathrm{M}}\left(\left(\mathrm{T}_{\mathrm{m}} \mathrm{M}\right)_{\mathrm{p}, \mathrm{q}}\right), \\
A^{p}(\mathrm{M}):=\mathrm{t} \underset{\mathrm{m} \in \mathrm{M}}{ }\left(\wedge^{\mathrm{p}}\left(\mathrm{T}_{\mathrm{m}}^{*} \mathrm{M}\right)\right), \\
A(\mathrm{M}):=\mathrm{t} \underset{\mathrm{m} \in \mathrm{M}}{ }\left({\left.\underset{\mathrm{p}=0}{\infty} \wedge^{\mathrm{p}}\left(\mathrm{T}_{\mathrm{m}}^{*} \mathrm{M}\right)\right),}^{\infty},\right.
\end{gathered}
$$

where

$$
\left(T_{m} M\right)_{p, q}=\overbrace{T_{m} M \otimes . . \otimes T_{m} M}^{\text {p-times }} \otimes \overbrace{T_{m}^{*} M \otimes . . \otimes T_{m}^{*} M}^{\text {q-times }}
$$

and

$$
\wedge^{\mathrm{p}}\left(\mathrm{T}_{\mathrm{m}}^{*} \mathrm{M}\right)=\overbrace{\mathrm{T}_{\mathrm{m}}^{*} \mathrm{M} \wedge \ldots \wedge \mathrm{T}_{\mathrm{m}}^{*} \mathrm{M}}^{\mathrm{p} \text {-times }} .
$$

Definition 26. (1) The vector bundle $\mathrm{T}_{\mathrm{p}, \mathrm{q}}(\mathrm{M})$ (resp., $A^{p}(\mathrm{M}), A(\mathrm{M})$ ) is called the tensor bundle of type $(p, q)$ (resp., the exterior p-bundle, exterior algebra bundle) over $\mathrm{M}$

(2) $A^{C^{\infty}-}$ section of the vector bundle $\mathrm{T}_{\mathrm{p}, \mathrm{q}}(\mathrm{M})_{(\text {resp. }}{ }^{p}(\mathrm{M}), A(\mathrm{M})$ ) is called a smooth tensor field of type $(p, q)$ (resp. a smooth differential ${ }^{p-}$ form, a smooth differential form) on $\mathrm{M}$.

The set of all smooth sections of $\mathrm{T}_{\mathrm{p}, \mathrm{q}}(\mathrm{M})$ (resp., $A^{p}(\mathrm{M}), A(\mathrm{M})$ ) will be denoted by $\mathrm{T}_{\mathrm{p}, \mathrm{q}}(\mathrm{M})$ (resp.,

$\left.\varepsilon^{p}(\mathrm{M}), \varepsilon(\mathrm{M})\right)$.
If $\left(\mathrm{x}_{1}, \ldots, \mathrm{x}_{n}\right)$ is a local coordinate system defined in an open subset $\mathrm{U}$ of $\mathrm{M}$, with $\mathrm{m} \in \mathrm{U},\left\{\frac{\partial}{\partial \mathrm{x}_{i}}\right\}_{i=1}^{\mathrm{n}}$ (resp. $\left\{\mathrm{dx}_{i}\right\}_{i=1}^{\mathrm{n}}$ ) is a $C^{\infty}-$ frame for $\mathrm{TM}\left(\right.$ resp. $_{\mathrm{m}} \mathrm{T}^{*} \mathrm{M}$ ) over $\mathrm{U}$.

Therefore we get $C^{\infty}-$ frames for $(\mathrm{TM})_{p, q}, \wedge^{\mathrm{p}}\left(\mathrm{T}^{*} \mathrm{M}\right)$ and $\otimes_{\mathrm{p}=0}^{\infty} \wedge^{\mathrm{p}}\left(\mathrm{T}^{*} \mathrm{M}\right)$ over $\mathrm{U}$.

For example, a differential
$\mathrm{p}-$ form $\omega$ in $\mathrm{U}$ will be written
\[ \omega(\mathrm{x})=\sum_{1 \leq \mathrm{i}_{1}<\ldots<\mathrm{i}_{p} \leq \mathrm{n}} a_{\mathrm{i}_{1}}, \ldots, \mathrm{i}_{p}(\mathrm{x}) \mathrm{dx}_{i_{1}} \wedge \ldots \wedge d \mathrm{x}_{i_{p}}, \]

where ${ }^{a_{\mathrm{i}_{1}}, \ldots, \mathrm{i}_{p}}$ are $C^{\infty}-$ functions in $\mathrm{U}$.

Definition 27. Let (resp. ${ }^{\beta}$ ) be a ${ }^{\mathrm{p}-}$ form (resp. ${ }^{\mathrm{q}-}$ form). The exterior product of $\alpha$ and $\beta$, denoted by $\alpha \wedge \beta$, is $a^{(\mathrm{p}+\mathrm{q})}$-form defined by

$$
-\left(\begin{array}{l}
\text { orm defined by } \\
\alpha \wedge \beta)\left(\xi_{1}, \ldots, \xi_{\mathrm{p}+\mathrm{q}}\right.
\end{array}\right):=\frac{1}{\mathrm{pq}} \sum_{\sigma \in s_{\mathrm{p}+\mathrm{q}}} \varepsilon(\sigma) \alpha\left(\xi_{\sigma(1)}, \ldots, \xi_{\sigma(\mathrm{p})}\right) \beta\left(\xi_{\sigma(\mathrm{p}+1)}, \ldots, \xi_{\sigma(\mathrm{p}+\mathrm{q})}\right)
$$

where $\xi_{1}, \ldots, \xi_{\mathrm{p}+\mathrm{q}}$ are $\mathrm{p}+\mathrm{q}$ vector fields, $S_{\mathrm{p}+\mathrm{q}}$ is the group of permutations of the set $\{1, \ldots, \mathrm{p}+\mathrm{q}\}$ and $\varepsilon(\sigma)$ is the signature of the permutation $\sigma$. 


\section{KÄHLER MANIFOLDS POSITIVE RICCI CURVATURE}

The exterior product is associative and satisfies

$$
\alpha \wedge \beta=(-1)^{\mathrm{pq}} \beta \wedge \alpha \text { for } \alpha \in \varepsilon^{\mathrm{p}}(\mathrm{M}) \text { and } \beta \in \varepsilon^{\mathrm{q}}(\mathrm{M}) \text {. }
$$

Theorem 28. There exists a unique operator

$$
\mathrm{d}: \varepsilon(\mathrm{M}) \rightarrow \varepsilon(\mathrm{M})
$$

(1) $d \varepsilon^{\mathrm{p}}(\mathrm{M}) \subset \varepsilon^{\mathrm{p}+1}(\mathrm{M})$

(2) $\mathrm{d}(\alpha \wedge \beta)=\mathrm{d} \alpha \wedge \beta+(-1)^{\mathrm{p}} \alpha \wedge \mathrm{d} \beta, \alpha \in \varepsilon^{\mathrm{p}}(\mathrm{M}), \beta \in \varepsilon(\mathrm{M})$.

(3) $\mathrm{d} \circ \mathrm{d}=0$

(4) If $\mathrm{f} \in C^{\infty}$, then $\mathrm{df}$ is the differential of $\mathrm{p}_{\mathrm{f}_{1}} \quad{ }^{i}$

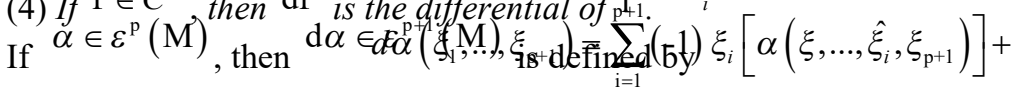

$$
\sum_{1 \leq \mathrm{j} \leq \mathrm{p}+1}^{\mathrm{p}+1}(-1) \alpha\left(\left[\xi_{i}, \xi_{j}\right], \xi_{1}, \ldots, \hat{\xi}_{i}, \ldots, \hat{\xi}_{j}, \ldots, \xi_{\mathrm{p}+1}\right)
$$

where $\hat{\xi}_{1}, \ldots, \xi_{\mathrm{p}+1}$ are vector fields and $\hat{\xi}_{i}$ means that the vector field $\xi_{i}$ is omitted.

\section{Riemannian manifolds}

Definition 29. A Riemannian metric on a $C^{\infty}$ differentiable manifold $M$ is a tensor field $g$ of type $(0,2)$, i.e., $\mathrm{g} \in \mathrm{T}_{0}, 2(\mathrm{M})$, such that at each $\mathrm{m} \in \mathrm{M}, \mathrm{g}_{\mathrm{m}}$ is a positive definite symmetric bilinear form, i. $e$., $\operatorname{gm}(\mathrm{X}, \mathrm{X})>0$, for all $\mathrm{X} \in \mathrm{T}_{\mathrm{m}} \mathrm{MA} \hat{\mathrm{A}}\{0\}$, $\operatorname{gm}(\mathrm{X}, \mathrm{Y})=\operatorname{gm}(\mathrm{Y}, \mathrm{X})$ for all $\mathrm{X}, \mathrm{Y} \in \mathrm{T}_{\mathrm{m}} \mathrm{M}$

Definition 30. A Riemannian manifold is a pair $(\mathrm{M}, \mathrm{g})$, where $\mathrm{M}$ is a $C^{\infty}$ differentiable manifold and $g$ is a Riemannian metric.

Let $\mathrm{X}$ and $\mathrm{Y}$ be two elements of $\mathrm{T}_{\mathrm{m}} \mathrm{M}$, and let $\left(\mathrm{x}_{1}, \ldots, \mathrm{x}_{\mathrm{n}}\right)$ dbe a local coprdinate system defined in an open subset $\mathrm{U}$ of $\mathrm{M}$, with $\mathrm{m} \in \mathrm{U}$, and suppose that $\mathrm{X}=\sum_{\mathrm{i}=1}^{\mathrm{n}} \xi \frac{\partial}{\partial \mathrm{x}_{i} \mid \mathrm{m}}$ and $\mathrm{Y}=\sum_{\mathrm{i}=1}^{\mathrm{h}} \xi_{i} \frac{\mathrm{x}_{i} \mid \mathrm{m}}{\partial \mathrm{x}_{i}}$ Then

$$
\operatorname{gm}(\mathrm{X}, \mathrm{Y})=\sum_{\mathrm{i}, \mathrm{j}=1}^{\mathrm{n}} \mathrm{g}_{\mathrm{ij}}(\mathrm{m}) \xi_{i} \zeta_{j}
$$

where

$$
\mathrm{g}_{\mathrm{i}, \mathrm{j}}(\mathrm{m})=\mathrm{g}_{\mathrm{m}}\left(\frac{\partial}{\partial \mathrm{x}_{i} \mid \mathrm{m}}, \frac{\partial}{\partial \mathrm{x}_{j} \mid \mathrm{m}}\right)
$$

We write

$$
\mathrm{g}=\sum_{\mathrm{i}, \mathrm{j}=1}^{\mathrm{n}} \mathrm{g}_{\mathrm{i}, \mathrm{j}} \mathrm{dx} \mathrm{x}_{i} \otimes d \mathrm{x}_{j}
$$




\section{BOUDJEMAA ANCHOUCHE}

Let $(\mathrm{M}, \mathrm{g})$ be a Riemannian manifold. Using the metric $\mathrm{g}$, it is possible to compute the length of any curve on $\mathrm{M}$ joining any two points $\mathrm{x}$ and ${ }^{y}$ of $\mathrm{M}$.

Definition 31. Let $(\mathrm{M}, \mathrm{g})$ and $(\mathrm{N}, \mathrm{h})$ be two Riemannian manifolds. $A C^{\infty}-$ map

$$
\mathrm{f}: \mathrm{M} \rightarrow \mathrm{N}
$$

is said to be an isometry if $\mathrm{f}$ is a $C^{\infty}$-diffeomorphism and if for every $\mathrm{m} \in \mathrm{M}$, and for every $\xi, \eta \in \mathrm{T}_{\mathrm{m}} \mathrm{M}$, we have

$$
\mathrm{h}_{\mathrm{f}(\mathrm{m})}\left(\mathrm{df}_{\mathrm{m}}(\xi), \mathrm{df}_{\mathrm{m}}(\eta)\right)=\mathrm{gm}(\xi, \eta)
$$

We write

$$
g=f * h
$$

Example 32. (1) Since the tangent bundle of $\square^{\mathrm{n}}$ is trivial, i. e., $\mathrm{T}^{\mathrm{n}} \cong \square^{\mathrm{n}} \times{ }^{\mathrm{n}}$, the Euclidean metric on $\square^{\mathrm{n}}$ denoted by $\mathrm{g}_{\mathrm{ec}}$ is defined by $\left(\mathrm{m}_{1}, \mathrm{v}_{1}\right),\left(\mathrm{m}_{1}, \mathrm{v}_{1}\right) \in \mathrm{T} \square{ }^{\mathrm{T}}$

$$
\mathrm{g}_{\mathrm{ec}}\left(\left(\mathrm{m}_{1}, \mathrm{v}_{1}\right) \cdot\left(\mathrm{m}_{1}, \mathrm{v}_{2}\right)\right)=\mathrm{v}_{1} \cdot \mathrm{v}_{2} \text {. }
$$

(2) Consider the unit sphere

$$
\mathrm{S}^{\mathrm{n}}=\left\{\left(\mathrm{x}_{1}, \ldots, \mathrm{x}_{\mathrm{n}+1}\right) \in \square^{\mathrm{n}+1} \mid \mathrm{x}_{1}^{2}+\ldots+\mathrm{x}_{\mathrm{n}+1}^{2}=1\right\}
$$

The Euclidean metric on $\square^{\mathrm{n}+1}$ induces a metric on $\mathrm{S}^{\mathrm{n}}$, i.e., if $\mathrm{S}^{\mathrm{n}} \stackrel{i}{\longrightarrow} \square^{\mathrm{n}+1}$

is the obvious embedding of $\mathrm{S}^{\mathrm{n}}$ in $\square^{\mathrm{n}+1}$, then $\mathrm{g}_{\mathrm{Sn}}=\mathrm{i}^{*} \mathrm{~g}_{\mathrm{ec}}$ is the "canonical" metric on $\mathrm{S}^{\mathrm{n}}$, where $\mathrm{g}_{\mathrm{ec}}$ is the Euclidean metric on $\square^{\mathrm{n}+1}$.

(3) Let

$$
\mathrm{D}^{\mathrm{n}}=\left\{\mathrm{x}=\left(\mathrm{x}_{1}, \ldots, \mathrm{x}_{\mathrm{n}}\right) \in \square^{\mathrm{n}}\|\mathrm{x}\|^{2}=\mathrm{x}_{1}^{2}+\ldots+\mathrm{x}_{\mathrm{n}}^{2}<1\right\}
$$

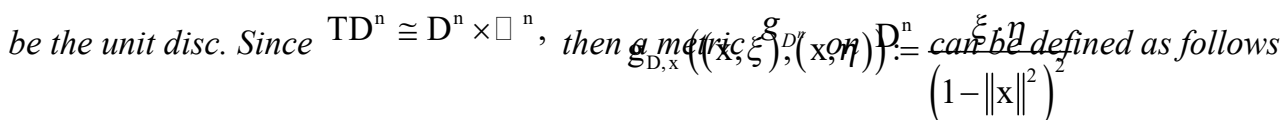

(4) Every compact connected Lie group admits a bi-invariant metric, i.e., a metric for which left and right translations are isometries. For details see (Gallot and Hulin, 1990).

\section{Partition of unity}

The aim of this section is to introduce a very powerful tool called" partition of unity" which allows one to construct global objects such as metrics, differential forms, vector fields,..., by gluing local ones. Partition of unity plays also a fundamental role in the definition of integration on manifolds.

Definition 33. Let $\mathrm{M}$ be a $C^{\infty}$-manifold and let ${ }^{\left(\mathrm{U}_{i}\right)_{\mathrm{i} \in \mathrm{I}}}$ be a covering of $\mathrm{M} . A^{C^{\infty}}$ - partition of unity subordinate to the covering $\left(\mathrm{U}_{i}\right)_{\mathrm{i} \in \mathrm{I}}$ is a collection of maps $\left(\theta_{i}\right)_{\mathrm{i} \in \mathrm{I}}$, where ${ }^{\theta_{i} \in C^{\infty}(\mathrm{M}, \square)}$ satisfying:

(1) $\operatorname{supp}\left(\theta_{i}\right) \subseteq \mathrm{U}_{i}$ for all $\mathrm{i} \in \mathrm{I}$, where supp $\left(\varphi_{i}\right)=\overline{\left\{\mathrm{x} \in \mathrm{M} \mid \varphi_{\mathrm{i}}(\mathrm{x}) \neq 0\right\}}$.

$\theta_{i}\left(\mathrm{U}_{i}\right) \subseteq[0,1]$ for all $\mathrm{i} \in \mathrm{I}$ 


\section{KÄHLER MANIFOLDS POSITIVE RICCI CURVATURE}

(3) For every $\mathrm{x} \in \mathrm{M}$, there exists an open subset $\mathrm{V}_{\mathrm{x}}, \mathrm{x} \in \mathrm{V}_{\mathrm{x}}$ such that $\theta_{\mathrm{i}} \mathrm{V}_{\mathrm{V}_{\mathrm{x}}} \equiv 0$ except for a finite set of $\theta_{i}$.

(4) For every $\mathrm{x} \in \mathrm{M}, \sum_{\mathrm{i} \in \mathrm{I}} \theta_{i}(\mathrm{x})=1$ ((3). implies that the sum is finite).

Definition 34. A Hausdorff space $\mathrm{M}$ is said to be paracompact if every open covering $\left\{\mathrm{U}_{i}\right\}_{i \in \mathrm{I}}$ of $\mathrm{M}$ there exists an open covering $\left\{\mathrm{V}_{\mathrm{j}}\right\}_{\mathrm{j} \in \mathrm{J}}$ of $\mathrm{M}_{\text {such that: }}$

(1) For every $\mathrm{j} \in \mathrm{J}$, there exists $\mathrm{i}_{\mathrm{j}} \in \mathrm{I}$ such that $\mathrm{V}_{j} \subset \mathrm{U}_{\mathrm{i}_{\mathrm{j}}}$ (we say that $\left\{\mathrm{V}_{\mathrm{j}}\right\}_{\mathrm{j} \in \mathrm{J}}$ is a refinement of $\left\{\mathrm{U}_{\mathrm{i}}\right\}_{\mathrm{i} \in \mathrm{I}}$ ).

(2) Each point $\mathrm{m} \in \mathrm{M}$ has a neighborhood $\mathrm{W}_{\mathrm{m}}$ such that $\mathrm{W}_{\mathrm{m}} \cap \mathrm{V}_{\mathrm{j}} \neq \phi$ only for finitely many values $\mathrm{j}$ of $\mathrm{J}$ (we say that $\left\{\mathrm{V}_{\mathrm{j}}\right\}_{\mathrm{j} \in \mathrm{J}}$ is locally finite).

Paracompactness is a generalization of compactness (every Hausdorff compact topological space is paracompact).

Theorem 35. Let $\mathrm{M}$ be a paracompact $C^{\infty}$-manifold and let $\left(\mathrm{U}_{\mathrm{i}}\right)_{\mathrm{i} \in \mathrm{I}}$ be a covering of $\mathrm{M}$. Then there exists a $C^{\infty}$ - partition of unity subordinated to $\left(\mathrm{U}_{\mathrm{i}}\right)_{\mathrm{i} \in \mathrm{I}}$.

Theorem 36. There exists at least one Riemannian metric on any paracompact $C^{\infty}$-manifold.

The construction goes as follows: Let $\left(U_{i}, \varphi_{i}\right)_{\mathrm{i} \in \mathrm{I}}$ be an atlas of $\mathrm{M}$ and let $\left(\theta_{i}\right)_{\mathrm{i} \in \mathrm{I}}$ be a partition of unity subordinate to the covering $\left(\mathrm{U}_{\mathrm{i}}\right)_{\mathrm{i} \in \mathrm{I}}$. Fix a scalar product $\mathrm{Q}(.,$.$) on \square^{\mathrm{n}}$ where $n=\operatorname{dim} \mathrm{M}$. Then it is easy to see that $\sum_{i \in 1} \theta_{i}\left[\varphi_{i}^{*}(Q)\right]$

is a metric on M. For more details, see (Aubin, 2001).

\section{The levi-Civita connection}

Definition 37. Let $\mathrm{M}$ be a differentiable manifold. A Linear connection $\nabla$ on $\mathrm{M}$ is a map $\nabla: \mathrm{TM} \times \Gamma(\mathrm{TM}) \rightarrow \mathrm{TM}$

$$
(\xi, \mathrm{Y}) \mapsto \nabla_{\xi} \mathrm{Y}
$$

satisfying the following conditions

(1) If $\xi \in \mathrm{T}_{\mathrm{m}} \mathrm{M}$ and $\mathrm{Y} \in \Gamma(\mathrm{TM})$, then $\nabla_{\xi} \mathrm{Y} \in \mathrm{T}_{\mathrm{m}} \mathrm{M}$.

(2) The restriction of $\nabla$ to $\mathrm{T}_{\mathrm{m}} \mathrm{M} \times \Gamma(\mathrm{TM})$ is bilinear.

(3) $\nabla_{\xi}(\mathrm{fY})=(\xi \cdot \mathrm{f}) \mathrm{Y}_{\mid \mathrm{m}}+\mathrm{f}(\mathrm{m}) \nabla_{\xi} \mathrm{Y}$ for all $\xi \in \mathrm{T}_{\mathrm{m}} \mathrm{M}, \mathrm{Y} \in \Gamma(\mathrm{TM})$ and for all $\mathrm{f}$ differentiable function on $\mathrm{M}$.

(4) If $\mathrm{X} \in \Gamma(\mathrm{TM})$ and $\mathrm{Y} \in \Gamma(\mathrm{TM})$ are such that $\mathrm{X}$ is of class $C^{r}$ and $\mathrm{Y}$ is of class $C^{r+1}$, then $\nabla_{\mathrm{x}} \mathrm{Y} \in \Gamma(\mathrm{TM})$ is of class $C^{r}$.

Definition 38. (1) The torsion of a linear connection $\nabla$ is a map $\mathrm{T}$ defined by

$$
\begin{gathered}
\mathrm{T}: \Gamma(\mathrm{TM}) \times \Gamma(\mathrm{TM}) \rightarrow \Gamma(\mathrm{TM}) \\
(\mathrm{X}, \mathrm{Y}) \mapsto \mathrm{T}(\mathrm{X}, \mathrm{Y})=\nabla_{\mathrm{x}} \mathrm{Y}-\nabla_{\mathrm{Y}} \mathrm{X}-[\mathrm{X}, \mathrm{Y}]
\end{gathered}
$$




\section{BOUDJEMAA ANCHOUCHE}

where $[\mathrm{X}, \mathrm{Y}]$ is the Lie bmcket of the vector fields $\mathrm{X}$ and $\mathrm{Y}$.

(2) The curvature $\mathrm{R}$ of a linear connection $\nabla$ is a two form with values in $\mathrm{Hom}(\Gamma(\mathrm{TM}), \Gamma(\mathrm{TM}))$, defined by

$$
\begin{array}{cc}
\mathrm{R}: & \Gamma(\mathrm{TM}) \times \Gamma(\mathrm{TM}) \quad \rightarrow \quad \operatorname{Hom}(\Gamma(T M), \Gamma(T M)) \\
(\mathrm{X}, \mathrm{Y}) \quad \mapsto \quad \mathrm{R}(\mathrm{X}, \mathrm{Y})=\nabla_{\mathrm{x}} \nabla_{\mathrm{Y}}-\nabla_{\mathrm{Y}} \nabla_{\mathrm{x}}-\nabla_{[\mathrm{x}, \mathrm{Y}]}
\end{array}
$$

For simplicity we write

$$
\mathrm{R}(\mathrm{X}, \mathrm{Y})=\left[\nabla_{\mathrm{x}}, \nabla_{\mathrm{Y}}\right]-\nabla_{\left[\nabla_{\mathrm{x}}, \nabla_{\mathrm{Y}}\right]} .
$$

Remark 39. One can easily check that:

(1) The curyature $\mathrm{R}$ is a $(1,3)$ tensor.

(2)

(3) If $\mathrm{T}=0$, then

$\mathrm{R}(\mathrm{X}, \mathrm{Y}) \mathrm{Z}+\mathrm{R}(\mathrm{Y}, \mathrm{Z}) \mathrm{X}+\mathrm{R}(\mathrm{Z}, \mathrm{X}) \mathrm{Y}=0$ (Bianchi's Identity).

(4) The value of $\mathrm{R}(\mathrm{X}, \mathrm{Y}) \mathrm{Z}$ at a point $\mathrm{m} \in \mathrm{M}$ depends only on the values $\mathrm{X}, \mathrm{Y}$ and $\mathrm{Z}$ at $\mathrm{m}$.

Theorem 40. Let $(\mathrm{M}, \mathrm{g})$ be a Riemannian manifold. Then there exists a unique linear connection which is torsion free and compatible with the metric, i.e., a connection $\nabla^{\mathrm{g}}$ satisfying the following two conditions:

(1) $\mathrm{T}(\mathrm{X}, \mathrm{Y})=0$ for all $\mathrm{X}, \mathrm{Y} \in \Gamma(\mathrm{T} \mathrm{M})$

$$
\mathrm{X} \cdot \mathrm{g}(\mathrm{Y}, \mathrm{Z})=\mathrm{g}\left(\nabla_{\mathrm{x}}^{\mathrm{g}} \mathrm{Y}, \mathrm{Z}\right)+\mathrm{g}\left(\mathrm{X}, \nabla_{\mathrm{x}}^{\mathrm{g}} Z\right) \text { for all } \mathrm{X}, \mathrm{Y}, \mathrm{Z} \in \Gamma(\mathrm{TM}) \text {. }
$$

where $\mathrm{T}$ is the torsion of the connection $\nabla^{\mathrm{g}}$. The connection $\nabla^{\mathrm{g}}$ defined above is called the Levi-civita a connection of the metric $\mathrm{g}$ and will simply be denoted by $\nabla$.

For a proof, see (Aubin, 2001).

The vector field $\nabla_{\mathrm{x}} \mathrm{Y}$ is called the covariant derivative of the vector field $\mathrm{Y}$ in the direction of the vector field $\mathrm{X}$.

The covariant differentiation can be extended to tensors of type ${ }^{(\mathrm{p}, \mathrm{q})}$, see (Kobayashi and Nomizu, 1969) . In a local coordinate system $\left(\mathrm{x}_{1}, \ldots, \mathrm{x}_{\mathrm{n}}\right)$ defined in an open subset $\mathrm{U}_{\partial \mathrm{of}} \mathrm{M}$, we write

$$
\nabla_{\frac{\partial}{\partial x_{i}}} \frac{\partial x_{j}}{\partial \sum_{k}=1} \sum_{i j}^{k} \frac{\partial x_{k}}{\partial x_{k}} \text {. }
$$

Definition 41. The functions $\Gamma_{\mathrm{ij}}^{\mathrm{k}}$ defined in $\mathrm{U}$ are called the ChristoffeL SymboLs of the Levi-Cevita connection $\nabla$.

Easy computations in a local coordinate system $\left(\mathrm{x}_{1}, \ldots, \mathrm{x}_{\mathrm{n}}\right)$ defined in an open subset $\mathrm{U}$ of $\mathrm{M}$ show that the

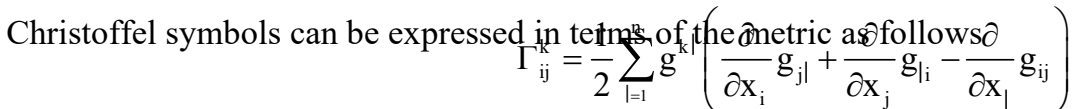

where $\mathrm{g}^{\left(\mathrm{g}^{\mathrm{k} l}\right)_{1 \leq \mathrm{k}, \mid \leq \mathrm{n}} \text { is the inverse of the matrix }}\left(\mathrm{g}_{\mathrm{ij}}\right)_{1 \leq \mathrm{i}, \mathrm{j} \leq \mathrm{n}}$. 


\section{KÄHLER MANIFOLDS POSITIVE RICCI CURVATURE}

\section{Sectional and ricci curvatures}

Curvature is a fundamental and central concept in Riemannian geometry. In this section we will introduce two types of curvatures, namely the sectional curvature and the Ricci curvature.

Let $(\mathrm{M}, \mathrm{g})$ be a Riemannian manifold and $\mathrm{R}$ its curvature. Using the metric $\mathrm{g}$, we can view $\mathrm{R}$ as a

tensor (denoted also by $\mathrm{R}$ ) as follows

$\mathrm{R}(\mathrm{X}, \mathrm{Y}, \mathrm{Z}, \mathrm{W}):=\mathrm{g}(\mathrm{R}(\mathrm{X}, \mathrm{Y}) \mathrm{Z}, \mathrm{W})$

The properties of $\mathrm{R}$ can be summarized in the following

Proposition 42. The Riemannian curvature $\mathrm{R}$ satisfies the following properties

(1)

(2) $\mathrm{R}(\mathrm{X}, \mathrm{Y}, \mathrm{Z}, \mathrm{W})=\mathrm{R}(\mathrm{Z}, \mathrm{W}, \mathrm{X}, \mathrm{Y})$

Let $\mathrm{G}\left(2, \mathrm{~T}_{\mathrm{m}} \mathrm{M}\right)$ be the Grassmannian of 2-dimensional vector subspaces of $\mathrm{T}_{\mathrm{m}} \mathrm{M}$ and let $\mathrm{G}(2, \mathrm{TM})=\mathrm{U}_{\mathrm{m} \in \mathrm{M}} \mathrm{G}\left(2, \mathrm{~T}_{\mathrm{m}} \mathrm{M}\right)$

be the corresponding Grassman bundle.

Let $\mathrm{u}_{\mathrm{m}}$ be a two dimensional vector subspace of $\mathrm{T}_{\mathrm{m}} \mathrm{M}$ with basis $(\xi, \eta)$. Then it can be shown that the real number

$$
\mathrm{T}\left(\mathrm{u}_{\mathrm{m}}\right)=\frac{\mathrm{g}_{\mathrm{m}}(\mathrm{R}(\xi, \eta) \xi, \eta)}{\mathrm{g}_{\mathrm{m}}(\xi, \xi) \mathrm{g}_{\mathrm{m}}(\eta, \eta)-\mathrm{g}_{\mathrm{m}}(\xi, \eta)^{2}}
$$

is independent of the choice of the basis $(\xi, \eta)$ of $\mathrm{u}_{\mathrm{m}}$.

Definition 43. Let $(\mathrm{M}, \mathrm{g})$ be a Riemannian manifold. The sectional curvature of ${ }^{(\mathrm{M}, \mathrm{g})}$ at $\mathrm{m} \in \mathrm{M}$, denoted by $\operatorname{sect}(\mathrm{m})$, is the function

$$
\begin{aligned}
\operatorname{sect}(\mathrm{m}): \mathrm{G}\left(2, \mathrm{~T}_{\mathrm{m}} \mathrm{M}\right) & \rightarrow \\
\mathrm{u}_{\mathrm{m}} & \mapsto \operatorname{sect}(\mathrm{m})\left(\mathrm{u}_{\mathrm{m}}\right)=\mathrm{T}\left(\mathrm{u}_{\mathrm{m}}\right)
\end{aligned}
$$

Remark 44. If $\xi, \eta$ are two linearly independent vectors in $\mathrm{T}_{\mathrm{m}} \mathrm{M}$, then we put $\operatorname{sect}(\mathrm{m})(\xi, \eta)=\mathrm{T}\left(\mathrm{u}_{\mathrm{m}}\right)$

where $\mathrm{u}_{\mathrm{m}}$ is the plane spanned by the vectors $\xi, \eta$.

We will say that $\operatorname{sect} \geq c($ resp. $\leq,>,<\mathrm{c})$ if

$$
\operatorname{sect}(\mathrm{m})(\xi, \xi) \geq \operatorname{cg}_{\mathrm{m}}(\xi, \xi) \quad\left(\operatorname{resp} \cdot \operatorname{sect}(\mathrm{m})(\xi, \xi) \leq,>,<\operatorname{cg}_{\mathrm{m}}(\xi, \xi)\right),
$$

for all vectors, $\xi \in \mathrm{T}_{\mathrm{m}} \mathrm{M}$ and for all $\mathrm{m} \in \mathrm{M}$.

Definition 45. Let $(\mathrm{M}, \mathrm{g})$ be a Riemannian manifold. For each $\mathrm{m} \in \mathrm{M}$, the Ricci curvature tensor of $(\mathrm{M}, \mathrm{g})$ at $\mathrm{m}$, denoted by $\mathrm{Ri}_{\mathrm{g}}(\mathrm{m})$ is defined $\mathrm{k} \dot{\mathrm{r}} \mathrm{g}_{\mathrm{g}}(\mathrm{m}): \mathrm{T}_{\mathrm{m}} \mathrm{M} \times \mathrm{T}_{\mathrm{m}} \mathrm{M} \rightarrow$

$$
(\xi, \eta) \quad \mapsto \quad \operatorname{Ric}(\xi, \eta)
$$




\section{BOUDJEMAA ANCHOUCHE}

where

$$
\begin{aligned}
\operatorname{Ric}(\xi, \eta) & =\operatorname{Trace}(\zeta \mapsto \operatorname{Ric}(\xi, \zeta) \eta) \\
& =\sum_{\mathrm{i}=1}^{\mathrm{n}}\left\langle\operatorname{Ric}\left(\xi, e_{i}\right) \eta, \mathrm{e}_{i}\right\rangle,
\end{aligned}
$$

and $\left(e_{i}\right)_{1 \leq i \leq n}$ is a $\mathrm{g}_{\mathrm{m}}$-orthonormal basis of $\mathrm{T}_{\mathrm{m}} \mathrm{M}$.

As defined, ${ }^{\mathrm{Ri}} \mathrm{c}_{\mathrm{g}}$ is a bilinear form which will sometimes simply be denoted by Ric if the metric is clear from the context, and $\operatorname{Ric}_{\mathrm{g}}(\mathrm{m})$ will simply be denoted by $\mathrm{Ri} \mathrm{m}_{\mathrm{m}}$.

As in the case of sectional curvature, we will say that $\operatorname{Ric} \geq c($ resp. $\leq,>,<\mathrm{c})$ if

$$
\operatorname{Ric}_{\mathrm{m}}(\xi, \xi) \geq \operatorname{cg}_{\mathrm{m}}(\xi, \xi)\left(\operatorname{resp} . \operatorname{Ric}_{\mathrm{m}}(\xi, \xi) \leq,>,<\operatorname{cg}_{\mathrm{m}}(\xi, \xi)\right),
$$

for all vectors $\xi \in \mathrm{T}_{\mathrm{m}} \mathrm{M}$ and for all $\mathrm{m} \in \mathrm{M}$.

\section{A volume comparison theorem}

The positivity of the Ricci curvature imposes strong topological and geometric constraints on Riemannian Manifolds as shown in Theorem 46, Theorem 57 and Theorem 58 below.

Theorem 46. ( Myers, 1941) Let $(\mathrm{M}, \mathrm{g})$ be a complete Riemannian manifold and suppose that $\operatorname{Ric}_{\mathrm{g}} \geq c$,

where ${ }^{c}$ is a positive constant. Then $\mathrm{M}$ is compact and its fundamental group is finite.

Remark 47. Negative Ricci curvature has no topological implications on Riemannian manifolds of dimension $\geq 3$ as is shown by the following result.

Theorem 48. (Lohkamp, 1994) Any manifold of dimension $\geq 3$ admits a metric with negative Ricci curvature.

Definition 49. Let $(\mathrm{M}, \mathrm{g})$ be a Riemannian manifold and let $\gamma:(\mathrm{a}, \mathrm{b}) \rightarrow \mathrm{M}$, be a differentiable map (called a smooth curve). The length of the curve denoted by ${ }^{l}(\gamma)$ is given by

$$
\imath(\gamma)=\int_{a}^{b} \sqrt{\mathrm{g}_{\gamma(\mathrm{t})}(\dot{\gamma}(\mathrm{t}), \dot{\gamma}(\mathrm{t}))} \mathrm{dt},
$$

where

$$
\dot{\gamma}(\mathrm{t})=\frac{\mathrm{d} \gamma}{\mathrm{dt}}(\mathrm{t})=\left[\mathrm{d} \gamma\left(\frac{\mathrm{d}}{\mathrm{dt}}\right)\right]_{\mid \mathrm{t}}, \mathrm{t} \in(\mathrm{a}, \mathrm{b}),
$$

$\mathrm{d} \gamma$ is the differential of the map $\gamma$ and $\frac{\mathrm{d}}{\mathrm{dt}}$ is the unit vector on $\square$.

The length of a piecewise smooth curve is the sum of the lengths of its smooth pieces.

Definition 50. (1) The distance between two points $\mathrm{x}$ and $\mathrm{y}$, denoted by $\mathrm{d}_{\mathrm{g}}(\mathrm{x}, \mathrm{y})$, is the infimum of the lengths (With respect to the metric ${ }^{\mathrm{g}}$ ) of all piecewise $C^{1}$-curves from $\mathrm{x}$ to $\mathrm{y}$. 


\section{KÄHLER MANIFOLDS POSITIVE RICCI CURVATURE}

(2) The metric ${ }^{\mathrm{g}}$ induces a distance function ${ }^{\mathrm{d}_{\mathrm{g}}}$ on $\mathrm{M}$, giving a metric space $\left(\mathrm{M}, \mathrm{d}_{\mathrm{g}}\right)$. We say that the metric $\mathrm{g}$ is complete if $\left(\mathrm{M}, \mathrm{d}_{\mathrm{g}}\right)$ is a complete metric space.

Remark 51. It can be proved that the topology of $\mathrm{M}$ induced by the metric $\mathrm{d}_{\mathrm{g}}$ is the same as the original topology of $\mathrm{M}$.

Definition 52. The geodesic ball $\mathrm{B}_{\mathrm{g}}(\mathrm{m}, \mathrm{r})$ centered at $\mathrm{m}$ and with radius $\mathrm{r}$ is defined by $\mathrm{B}_{\mathrm{g}}(\mathrm{m}, \mathrm{r})=\left\{\mathrm{x} \in \mathrm{M} \mid \mathrm{d}_{\mathrm{g}}(\mathrm{m}, \mathrm{x})<\mathrm{r}\right\}$,

where $\mathrm{d}_{\mathrm{g}}$ is the distance function induced by the Riemannian metric.

\section{Integration of differential forms on manifolds}

Let $\mathrm{M}$ be an $C^{\infty}$-manifold of dimension ${ }^{n}$ and let $\varpi$ be a smooth ${ }^{n}$-form defined on $\mathrm{M}$. The aim of this section is to give a meaning to the following expression $\int_{\mathrm{M}} \rho \varpi$

where $\rho$ is a compactly supported function on $\mathrm{M}$, i.e., supp $(\rho) \subseteq \mathrm{K}$, where $\mathrm{K}$ is a compact subset of $\mathrm{M}$. Let us start first with the following

Definition 53. Let $\mathrm{M}$ and $\mathrm{N}$ be two $C^{\infty}$-manifolds and $\mathrm{f}: \mathrm{M} \rightarrow \mathrm{N}{ }_{a} C^{\infty}{ }_{-m a p}$. If $\Phi$ is a smooth ${ }_{\text {-form on }}$

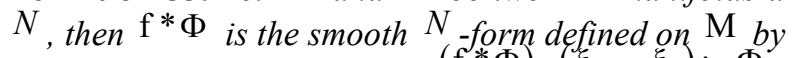

$$
\left(\mathrm{f}^{*} \Phi\right)_{\mathrm{m}}\left(\xi_{1}, \ldots, \xi_{\mathrm{n}}\right):=\Phi_{\mathrm{f}(\mathrm{m})}\left(\mathrm{df}_{\mathrm{m}}\left(\xi_{1}\right), \ldots, \mathrm{df}_{\mathrm{m}}\left(\xi_{\mathrm{n}}\right)\right),
$$

for all $\mathrm{m} \in \mathrm{M}$ and for all $\xi_{1}, \ldots, \xi_{\mathrm{n}} \in \mathrm{T}_{\mathrm{m}} \mathrm{M}$

Let $\mathrm{M}, \rho$ and $\varpi_{\mathrm{w}}$ be as above. Suppose first that supp $(\rho) \subseteq \mathrm{U}_{\mathrm{i}}$, where $\left(\mathrm{U}_{\mathrm{i}}, \varphi_{\mathrm{i}}\right)$ is a local chart and $\left(\mathrm{x}_{1}, \ldots, \mathrm{x}_{\mathrm{n}}\right)$ are the corresponding local coordinates. Then

$$
\left(\varphi_{\mathrm{i}}^{-1}\right) * \varpi=\vartheta_{i}\left(\mathrm{x}_{1}, \ldots, \mathrm{x}_{\mathrm{n}}\right) \mathrm{dx} \mathrm{x}_{1} \wedge \ldots \wedge \mathrm{dx_{ \textrm {n } }},
$$

where $\vartheta_{\mathrm{i}}$ is a smooth function defined in $\varphi_{\mathrm{i}}\left(\mathrm{U}_{\mathrm{i}}\right)$ with real values. We put

(1)

$\int_{\varphi_{i}\left(\mathrm{U}_{\mathrm{i}}\right)}\left(\rho \mathrm{o} \varphi_{\mathrm{i}}^{-1}\right)\left(\mathrm{x}_{1}, \ldots, \mathrm{x}_{\mathrm{n}}\right) \vartheta_{i}\left(\mathrm{x}_{1}, \ldots, \mathrm{x}_{\mathrm{n}}\right) \mathrm{dx} \mathrm{x}_{1} \wedge \ldots \wedge \mathrm{dx} \mathrm{x}_{\mathrm{n}}$

We have to prove that the definition is independent of the choice of the local chart containing the support of $\rho$. For this, suppose that $\left(\mathrm{U}_{\mathrm{j}}, \varphi_{\mathrm{j}}\right)$ is a local chart and $\left(\mathrm{y}_{1}, \ldots, \mathrm{y}_{\mathrm{n}}\right)$ are the corresponding local coordinates with $\operatorname{supp}_{\text {(3) }}(\rho) \subseteq \mathrm{U}_{\mathrm{M}} \rho \sigma=\int_{\varphi_{\mathrm{j}}\left(\mathrm{U}_{\mathrm{j}}\right)}^{\text {, and put }}\left(\varphi_{\mathrm{j}}^{+}\right) \varpi$

$$
\int_{\varphi\left(\mathrm{U}_{\mathrm{j}}\right)}\left(\rho \mathrm{o} \varphi_{\mathrm{j}}^{-1}\right)\left(\mathrm{y}_{1}, \ldots, \mathrm{y}_{\mathrm{n}}\right) \vartheta_{\mathrm{j}}\left(\mathrm{y}_{1}, \ldots, \mathrm{y}_{\mathrm{n}}\right) \mathrm{dy}_{1} \wedge \ldots \wedge \mathrm{dy}_{\mathrm{n}}
$$

where $\vartheta_{\mathrm{j}}$ is defined by

$$
\left(\varphi_{\mathrm{j}}^{-1}\right) * \varpi=\vartheta_{\mathrm{j}}\left(\mathrm{y}_{1}, \ldots, \mathrm{y}_{\mathrm{n}}\right) \mathrm{dy}_{1} \wedge \ldots \wedge \mathrm{dy}_{\mathrm{n}}
$$




\section{BOUDJEMAA ANCHOUCHE}

In general the right hand side of the expressions (1) and (3) are not necessarily equal, but if we restrict ourselves to "orientable manifolds" then we can choose an atlas of local charts such that (1) and (3) are equal. To be more precise, let us introduce the following

Definition 54. (1) $A C^{\infty}$-manifold $\mathrm{M}$ is said to be orientable if there exists a $C^{\infty}$-atlas $\left(\mathrm{U}_{\mathrm{i}}, \varphi_{\mathrm{i}}\right)_{\mathrm{i} \in \mathrm{I}}$ such that the

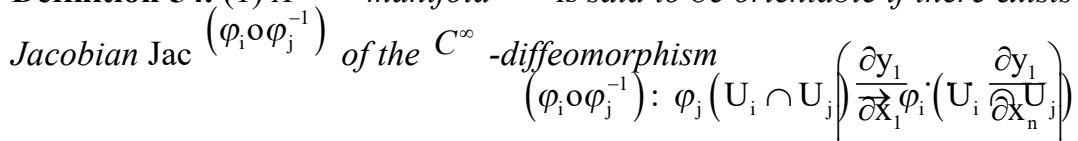

is positive for all $\mathrm{i}, \mathrm{j} \in \mathrm{I}$, i.e.,

$$
\operatorname{Jac}\left(\varphi_{\mathrm{i}} \mathrm{O} \varphi_{\mathrm{j}}^{-1}\right)\left(\varphi_{\mathrm{j}}(\mathrm{x})\right):=\operatorname{det}\left(\begin{array}{ccc}
\cdot & \cdots & \cdot \\
\cdot & \cdots & \cdot \\
\cdot & \cdots & \cdot \\
\frac{\partial \mathrm{y}_{\mathrm{n}}}{\partial \mathrm{x}_{1}} & \cdots & \frac{\partial \mathrm{y}_{\mathrm{n}}}{\partial \mathrm{x}_{\mathrm{n}}}
\end{array}\right)>0
$$

for all $\mathrm{i}, \mathrm{j} \in \mathrm{I}$ and for all $\mathrm{x} \in \mathrm{U}_{\mathrm{i}} \cap \mathrm{U}_{\mathrm{j}}$, where $\left(\mathrm{x}_{1}, \ldots, \mathrm{x}_{\mathrm{n}}\right)\left(\right.$ resp. $\left.\left(\mathrm{y}_{1}, \ldots, \mathrm{y}_{\mathrm{n}}\right)\right)$ is the system of local coordinates corresponding to the chart $\left(\mathrm{U}_{\mathrm{j}}, \varphi_{\mathrm{j}}\right)\left(\operatorname{resp} .\left(\mathrm{U}_{\mathrm{i}}, \varphi_{\mathrm{i}}\right)\right)$.

(2) The manifold $\mathrm{M}$ is said to be oriented if such an atlas has been chosen.

(3) A chart $(\mathrm{U}, \varphi)$ is said to be compatible with the orientation if

$$
\operatorname{Jac}\left(\varphi \circ \varphi_{\mathrm{i}}^{-1}\right)>0 \text {, for all } \mathrm{i}
$$

It can be shown that

Theorem 55. $A^{C^{\infty}}$-man(fold $\mathrm{M}$ of dimension $n$ is orientable if and only (f there exists a differential ${ }^{n}$-form ${ }^{\omega}$ such that $\omega_{\mathrm{m}} \neq 0$ for all $\mathrm{m} \in \mathrm{M}$

If $\mathrm{M}$ is oriented and the atlas $\left(\dot{\mathrm{U}}_{i}, \varphi_{i}\right)_{\mathrm{i} \in \mathrm{I}}$ is compatible with the orientation, then

$$
\int_{\varphi_{\mathrm{i}}\left(\mathrm{U}_{\mathrm{i}}\right)}\left(\varphi_{\mathrm{i}}^{-1}\right) * \varpi=\int_{\varphi_{\mathrm{j}}\left(\mathrm{U}_{\mathrm{j}}\right)}\left(\varphi_{\mathrm{j}}^{-1}\right) * \varpi
$$

i.e., the integral $\int_{M} \rho \varpi$ is independent of the choice of the local chart.

Suppose now that $\rho$ is a smooth function defined on $M$ with compact support. Then we define $\int_{M} \rho \varpi$ as follows

$$
\int_{M} \rho \varpi=\sum_{i \in I} \int_{M} X_{i} \rho \varpi
$$

where $\left(\mathrm{X}_{\mathrm{i}}\right)_{\mathrm{i} \in \mathrm{I}}$ is a partition of unity subordinate to an atlas $\left(\mathrm{U}_{i}, \varphi_{i}\right)_{\mathrm{i} \in \mathrm{I}}$ which is compatible with the orientation. The right hand side of (5) is a finite sum and it can be proved that it is independent of the choice of the partition of unity. 


\section{KÄHLER MANIFOLDS POSITIVE RICCI CURVATURE}

\section{Integration over riemannian manifolds.}

Let $(\mathrm{M}, \mathrm{g})$ be a Riemannian manifold of dimension $n$, let $(\mathrm{U}, \varphi)=\left(\mathrm{U},\left(\mathrm{x}_{\mathrm{i}}\right)_{1 \leq \mathrm{i} \leq \mathrm{n}}\right)$ be a local chart, and suppose that $\mathrm{f}$ is a measurable function on $\mathrm{M}$ with compact support included in $\mathrm{U}$. Then the integral $\int_{\mathrm{M}} \mathrm{fdV}_{\mathrm{g}}$ is defined as follows

$$
\int_{M} \mathrm{fdV}_{\mathrm{g}}=\int_{\varphi(\mathrm{M})} \mathrm{f}\left(\varphi^{-1}(\mathrm{x})\right) \sqrt{\operatorname{det}\left(\mathrm{g}_{\mathrm{ij}}\left(\varphi^{-1}(\mathrm{x})\right)\right)} \mathrm{dx} \mathrm{x}_{1} \ldots \mathrm{dx} \mathrm{x}_{\mathrm{n}}
$$

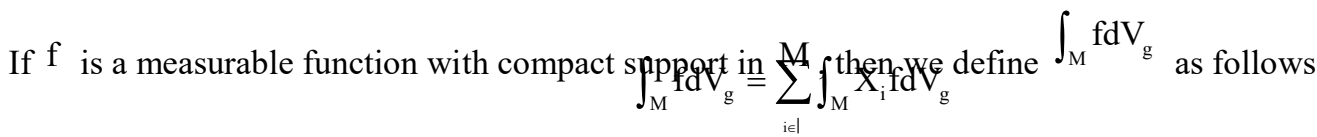

where $\left(\mathrm{X}_{\mathrm{i}}\right)_{\mathrm{i} \in \mathrm{I}}$ is a partition of unity subordinate to an atlas $\left(\mathrm{U}_{i}, \varphi_{i}\right)_{\mathrm{i} \in \mathrm{I}}$.It can be proved that the sum is well defined, i.e., only a finite number of terms in the sum are nonzero, the sum is independent of the choice of the atlas and of the partition of unity subordinated to it. $\left.\dot{\varphi}_{i}\right)$

Suppose now that $\mathrm{M}$ is oriented and let $(\mathrm{U}, \varphi)$ be a local chart belonging to $\mathrm{A}$ and let $\left(\mathrm{x}_{1} \ldots, \mathrm{x}_{\mathrm{n}}\right)$ be the local coordinate system associated to $\varphi$ and consider the following $n$-form:

$$
\varpi_{\mathrm{x}}=\sqrt{\operatorname{det}\left(\mathrm{g}_{\mathrm{ij}}(\mathrm{x})\right) \mathrm{d}_{\mathrm{x} 1}} \wedge \ldots \wedge \mathrm{dx}_{\mathrm{n}}
$$

where det $\left(\mathrm{g}_{\mathrm{ij}}\right)$ is the determinant of the metric $\mathrm{g}=\sum_{\mathrm{i}=1}^{\mathrm{n}} \mathrm{g}_{\mathrm{ij}} \mathrm{dx}_{\mathrm{i}} \otimes \mathrm{dx}_{\mathrm{j}}$. Consider another local chart $(V, \psi) \in \mathrm{A}$ and let $\left(\mathrm{y}_{1}, \ldots, \mathrm{y}_{\mathrm{n}}\right)$ the corresponding local coordinates, and put

$$
\varpi_{\mathrm{y}}=\sqrt{\operatorname{det}\left(\mathrm{g}_{\mathrm{ij}}(\mathrm{y})\right) \mathrm{dy}_{1} \wedge \ldots \wedge \mathrm{dy}_{\mathrm{n}}}
$$

An easy computation shows that

$$
\varpi_{\mathrm{x}}=\varpi_{\mathrm{y}} \text { in } \mathrm{U} \cap \mathrm{V} \text {. }
$$

Therefore $\varpi$ is a global ${ }^{n}$-form, called the volume form associated to the Riemannian metric ${ }^{\mathrm{g}}$ and it will be denoted by $\mathrm{dV}_{\mathrm{g}}$.

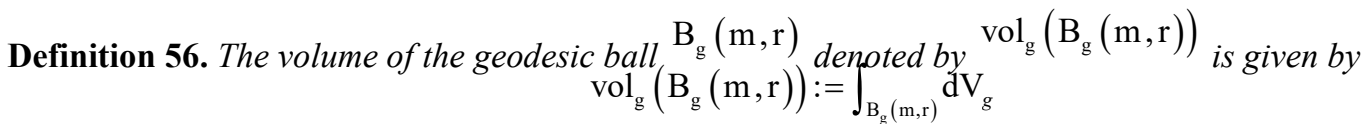

The following two results are very important and will be needed in part 4 .

Theorem 57. (Bishop and Crittenden, 1964) Let ${ }^{(\mathrm{M}, \mathrm{g})}$ be a complete noncompact Riemannian manifold of positive Ricci curvature,

$$
\begin{aligned}
\operatorname{dim}_{\mathrm{R}} \mathrm{M}=n & \text {. Then } \\
& \operatorname{vol}_{\mathrm{g}}\left(\mathrm{B}_{\mathrm{g}}(\mathrm{m}, \mathrm{r})\right) \leq \mathrm{cr}{ }^{\mathrm{n}} \text { for all } \mathrm{r}>0,
\end{aligned}
$$

where ${ }^{c}$ is a positive constant independent of $\mathrm{r}$.

There is a generalization of Bishop's Theorem by Gromov, but for our purposes, Bishop's Theorem is enough.

The proof of Bishop's (resp. Gromov's) Theorem (Theorem 57) uses special local coordinates coming from the exponential map and some properties of Jacobi fields, for more details, see (Gallot and Hulin, 1990). 


\section{BOUDJEMAA ANCHOUCHE}

Theorem 58. (Calabi, Yau, see [14]) Let ${ }^{(\mathrm{M}, \mathrm{g})}$ be a complete noncompact Riemannian manifold of nonnegative

Ricci curyature. Then

$\operatorname{vol}_{\mathrm{g}}\left(\mathrm{B}_{\mathrm{g}}(\mathrm{m}, \mathrm{r})\right) \geq \mathrm{cr}$ for all $\mathrm{r}>0$

, large enough.

de Rham isomorphism

Definition 59. (1) $A^{\mathrm{p}}$ - form $\mathrm{w}$ is called closed, or $\mathrm{d}$ - closed, if $\mathrm{d} \omega=0$.

(2) $A^{\mathrm{p}}$-form $\omega$ is called exact if ${ }^{\omega=\mathrm{d} \beta}$ for some $(\mathrm{p}-1)$-form $\beta$.

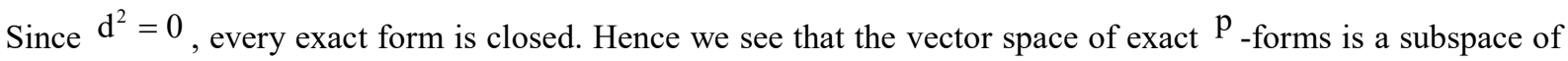
the space of closed p-forms.

Definition 60. The $\mathrm{p}^{\text {th }}$ de Rham cohomology group of $\mathrm{M}$, denoted by $\mathrm{H}_{\mathrm{DR}}^{\mathrm{p}}(\mathrm{M})$, is given by

$$
\mathrm{H}_{\mathrm{DR}}^{\mathrm{p}}(\mathrm{M})=\{\text { closed } \mathrm{p}-\text { forms }\} /\{\text { exact } \mathrm{p}-\text { forms }\}
$$

de Rham's Theorem says that $\mathrm{H}_{\mathrm{DR}}^{\mathrm{p}}(\mathrm{M})$ is isomorphic to the $\mathrm{p}^{\text {th }}$ singular cohomology5 of $\mathrm{M}$. More precisely consider the following map$$
\mathrm{X}: \mathrm{H}_{\mathrm{DR}}^{\mathrm{p}}(\mathrm{M}) \rightarrow \mathrm{H}_{\mathrm{p}}(\mathrm{M}, \square)^{*}
$$$$
[\omega] \mapsto[\omega]([Z])=\int_{Z} \omega
$$

where $H_{p}(M, \square)$ is the singular $\mathrm{p}^{\text {th }}$ homology group with real coefficients, $H_{p}(M, \square)^{*}$ its dual, W is a representative of its de Rham cohomology class $[\omega]$, and $Z$ is a $\mathrm{p}^{\text {th }}$ cycle representing its real differentiable singular homology class $[Z]$. The fact that the map $X$ is well defined is an easy consequence of Stokes theorem. For more details, see (Warner, 1983).

Theorem 61. (de Rham) The map $\mathrm{X}$ is an isomorphism.

If $\mathrm{M}$ is a compact oriented manifold, then Poincare duality implies that

$$
\mathrm{H}_{\mathrm{p}}(\mathrm{M}, \square) \cong \mathrm{H}^{\mathrm{p}}(\mathrm{M}, \mathrm{D})
$$

Combining de Rham isomorphism and Poincare isomorphism, we obtain

$$
\mathrm{H}_{\mathrm{p}}(\mathrm{M}, \mathrm{\square}) \cong \mathrm{H}_{\mathrm{DR}}^{\mathrm{p}}(\mathrm{M})
$$

Definition 62. Let $\mathrm{M}$ be a compact manifold. The nonnegative integer $\mathrm{b}_{\mathrm{i}}(\mathrm{M})$ defined by

$$
\mathrm{b}_{\mathrm{i}}(\mathrm{M})=\operatorname{dim}_{\square} \mathrm{H}_{\mathrm{DR}}^{\mathrm{i}}(\mathrm{M}) \text {, }
$$

is called the $e^{\mathrm{i}-\text { th }}$ Betti number of the manifold $\mathrm{M}$.

\section{Holonomy groups}

The aim of this section is to introduce the "holonomy group" of a Riemannian manifold and to state two of the fundamental results in Riemannian Geometry, namely de Rham's and Berger's Theorems. The material of this section will not be used elsewhere in this paper, so it may be skipped if the reader whishes to do so,

To any Riemannian manifold $(\mathrm{M}, \mathrm{g})$ of dimension $n_{\mathrm{n}}$, we can associate a closed subgroup of $\mathrm{SO}(n)$, called the holonomy group of the metric; lots of information about a Riemannian metric is encoded in its holonomy group. Let us first define the holonomy group.

${ }_{5}$ For more details on singular (co)-homology, the readers can consult [20]. 


\section{KÄHLER MANIFOLDS POSITIVE RICCI CURVATURE}

Let $\gamma:(a, b) \rightarrow M$ be a smooth curve. The tangent vector $\frac{\mathrm{d} \gamma}{\mathrm{dt}}$ to the curve $\gamma$ is defined by

$$
\frac{\mathrm{d} \gamma}{\left.\mathrm{dt}\right|_{\mathrm{t}_{0}}}=\left[d \gamma\left(\frac{\mathrm{d}}{\mathrm{dt}}\right)\right]_{\mid \mathrm{t}_{0}}, \mathrm{t}_{0} \in(\mathrm{a}, \mathrm{b})
$$

where $\mathrm{d} \gamma$ is the differential of the map $\gamma$ and $\frac{\mathrm{d}}{\mathrm{dt}}$ is the unit vector on $\square$. For a function $\mathrm{f}$ defined in a neighborhood of $\gamma\left(t_{0}\right)$, we get

$$
\left.\frac{\mathrm{d} \gamma}{\mathrm{dt}}\right|_{\mathrm{t}_{0}}(\mathrm{f})=\left(\frac{\mathrm{d}(\mathrm{f} \circ \gamma)}{\mathrm{dt}}\right)\left(\mathrm{t}_{0}\right)
$$

Let $(\mathrm{M}, \mathrm{g})$ be a Riemannian manifold of dimension $\mathrm{n}$ and let $\nabla$ be the Levi-Cevita on $\mathrm{M}$.

Definition 63. (1) A vector field $\mathrm{X}$ along a curve $\gamma:(\mathrm{a}, \mathrm{b}) \rightarrow \mathrm{TM}$ is a map

$$
\mathrm{X}:(\mathrm{a}, \mathrm{b}) \rightarrow \mathrm{TM}
$$

such that $\mathrm{X}(\mathrm{t}) \in \mathrm{T}_{\gamma(\mathrm{t})} \mathrm{M}$ for all $\mathrm{t} \in(\mathrm{a}, \mathrm{b})$

(2) A vector field $\mathrm{X}$ is said to be parallel along a diffexentiogle curve ${ }_{\frac{\mathrm{d \gamma}}{\mathrm{d}}}^{\gamma}$ if

Let

$$
\mathrm{X}=\sum_{\mathrm{i}=1}^{\mathrm{n}} \mathrm{X}^{\mathrm{i}} \frac{\partial}{\partial \mathrm{x}_{\mathrm{i}}} \text { and } \gamma=\left(\gamma^{1}, \ldots, \gamma^{\mathrm{n}}\right)
$$

be the expression of the vector field $\mathrm{X}$ and the curve ${ }^{\gamma}$ in a local chart $\left(\mathrm{U},\left(\mathrm{x}_{1}, \ldots, \mathrm{x}_{\mathrm{n}}\right)\right)$.

Then

$$
\nabla_{\frac{d \gamma}{d t}} X=0 \Leftrightarrow \sum_{j=1}^{n}\left[\frac{d X^{j}(t)}{d t}+\sum_{i, k=1}^{n} \Gamma_{i k}^{j}(\gamma(t)) X^{k}(t) \frac{d \gamma^{i}(t)}{d t}\right] \frac{\partial}{\partial x_{j}}=0 .
$$

Let $\mathrm{m}_{1}$ and $\mathrm{m}_{2}$ be two points of $\mathrm{M}$ and let $\gamma:[\mathrm{a}, \mathrm{b}] \rightarrow \mathrm{M}$ be a continuous curve which is smooth in $(\mathrm{a}, \mathrm{b})$, and joining $\mathrm{m}_{1}$ and $\mathrm{m}_{2}$, i.e., $\gamma(\mathrm{a})=\mathrm{m}_{1}$ and $\gamma(\mathrm{b})=\mathrm{m}_{2}$ and let $\mathrm{X}_{1}$ be a vector in $\mathrm{T}_{\mathrm{m} 1} \mathrm{M}$. Since the equation (6) is linear, by Cauchy's theorem, it has a unique solution $X(t)$ for all $t \in[a, b]$ satisfying $X(a)=X_{1}$.

Definition 64. The vector $\mathrm{X}_{2}=\mathrm{X}(\mathrm{b})$ is called the parallel transport of $\mathrm{X}_{1}$ from $\mathrm{m}_{1}$ to $\mathrm{m}_{2}$ along the curve $\gamma$. The parallel transport along a piecewise smooth curve ${ }^{\gamma}$ is defined in an obvious way. Then to each piecewise

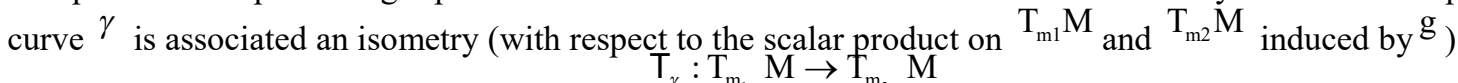

This map is both linear and invertible and so defines an element of $\mathrm{GL}\left(\mathrm{T}_{\mathrm{m}} \mathrm{M}\right)$. Let $\mathrm{m} \in \mathrm{M}$ and consider

$$
l \mathrm{o}(\mathrm{m})=\{\gamma:[\mathrm{a}, \mathrm{b}] \rightarrow \mathrm{M} \mid \gamma \text { piecewise and smooth, } \gamma(a)=\gamma(b)=m\} \text {. }
$$




\section{BOUDJEMAA ANCHOUCHE}

It can be shown that $l o(m)$ is a group under composition of paths. To a composition $\gamma_{1}^{\circ} \circ \gamma_{2}$, we associate the linear transformation

$$
l_{\gamma_{1} \circ \gamma_{2}}=l_{\gamma_{1}} \mathrm{o} l_{\gamma_{2}}: \mathrm{T}_{\mathrm{m}} \mathrm{M} \rightarrow \mathrm{T}_{\mathrm{m}} \mathrm{M}
$$

Definition 65. The holonomy of $\nabla^{\mathrm{g}}($ or $\mathrm{g})$ based at $\mathrm{m}$ is defined as

$$
\operatorname{hol}_{\mathrm{m}}\left(\nabla^{\mathrm{g}}\right)=\left\{1_{\gamma} \in \mathrm{GL}\left(\mathrm{T}_{\mathrm{m}} \mathrm{M}\right) \mid \gamma \in l \mathrm{o}(\mathrm{m})\right\}
$$

The holonomy $\operatorname{hol}_{\mathrm{m}}\left(\nabla^{\mathrm{g}}\right)$ is a subgroup of the orthogonal group $\mathrm{O}(\mathrm{n})$, moreover, it is a Lie group. If $\mathrm{hol}_{\mathrm{m}_{1}}\left(\nabla^{\mathrm{g}}\right)$ and $\mathrm{hol}_{\mathrm{m}_{2}}\left(\nabla^{\mathrm{g}}\right)$ are the holonomy groups of the connection $\nabla^{\mathrm{g}}$ at the points $\mathrm{m}_{1}, \mathrm{~m}_{2}$, then there exists an element $\mathrm{A} \in \mathrm{O}(\mathrm{n})$ such that

$$
\operatorname{hol}_{\mathrm{m}_{2}}\left(\nabla^{\mathrm{g}}\right)=\operatorname{Ahol}_{\mathrm{m}_{1}}\left(\nabla^{\mathrm{g}}\right) \mathrm{A}^{-1}
$$

This allows us to speak of "the" holorromy group of a Riemannian manifold $(\mathrm{M}, \mathrm{g})$ and denote it simply by $\mathrm{hol}\left(\nabla^{\mathrm{g}}\right)$. If we consider in the definition of the holonomy group only contractible closed curves, then we obtain what is called the restricted holonomy group, and it can be proved that the two coincide in case the manifold $\mathrm{M}$ is simply connected.

Remark 66. The following set ${ }_{\text {hol }}^{\mathrm{s}}\left(\nabla^{\mathrm{g}}\right)=\left\{1 \in \mathrm{GL}\left(\mathrm{T}_{\mathrm{m}} \mathrm{M}\right) \mid \gamma \in \operatorname{lo}(\mathrm{m}), \gamma\right.$ is a contractible curve $\}$

is a connected normal subgroup of $\mathrm{hol}_{\mathrm{m}}\left(\nabla^{\mathrm{g}}\right)$, and is called the restricted holonomy group.

Definition 67. (1) The representations of $\mathrm{hol}_{\mathrm{m}}\left(\nabla^{\mathrm{g}}\right)$ in $\mathrm{T}_{\mathrm{m}} \mathrm{M}$ are isomorphic and therefore called the holonomy representation.

(2) A Riemannian manifold $(\mathrm{M}, \mathrm{g})$ is irreducible if its holonomy representation is irreducible.

Theorem 68. (de Rham 1952) Let $(\mathrm{M}, \mathrm{g})$ be a connected, simply connected complete Riemannian manifold.

Then:

(1) there exists a canonical decomposition

$$
(\mathrm{M}, \mathrm{g}) \stackrel{\text { ssometric }}{\cong}\left(\mathrm{M}_{0}, \mathrm{~g}_{0}\right) \times\left(\mathrm{M}_{1}, \mathrm{~g}_{1}\right) \times \ldots \times\left(\mathrm{M}_{\mathrm{k}}, \mathrm{g}_{\mathrm{k}}\right)
$$

where $\left(\mathrm{M}_{0}, \mathrm{~g}_{0}\right)$ is a Euclidean space (possibly reduced to a point) and $\left(\mathrm{M}_{\mathrm{i}}, \mathrm{g}_{\mathrm{i}}\right), \mathrm{i}=1, \ldots, \mathrm{k}$ are irreducible simply connected complete Riemannian manifolds

(2) For $\mathrm{m}=\left(\mathrm{m}_{1}, \ldots, \mathrm{m}_{\mathrm{k}}\right) \in \mathrm{M}$, let $\mathrm{hol}_{\mathrm{m}_{i}}\left(\nabla^{\mathrm{g}}\right) \subset \mathrm{O}\left(\mathrm{T}_{\mathrm{m}_{\mathrm{i}}} \mathrm{M}_{\mathrm{i}}\right)$ be the holonomy group of $\mathrm{M}_{\mathrm{i}}$ at $\mathrm{m}_{\mathrm{i}}$ and let $\mathrm{hol}_{\mathrm{m}}\left(\nabla^{\mathrm{g}}\right)$ be then the holonomy of $(\mathrm{M}, \mathrm{g})$ at $\mathrm{m}$.

Then

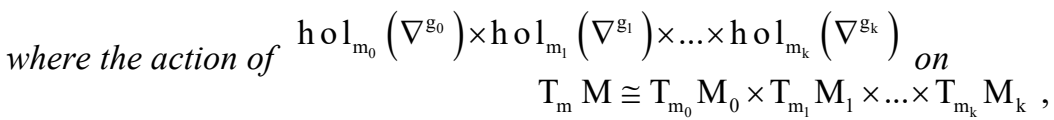

is through the product representation. Such a decomposition is unique up to an order. 


\section{KÄHLER MANIFOLDS POSITIVE RICCI CURVATURE}

The symmetric spaces were classified by E. Cartan around 1920 and their holonomy groups are well understood. For example, a compact symmetric space is a homogeneous space $\mathrm{G} / \mathrm{H}$, where $\mathrm{G}_{\text {is a compact Lie }}$ group and $\mathrm{H}$ is the identity component of the fixed locus of an involution of $\mathrm{G}_{\text {and }}$ the holonomy $\mathrm{G} / \mathrm{H}_{\text {is }} \mathrm{H}_{6}$. So we can exclude symmetric spaces from our study of the holonomy of Riemannian manifolds.

Theorem 69. (Berger, 1953) Let $(\mathrm{M}, \mathrm{g})$ be an irreducible simply connected Riemannian manifold which is not isomorphic to a symmetric space. Then the holonomy $\mathrm{hol}^{\left(\nabla^{\mathrm{g}}\right)}$ of $(\mathrm{M}, \mathrm{g})$ is one of the following groups

\begin{tabular}{|c|c|l|}
\hline $\operatorname{nol}\left(\mathrm{V}^{\circ}\right)$ & $\operatorname{dim} \mathrm{M}$ & Type of the metric \\
\hline $\mathrm{SO}(\mathrm{n})$ & $\mathrm{n}$ & Generic Riemannian \\
\hline $\mathrm{U}(\mathrm{r})$ & $2 \mathrm{r}$ & Kähler \\
\hline $\mathrm{SU}(\mathrm{r}), \mathrm{r} \geq 3$ & $2 \mathrm{r}$ & Calabi-Yau \\
\hline $\mathrm{Sp}(\mathrm{r})$ & $4 \mathrm{r}$ & Hyper Kähler \\
\hline $\mathrm{Sp}(\mathrm{r}) \mathrm{Sp}(1)$ & $4 \mathrm{r}$ & Quaternion - Kähler \\
\hline $\mathrm{G}_{2}$ & 7 & Ricci Flat \\
\hline $\operatorname{Spin}(7)$ & 8 & Ricci Flat \\
\hline
\end{tabular}

Remark 70. (1) Initially it was thought that there is no manifold with holonomy $\mathrm{G}_{2}$ or $\mathrm{Spin}(7)$, but recently, D. Joyce was able to construct a compact 7-dimensional manifold with holonomy $\mathrm{G}_{2}$ (see [28] ), and a compact 8dimensional manifold with holonomy Spin (7), (see Joyce, 1996).

(2) $\operatorname{Since}(\mathrm{m}) \subset \mathrm{SU}(2 \mathrm{~m}) \subset \mathrm{U}(2 \mathrm{~m}) \subset \mathrm{SO}(4 \mathrm{~m})$

we deduce that every hyperkahler manifold is a Calabi- Yau manifold, every Calabi- Yau manifold is a Kähler manifold, and every Kähler manifold is orientable. Kähler manifolds will be introduced in Part 2, but we will not study the other types of manifolds in this paper.

(3) It is very well known that the groups appearing in Berger's list (Theorem 69) are connected to the three division algebras $\square$ (real numbers), ${ }^{c}$ (complex numbers), $\mathrm{H}$ (quaternions). The connection is stated as

- $\left.\begin{array}{l}\text { follows } \\ \text { - }(n)\end{array}\right)$ is a group of automorphism of $\square^{\mathrm{n}}$.

- $\mathrm{U}(\mathrm{n})$ and $\mathrm{SU}(\mathrm{n})$ are groups of automorphisms of $c^{\mathrm{n}}$.

- $\mathrm{Sp}(n)$ and $\mathrm{Sp}(n) \mathrm{Sp}(1)$ are groups of automorphisms of $\mathrm{H}^{\mathrm{n}}$, where $\mathrm{H}$ is the space of quaternions.

- $\mathrm{G}_{2}$ and $\mathrm{Spin}$ (7) can also be realized as automorphism groups of some other structures.

Kähler manifolds will be the subject of Part 2. As for the other classes of manifolds, excellent accounts can be found in (Salamon, 1989, Joyce, 2000, Beauville, 2006, Bryant, ).

\section{Part 2. Kähler manifolds}

We have seen in the previous part that if the holomony $\operatorname{hol}\left(\nabla^{\mathrm{g}}\right)$ of a simply connected irreducible complete Riemannian manifold $(\mathrm{M}, \mathrm{g})$ of dimension $2 n$ is icluded in $\mathrm{U}(\mathrm{n})$, then the manifold is "Kähler".

6 For more details on symmetric spaces, see [23]. 


\section{BOUDJEMAA ANCHOUCHE}

The aim in this part is to give a short introduction to" Kähler manifolds". Since we mentioned the Hodge decomposition theorem without proof, skipped some other fundamental results in Klihler geometry, and since most of the proofs are either sketchy or missing, we suggest the following references (Kobayashi and nomizu, 1969, Griffiths and Harris, 1978 and Demailly, ) for more detail.

\section{Holomorphic functions}

Definition 71. Let $\Omega$ be g nonempty gonnected open subset of $\mathrm{C}^{\mathrm{n}}$. A complex valued function $\mathrm{f}$ on $\Omega$ is called

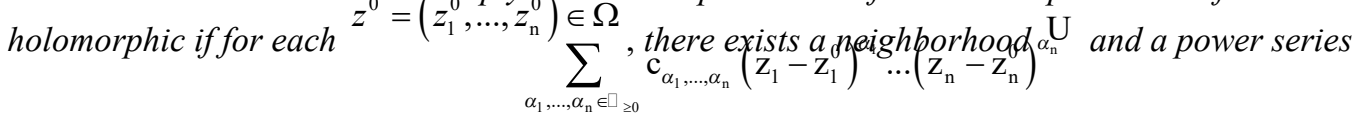

$$
\sum_{\alpha_{1}, \ldots, \alpha_{\mathrm{n}} \in \square}{ }_{\mathrm{c}_{20}} \mathrm{c}_{\alpha_{1}, \ldots, \alpha_{\mathrm{n}}}\left(\mathrm{z}_{1}-\mathrm{z}_{1}\right) \cdots\left(\mathrm{z}_{\mathrm{n}}-\mathrm{z}_{\mathrm{n}}\right)
$$

that converges to $\mathrm{f}(\mathrm{z})$ for $\mathrm{z} \in \mathrm{U}$, where $\mathrm{c}_{\alpha_{1}, \ldots, \alpha_{\mathrm{n}}}$ are complex numbers and $\square_{\geq 0}$ is the set of nonnegative integers. We denote by $H(\Omega)$ the set of holomorphic functions on $\Omega$.

Let $\mathrm{z}=\left(\mathrm{z}_{1}, \ldots, \mathrm{z}_{\mathrm{n}}\right)$ be the coordinate system of $\square^{\mathrm{n}}$. Write $\mathrm{z}_{j}=\mathrm{x}_{2 \mathrm{j}-1}+\sqrt{-1 \mathrm{x}_{2 \mathrm{j}}}$ and identify $\square^{\mathrm{n}}$ with $\square^{2 \mathrm{n}}$ via the correspondence

$$
\left(\mathrm{z}_{1}, \ldots, \mathrm{z}_{\mathrm{n}}\right) \mapsto\left(\mathrm{x}_{1}, \mathrm{x}_{2}, \ldots, \mathrm{x}_{2 \mathrm{n}}\right),
$$

and consider the following notatian $\frac{\partial}{\partial \mathbf{z}_{j}}:=\frac{\partial}{2}\left(\frac{\partial}{\partial \mathrm{x}_{2 j-1}}-\sqrt{-1} \frac{\partial}{\partial \mathrm{x}_{2 j}}\right), \frac{\partial}{\partial \overline{\mathbf{z}}_{j}}:=\frac{1}{2}\left(\frac{\partial}{\partial \mathrm{x}_{2 j-1}}+\sqrt{-1} \frac{\partial}{\partial \mathrm{x}_{2 j}}\right)$

The following characterization of holomorphic functions is very useful

Theorem 72.

$$
H(\Omega)=\left\{\mathrm{f} \in \mathrm{L}_{\text {loc }}^{2}(\Omega) \mid \frac{\partial \mathrm{f}}{\partial \overline{\mathrm{z}}_{\mathrm{j}}}=0 \text { for } \mathrm{j}=1,2, \ldots, \mathrm{n}\right\},
$$

where $\mathrm{L}_{\text {loc }}^{2}(\Omega)$ is the set of locally square integrable functions on $\Omega$ and the derivative is taken in the sense of distributions.

For a proof of Theorem 72 see (Ohsawa, 2002).

Definition 73. Let $\Omega$ (resp. $\Omega^{\prime}$ ) be a nonempty connected open subset of $\square^{\mathrm{n}}$ (resp. $\square^{m}$ ).

(1) A map

$$
\varphi=\left(\varphi_{1}, \ldots, \varphi_{\mathrm{k}}\right): \Omega \rightarrow \square^{\mathrm{m}}
$$

is called holomorphic if each $\varphi_{\mathrm{j}}: \Omega \rightarrow \square$ is holomorphic, $1 \leq \mathrm{j} \leq \mathrm{m}$. If $\varphi(\Omega) \subseteq \Omega^{\prime}$, then we write

$$
\varphi=\left(\varphi_{1}, \ldots, \varphi_{\mathrm{k}}\right): \Omega \rightarrow \Omega^{\prime}
$$

Suppose that $\mathrm{m}=n$. A holomorphic map

$$
\psi: \Omega \rightarrow \Omega^{\prime}
$$

is called a biholomorphism if there is a holomorphic map $\phi: \Omega \rightarrow \Omega$ 


\section{KÄHLER MANIFOLDS POSITIVE RICCI CURVATURE}

such that

$$
\psi \mathrm{o} \psi=\mathrm{id}_{\Omega^{\prime}} \text { and } \phi \mathrm{o} \Psi=\mathrm{id}_{\Omega},
$$

where $\operatorname{id}_{\Omega}$ (resp. ${ }^{\operatorname{id}_{\Omega^{\prime}}}$ ) is the identity map of $\Omega$ (resp. $\Omega^{\prime}$ ). In case $\Omega=\Omega^{\prime}$, a bihlomorphism $\psi: \Omega \rightarrow \Omega$ is called an automorphism of $\Omega$.

The set of automorphisms of $\Omega$ denoted by Aut $(\Omega)$ is a group under composition of mappings. A beautiful theorem of H. Carlan says that if $\Omega$ is a bounded domain in $\mathrm{c}^{\mathrm{n}}$, then Aut $(\Omega)$ is a Lie group. Bedford \& Dadok and Saerens and Zame proved independently that any compact Lie group can be realized as the automorphism group of a pseudoconvex domain in some $\mathrm{C}^{\mathrm{n}} 7$.

\section{Complex manifolds}

If in Definition 2 we consider open subsets of $\square^{\mathrm{n}}$ instead of open subsets of $\square^{\mathrm{n}}$, and biholomorphisms instead of $C^{\infty}$-diffeomorphism, then we get what we call" a complex structure" on $\mathrm{M}$.

Definition 74. A complex manifold of dimension $n$ is a pair $(\mathrm{M}, \psi)$, where $\mathrm{M}$ is a locally Euclidean space of dimension $n$ and $\Psi$ is a complex structure on $\mathrm{M}$. The manifold $(\mathrm{M}, \Psi)$ will be denoted simply by $\mathrm{M}$.

The pair $\left(\mathrm{U}_{\mathrm{i}}, \varphi_{\mathrm{i}}\right)\left(\right.$ or $\left.\left(\mathrm{U}_{\mathrm{i}}, \mathrm{z}_{1}, \ldots, \mathrm{z}_{\mathrm{n}}\right)\right)$, is called a local complex chart and $\left(\mathrm{z}_{1}, \ldots, \mathrm{z}_{\mathrm{n}}\right)$ is called a local complex coordinate system defined in $\mathrm{U}_{\mathrm{i}}$.

We have already defined in the category of $C^{\infty}$ - manifolds what. we mean by a submanifold, an embedding, an immersion, a $C^{\infty}$-map between manifolds, isomorphism of vector bundles, pull back of vector bundles,...etc. With obvious modifications, we get the notions of complex submanifolds, holomorphic embeddings,...etc.

For more details, the interested reader can consult (Kobayashi and Nomizu (1969) or other textbooks dealing

with complex manifolds.
If $\left(U_{i}, \varphi_{i}\right)$, is called a local complex chart and $\left(z_{1}, \ldots, z_{n}\right)$ is a local complex coordinate system defined in $U_{i}$,

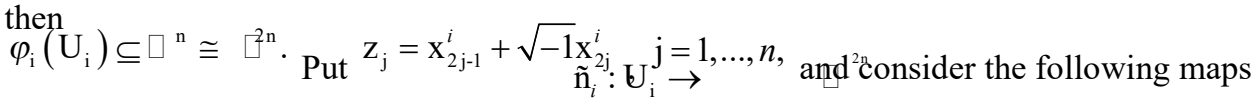

$$
\mathrm{m} \mapsto\left(\mathrm{x}_{1}^{i}(\mathrm{~m}), \ldots, \mathrm{x}_{2 \mathrm{n}}^{i}(\mathrm{~m})\right),
$$

The maps

$$
\tilde{\mathrm{n}}_{\alpha} \circ \tilde{\mathrm{n}}_{\beta}^{-1}: \tilde{\mathrm{n}}_{\beta}\left(\mathrm{U}_{\alpha} \cap \mathrm{U}_{\beta}\right) \rightarrow \tilde{\mathrm{n}}_{\alpha}\left(\mathrm{U}_{\alpha} \cap \mathrm{U}_{\beta}\right)
$$

are $C^{\infty}$ - diffeomprphisms.

The collection $\left({ }_{i}, \mathrm{n}_{i}\right)_{\text {iel }}$ is a $C^{\infty}$-atlas on $\mathrm{M}$. This $C^{\infty}$-structure on $\mathrm{M}$ is called the underlying $C^{\infty}$-structure of the complex manifold $\mathrm{M}$.

An example of a complex manifold, which will play a fundamental role in what follows, is given by:

Example 75. The projective space $\mathrm{P}^{\mathrm{n}}$

The projective space deserves a special attention. Since it plays a very important role in what follows, we will try to describe it in some detail. As a set, the projective space is defined by 


\section{BOUDJEMAA ANCHOUCHE}

$$
\mathrm{P}^{\mathrm{n}}=\left(\square^{\mathrm{n}+1} \backslash\{0\}\right) / \square
$$

where the equivalence $\downarrow$ is defined by
$\left(\mathrm{z}_{0}, \ldots, \mathrm{z}_{\mathrm{n}}\right)$
\[ \left(\mathrm{w}_{0}, \ldots, \mathrm{w}_{\mathrm{n}}\right) \stackrel{\text { such that }}{\Leftrightarrow}\left(\mathrm{z}_{0}, \ldots, \mathrm{z}_{\mathrm{n}}\right)=\mathrm{h}\left(\mathrm{w}_{0}, \ldots, \mathrm{w}_{\mathrm{n}}\right) . \]

Denote by $\pi$ the projection

$$
\begin{aligned}
\pi: \square^{\mathrm{n}+1} \backslash\{0\} \rightarrow & \mathrm{P}^{\mathrm{n}} \\
\left(\mathrm{z}_{0}, \ldots, \mathrm{z}_{\mathrm{n}}\right) & \mapsto\left[\mathrm{z}_{0}, \ldots, \mathrm{z}_{\mathrm{n}}\right],
\end{aligned}
$$

where $\left[\mathrm{z}_{0}, \ldots, \mathrm{z}_{\mathrm{n}}\right]$ is the equivalence class of $\left(\mathrm{z}_{0}, \ldots, \mathrm{z}_{\mathrm{n}}\right)$. The projective space $\mathrm{P}^{\mathrm{n}}$ can be equipped with a complex atlas $\left(\mathrm{U}_{i}, \varphi_{\mathrm{i}}\right)_{0 \leq \mathrm{i} \leq \mathrm{n}}$ as follows: Let

$$
\begin{gathered}
\tilde{\mathrm{U}}_{i}=\left\{\left.\left(\mathrm{z}_{0}, \ldots, \mathrm{z}_{\mathrm{n}}\right) \in \mathrm{C}^{\mathrm{n}+1}\right|_{\mathrm{z}_{i}} \neq 0\right\}, \quad \mathrm{i}=0, \ldots, \mathrm{n}, \\
\psi_{i}: \quad \tilde{\mathrm{U}}_{i} \rightarrow \square^{\mathrm{n}}
\end{gathered}
$$

and consider the following map

$$
\left(\mathrm{z}_{0}, \ldots, \mathrm{z}_{\mathrm{n}}\right) \mapsto\left(\frac{\mathrm{z}_{0}}{\mathrm{z}_{i}}, \ldots, \frac{\mathrm{z}_{\mathrm{i}-1}}{\mathrm{z}_{\mathrm{i}}}, \frac{\mathrm{z}_{\mathrm{i}+1}}{\mathrm{z}_{\mathrm{i}}}, \ldots, \frac{\mathrm{z}_{\mathrm{n}}}{\mathrm{z}_{i}}\right),
$$

The maps $\Psi_{i}$ are continuous and it is clear that

$$
\text { Let } \begin{aligned}
\mathrm{U}_{i}=\pi\left(\tilde{\mathrm{U}}_{i}\right) \text {.Then the map } \quad \varphi_{i}: \quad \mathrm{U}_{i} \rightarrow \square^{\mathrm{n}} \\
{\left[\mathrm{z}_{0}, \ldots, \mathrm{z}_{\mathrm{n}}\right] \mapsto\left(\frac{\mathrm{z}_{0}}{\mathrm{z}_{i}}, \ldots, \frac{\mathrm{z}_{\mathrm{i}-1}}{\mathrm{z}_{\mathrm{i}}}, \frac{\mathrm{z}_{\mathrm{i}+1}}{\mathrm{z}_{\mathrm{i}}}, \ldots, \frac{\mathrm{z}_{\mathrm{n}}}{\mathrm{z}_{i}}\right) }
\end{aligned}
$$

$$
\psi_{i}\left(\mathrm{z}_{0}, \ldots, \mathrm{z}_{\mathrm{n}}\right)=\psi_{i}\left(\mathrm{y}_{0}, \ldots, \mathrm{y}_{\mathrm{n}}\right) \Leftrightarrow\left[\mathrm{z}_{0}, \ldots, \mathrm{z}_{\mathrm{n}}\right]=\left[\mathrm{y}_{0}, \ldots, \mathrm{y}_{\mathrm{n}}\right]
$$

is a well defined bijective map. The maps $\varphi_{i}$ are open, for, if $\mathrm{V}$ is an open subset of $\mathrm{U}_{i}$, then

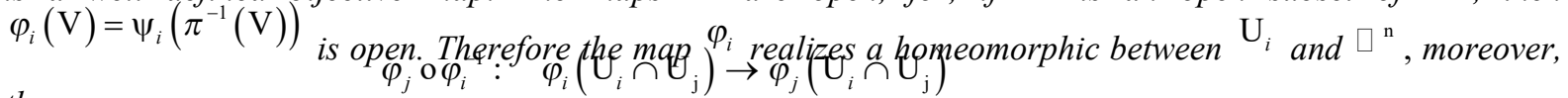
the maps

$$
\left(\mathrm{z}_{0}, \ldots, \mathrm{z}_{\mathrm{n}-1}\right) \mapsto\left(\frac{\mathrm{z}_{0}}{\mathrm{z}_{j}}, \ldots, \frac{\mathrm{z}_{\mathrm{i}-1}}{\mathrm{z}_{\mathrm{j}}}, \frac{1}{\mathrm{z}_{j}}, \frac{\mathrm{z}_{\mathrm{i}+1}}{\mathrm{z}_{\mathrm{j}}}, \ldots, \frac{\mathrm{z}_{\mathrm{n}-1}}{\mathrm{z}_{j}}\right),
$$

are biholomorphic.

Thus $\left(\mathrm{U}_{i}, \varphi_{\mathrm{i}}\right)_{1 \leq \mathrm{i} \leq \mathrm{n}}$ as defined above is a complex atlas, which gives $\mathrm{P}^{\mathrm{n}}$ the structure of a complex manifold. The projective space $\mathrm{P}^{\mathrm{n}}$ is a compact complex $\underset{\mathrm{P}^{\mathrm{n}}}{\operatorname{manold}}=\pi\left(\mathrm{S}^{2 \mathrm{n}+4}\right)$,

where

$$
\mathrm{S}^{2 \mathrm{n}+1}=\left\{\left.\left(\mathrm{z}_{0}, \ldots, \mathrm{z}_{\mathrm{n}}\right) \in \square^{\mathrm{n}+1}|| \mathrm{z}_{0}\right|^{2}+\ldots+\left|\mathrm{z}_{\mathrm{n}}\right|^{2}=1\right\}
$$

Example 76. The following are complex manifolds: 


\section{KÄHLER MANIFOLDS POSITIVE RICCI CURVATURE}

(1) $\square^{\mathrm{n}}$.

(2) Any open subset of $\square^{\mathrm{n}}$.

(3) Let $\mathrm{G}(\mathrm{r}, n)$ be the set of all $\mathrm{r}$-dimensional vector subspaces of $\square^{\mathrm{n}}$, called the Grassmannian manifold of $\mathrm{r}$ linear subspaces of $\square^{\mathrm{n}}$. It can be proved that $\mathrm{G}(\mathrm{r}, n)$ is a compact complex manifold of dimension $\mathrm{r}(\mathrm{n}-\mathrm{r})$. If $\mathrm{r}=1$, then we get the projective space $\mathrm{P}^{\mathrm{n}}$.

(4) If $\mathrm{M}_{1}$ and $\mathrm{M}_{2}$ are complex manifolds, then $\mathrm{M}_{1} \times \mathrm{M}_{2}$ is a complex manifold. More examples of complex manifolds will be given below.

Definition 77. A complex Lie group is a comfexGanifed $\mathrm{G}$ endowed with a group structure such that the map

$$
(\mathrm{g}, \mathrm{h}) \mapsto v(\mathrm{~g}, \mathrm{~h})=\mathrm{gh}^{-1},
$$

is holomorphic.

Example 78. The following are complex Lie groups:

(1) The linear group $\mathrm{GL}(\mathrm{n}, \square):$ is the set of all $n \times n$ invertible matrices with complex entries.

(2) Special linear group:

$$
\operatorname{SL}(\mathrm{n}, \square)=\{\mathrm{A} \in \mathrm{GL}(\mathrm{n}, \square) \mid \operatorname{det} \mathrm{A}=1\} .
$$

(3) The special orthogonal group

$$
\operatorname{SO}(\mathrm{n}, \square)=\left\{\mathrm{A} \in \mathrm{SL}(\mathrm{n}, \square) \mid \mathrm{A}^{\top} \mathrm{A}=\mathrm{I}_{\mathrm{n}}\right\}
$$

(4) The complex symplectic group:

$$
\operatorname{Sp}(\mathrm{n}, \square)=\left\{\mathrm{A} \in \mathrm{GL}(2 \mathrm{n}, \square) \mid \mathrm{A}^{\top} \mathrm{JA}=\mathrm{J}\right\}
$$

where

$$
J=\left(\begin{array}{cc}
0 & -I_{n} \\
I_{n} & 0
\end{array}\right),
$$

and $\mathrm{I}_{\mathrm{n}}$ is the identity matrix of $\mathrm{GL}(\mathrm{n}, \square)$.

For more details, the interested reader can consult (Warner,1983, Knapp,2001 or Helgason,1970).

\section{Quotient Manifolds}

A very important procedure to construct new complex manifolds from known ones is given as follows. Let $\mathrm{G}$ be a subgroup of the group of automorphisms of a complex manifold M. It is easy to see that the relation $\sqcup$ defined in $\mathrm{M}$ by $\mathrm{x} \square \mathrm{y}$ if there exists an element $\mathrm{g} \in \mathrm{G}$ such that $\mathrm{y}=\mathrm{g}(\mathrm{x})$ is an equivalence relation. The set of equivalence classes is denoted by $\mathrm{M} / \mathrm{G}$.In general, the quotient space $\mathrm{M} / \mathrm{G}$ of a complex manifold $\mathrm{M}$ is not necessarily a complex manifold. But by imposing some constraints on $\mathrm{G}$, the complex structure on $\mathrm{M}$ will induce a complex structure on the quotient $\mathrm{M} / \mathrm{G}$.

Definition79. (1) A subgroup $\mathrm{G}$ of the automorphism group of a complex manifold $\mathrm{M}$ is said to be properly discontinuous if for every compact sets $\mathrm{K}_{1}$ and $\mathrm{K}_{2}$ of $\mathrm{M}$,

$$
\#\left\{\mathrm{~g} \in \mathrm{G} \mid \mathrm{g}\left(\mathrm{K}_{1}\right) \cap \mathrm{K}_{2} \neq \phi\right\}<+\infty \text {, }
$$

i.e., the number of elements $\mathrm{g} \in \mathrm{G}$ such that $\mathrm{g}\left(\mathrm{K}_{1}\right) \cap \mathrm{K}_{2} \neq \phi \quad$ is finite. 


\section{BOUDJEMAA ANCHOUCHE}

(2) The subgroup $\mathrm{G}$ is said to be fixed point free if no element of $\mathrm{G} \backslash\left\{\mathrm{id}_{\mathrm{M}}\right\}$ has a fixed point, where $\mathrm{Id}_{\mathrm{M}}$ is the identity automorphism of $\mathrm{M}$.

Theorem 80. Let $\mathrm{G}$ be a subgroup of the group of automorphisms of a complex manifold $\mathrm{M}$. If $\mathrm{G}$ is fixed point free and properly discontinuous, then the quotient space $\mathrm{M} / \mathrm{G}$ has a canonical structure of a complex manifold induced from that of $\mathrm{M}$.

Example 81. Torus. Consider the vector space $\square^{\mathrm{n}}$ (which has the structure of a complex Lie graup) and take $2 n$ vectors
$v_{j}=\left(v_{j}, \ldots, v_{j}^{n}\right), \mathrm{j}=1, \ldots, 2 n$
which are $\square$-linearly independent. The vectors subgroup

$$
G=\left\{\sum_{j=1}^{2 n} r_{j} v_{j} \mid r_{j} \in \square\right\},
$$

of $\square^{\mathrm{n}}$. Then it can be shown that $\mathrm{T}^{\mathrm{n}}=\square^{\mathrm{n}} / \mathrm{G}$ is (avepmpoct ${ }^{\mathrm{n}}$ ) complex manifold (actually a compact complex commutative Lie group) called a Torus. The vectors $\left\{U_{j}\right\}_{1 \leq j \leq 2 \mathrm{n}}$. are called the periods of $\mathrm{T}^{\mathrm{n}}$ and the matrix

$$
\Lambda=\left(\begin{array}{ccc}
\cdot & \cdots & \cdot \\
\cdot & \cdots & \cdot \\
v_{2 \mathrm{n}}^{1} & \cdots & v_{2 \mathrm{n}}^{1}
\end{array}\right)
$$

is called the period matrix.

Example 82. Hopf Manifold.
Let $\varphi_{1}, \ldots, \varphi_{\mathrm{n}}$ an be $n$ complex numbers such that $\left|\alpha_{\mathrm{j}}\right|>1$ for $\mathrm{j}=1, \ldots, n$, and let $\mathrm{G}=\langle\mathrm{g}\rangle$ be the cyclic group generated by the automorphism

$$
\begin{aligned}
\mathrm{g}: \square^{\mathrm{n}} \backslash\{(0, \ldots, 0)\} & \rightarrow \quad \square \backslash\{(0, \ldots, 0)\} \\
\left(\mathrm{z}_{1}, \ldots, \mathrm{z}_{\mathrm{n}}\right) & \mapsto\left(\alpha_{1} \mathrm{z}_{1}, \ldots, \alpha_{\mathrm{n}} \mathrm{z}_{\mathrm{n}}\right) .
\end{aligned}
$$

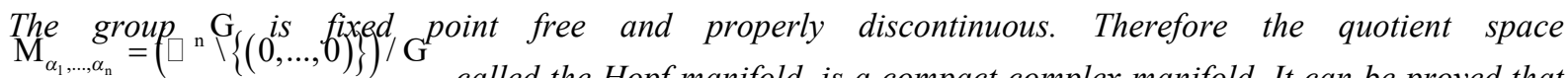
, called the Hopf manifold, is a compact complex manifold. It can be proved that $\mathrm{M}_{\alpha_{1}, \ldots, \alpha_{\mathrm{n}}}$ is diffeomorphic to $\mathrm{S}^{2 \mathrm{n}-1} \times \mathrm{S}^{1}$, where $\mathrm{S}^{\mathrm{j}}$ is the $\mathrm{j}_{\text {-dimensional sphere. }}$

Example 83. Iwasawa manifold.

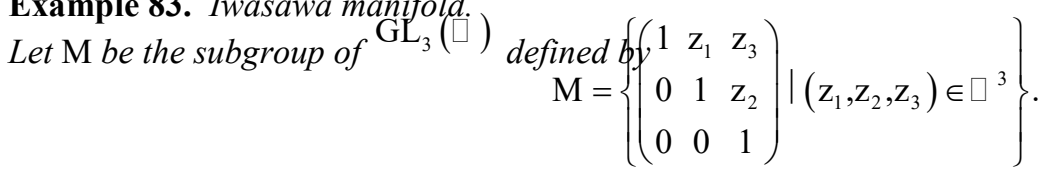




\section{KÄHLER MANIFOLDS POSITIVE RICCI CURVATURE}

Denote by $\mathrm{G}$ the discrete group of matrices with entries in the ring of Gaussian integers

$[i]=\{a+b i \mid a, b \in\}$, i.e.,

$$
\mathrm{G}=\left\{\left(\begin{array}{ccc}
1 & \mathrm{z}_{1} & \mathrm{z}_{3} \\
0 & 1 & \mathrm{z}_{2} \\
0 & 0 & 1
\end{array}\right) \mid\left(\mathrm{z}_{1}, \mathrm{z}_{2}, \mathrm{z}_{3}\right) \in(\square[\mathrm{i}])^{3}\right\},
$$

It can be shown $\mathrm{G}$ acts by biholomorphisms on $\mathrm{M}$ such that the quotient $\mathrm{M} / \mathrm{G}$, known as the Iwasawa manifold, is a compact complex manifold, with $\operatorname{dim}_{\square}(\mathrm{M} / \mathrm{G})=3$.

\section{Blow-Up of Manifolds}

A second procedure to construct new complex manifolds from given ones is the blow-up. In this section we will explain what is meant by blowing up a complex manifold at a point.

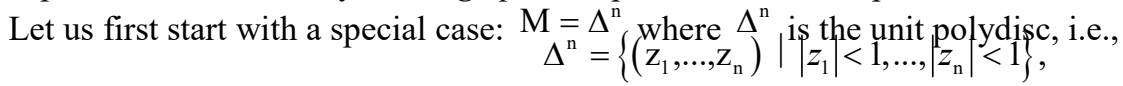

and consider the following set $\Delta_{0}^{\mathrm{n}}:=\left\{\left(\left(\mathrm{z}_{1}, \ldots, \mathrm{z}_{\mathrm{n}}\right),\left[\mathrm{w}_{1}, \ldots, \mathrm{w}_{\mathrm{n}}\right]\right) \in \Delta^{\mathrm{n}} \times \mathrm{P}^{\mathrm{n}-1} \mid \mathrm{z}_{\mathrm{i}} \mathrm{w}_{\mathrm{j}}-\mathrm{z}_{\mathrm{j}} \mathrm{w}_{\mathrm{i}}=0\right\}$

It can be shown that $\Delta_{0}^{\mathrm{n}}$ is a complex manifold and that

$$
\Delta^{\mathrm{n}} \backslash\{0\} \stackrel{\text { biholomorphic }}{\cong} \Delta_{0}^{\mathrm{n}} \backslash \pi^{-1}(0)
$$

and

$$
\pi^{-1}(0) \cong \mathrm{P}^{\mathrm{n}-1}
$$

where $\pi$ is the projection

$$
\begin{aligned}
\pi: \Delta_{0}^{\mathrm{n}} & \rightarrow \Delta^{\mathrm{n}} \\
\left(\left(\mathrm{z}_{1}, \ldots, \mathrm{z}_{\mathrm{n}}\right),\left[\mathrm{w}_{1}, \ldots, \mathrm{w}_{\mathrm{n}}\right]\right) & \mapsto\left(\mathrm{z}_{1}, \ldots, \mathrm{z}_{\mathrm{n}}\right)
\end{aligned}
$$

The complex manifold $\Delta_{0}^{\mathrm{n}}$ is called the blow-up of $\Delta^{\mathrm{n}}$ and $E=\pi^{-1}(0)$ is called the exceptional divisor.

Consider now the general case, i.e., let $\mathrm{M}$ be a complex manifold, $\operatorname{dim}_{\square} \mathrm{M}=n$ and let $\mathrm{m}$ be a point of $\mathrm{M}$. The "blow up" of $\mathrm{M}$ at $\mathrm{m}$ is defined as follows: Let $(\mathrm{U}, \varphi)$ be a local chart, with $\mathrm{m} \in \mathrm{U}, \varphi(\mathrm{m})=0$ and $\varphi(\mathrm{U})=\Delta^{\mathrm{n}}$, the unit polydisc in $\mathrm{c}^{\mathrm{n}}$. Then

Definition 84. The blow up of $\mathrm{M}$, denoted by $\mathrm{M}_{\mathrm{m}}$ is defined as follows

$$
\mathrm{M}_{\mathrm{m}}:=(\mathrm{M} \backslash\{\mathrm{m}\}) \cup_{\pi} \Delta_{0}^{\mathrm{n}}
$$

where $(\mathrm{M} \backslash\{\mathrm{m}\}) \cup_{\pi} \Delta_{0}^{\mathrm{n}}$ means that $\mathrm{U}$ is replaced with $\Delta_{0}^{\mathrm{n}}$.

It can be shown that the definition of $\mathrm{M}_{\mathrm{m}}$ is independent of the choice of the local coordinates.

From the definition, we see that $\overrightarrow{\mathrm{M}}_{\mathrm{m}}$ is a complex manifold which comes equipped with a projection

$$
\pi: \quad \mathrm{M}_{\mathrm{m}} \rightarrow \mathrm{M} \text {, }
$$

such that

$$
\mathrm{M}_{\mathrm{m}} \backslash \pi^{-1}(\mathrm{~m}) \stackrel{\text { biholomorphism }}{\cong} \mathrm{M} \backslash\{\mathrm{m}\}
$$




\section{BOUDJEMAA ANCHOUCHE}

and $\pi^{-1}(\mathrm{~m}) \cong \mathrm{P}^{\mathrm{n}-1}$ is called the exceptional divisor.

\section{Holomorphic vector bundles}

Definition 85. Let $\mathrm{M}$ be a complex manifold of dimension $\mathrm{n}$. A holomorphic vector bundle of rank rover $\mathrm{M}$ is a complex manifold $\mathrm{E}$ together with

(1) A surjective holomorphic map $\pi: E \rightarrow \mathrm{M}$, such that $E_{\mathrm{x}}=\pi^{-1}(\mathrm{x})$ has a structure of a complex $\mathrm{r}$ dimensional vector space, where $\mathrm{r}$ is independent of $\mathrm{x}$.

(2) An open covering $\left(\mathrm{C}_{\alpha \in \mid}\right.$ of $\mathrm{M}$ and biholomorphisms $\alpha$ called trivializations

$$
\varphi_{\alpha}: E_{\mathrm{U}_{\alpha}}=\pi^{-1}\left(\mathrm{U}_{\alpha}\right) \rightarrow \mathrm{U}_{\alpha} \times \square^{r}
$$

such that for each $\mathrm{x} \in \mathrm{U}_{\alpha}$, the map

$$
E_{\mathrm{x}} \stackrel{\varphi \alpha}{\longrightarrow}\{\mathrm{x}\} \times \square^{\mathrm{r}} \rightarrow \square
$$

is $a \square$-linear isomorphism. Example 86.

(1) If $\mathrm{M}$ is a complex manifold, then $\mathrm{M} \times \square^{r}$ is a vector bundle of rank ${ }^{\mathrm{r}}$, called the trivial bundle.

(2) The tangent bundle $\mathrm{T}^{1,0} \mathrm{M}$ of a complex manifold $\mathrm{M}$ (see 9 below for a definition).

(3) Let $\mathrm{M}$ be a compact complex manifold and denote by $\mathrm{M}$ its universal cover,

$\pi_{1}(\mathrm{M})$ its fundamental group acting on $\mathrm{M}$ on the right, and let $\rho: \pi_{1}(\mathrm{M}) \rightarrow \mathrm{GL}(\mathrm{V})$ be a complex linear representation of $\pi_{1}(\mathrm{M})$. Then $\mathrm{V}_{\rho}=\mathrm{M} \times{ }_{\rho} \mathrm{V}$ is a holomorphic vector bundle over $\mathrm{M}$, where $\mathrm{M} \times{ }_{\rho} \mathrm{V}=\mathrm{M} \times \mathrm{V} / \square$,

and

$$
\begin{aligned}
\left(\mathrm{m}_{1}, \mathrm{v}_{1}\right) \square\left(\mathrm{m}_{2}, \mathrm{v}_{2}\right) \Leftrightarrow & \exists \mathrm{g} \in \pi_{1}(\mathrm{M}) \text { such that } \\
& \mathrm{m}_{2}=\mathrm{m}_{1} \cdot \mathrm{g} \text { and } \mathrm{v}_{2}=\rho\left(\mathrm{g}^{-1}\right) \mathrm{v}_{1}
\end{aligned}
$$

\section{Almost Complex Manifolds}

Definition 87. An almost complex structure $\mathrm{J}$ on a $C^{\infty}$-differentiable manifold $\mathrm{M}$ is a section of $\mathrm{E} n \mathrm{~d}(\mathrm{TM})$, such that at each $\mathrm{m} \in \mathrm{M}, \mathrm{J}_{\mathrm{m}}^{2}=-\mathrm{id}_{\mathrm{T}_{\mathrm{m}} \mathrm{M}}$, where ${ }^{\mathrm{id}_{\mathrm{T}_{\mathrm{m}} \mathrm{M}}}$ is the identity transformation of $\mathrm{T}_{\mathrm{m}} \mathrm{M}$. An almost complex manifold is a pair $(\mathrm{M}, \mathrm{J})$ where $\mathrm{M}$ is a $C^{\infty}$-differentiable manifold and $\mathrm{J}$ is an almost complex structure.

Remark 88. (1) It can be shown that every almost complex manifold is orientable and of even dimension.

(2) Not every orientable manifold of even dimension can carry an almost complex structure, for example Borel and Serre (1951) proved that the spheres $\mathrm{S}^{\mathrm{n}}$ do not admit an almost complex structures if $n \neq 2,6$.

Proposition 89. Every complex manifold cames an almost complex structure.

Let $\left(z_{1}, \ldots, z_{n}\right) \in \square^{n}$, and put $z_{j}=x_{2 j-1}+\sqrt{-1 x_{2 j}}$ With respect to the coordinate system $\left(x_{1}, \ldots, x_{n}, x_{n+1}, \ldots, x_{2 n}\right)$, we

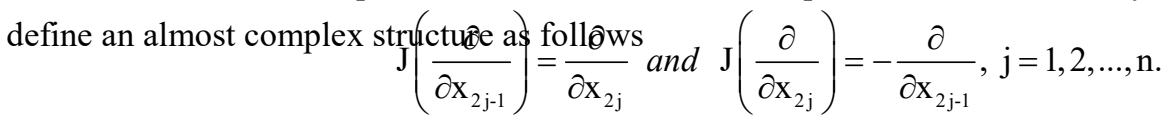




\section{KÄHLER MANIFOLDS POSITIVE RICCI CURVATURE}

Therefore, every complex manifold is an almost complex manifold. The converse is not true in general, i.e., an almost complex manifold need not be a complex manifold. But if we impose some restrictions on the almost complex structure then the converse becomes true. Define the torsion $N_{\mathrm{J}}$ of an almost complex structure $\mathrm{J}$ by

$$
N_{\mathrm{J}}(\mathrm{X}, \mathrm{Y})=[\mathrm{JX}, \mathrm{JY}]-[\mathrm{X}, \mathrm{Y}]-\mathrm{J}[\mathrm{X}, \mathrm{JY}]-\mathrm{J}[\mathrm{JX}, \mathrm{Y}]
$$

where $\mathrm{X}$ and $\mathrm{Y}$ are vector fields. The torsion $N_{\mathrm{J}}$ is a tensor, called the Nijenhuis tensor.

Definition 90. An almost complex structure is said to be integrable if has no torsion, i. e., if ${ }^{N_{\mathrm{J}}(\mathrm{X}, \mathrm{Y})=0}$ for all vector fields $\mathrm{X}$ and $\mathrm{Y}$.

Theorem 91. (Newlander and Nirenberg, 1957) An almost complex structure is a complex structure if and only if it has no torsion.

Let $\mathrm{M}$ be a complex manifold and $\mathrm{J} \in \mathrm{E} n d(\mathrm{TM})$ be the almost complex structure induced from the complex

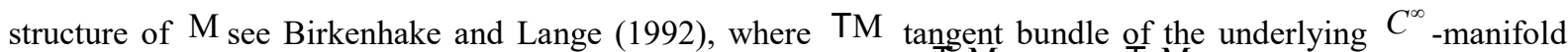
$M$. The endomorphism $J$ extends to the complex vector bundle $T_{\square} M$, where $T_{\square} M$ is the complexification of the real tangent space of the underlying $C^{\infty}$-manifold $\mathrm{M}$, i.e., $\mathrm{T}_{\square} \mathrm{M}=\mathrm{TM} \otimes{ }_{\square}$. From $\mathrm{J}^{2}=-\mathrm{id}_{\mathrm{T}_{\square} \mathrm{M}}$, we deduce that

$$
\begin{gathered}
T_{\square} M=T^{1,0} M \oplus T^{1,0} M, \\
T^{1,0} M=\left\{X \in T_{\square} M \mid J X=\sqrt{-1} X\right\} \text { and } T^{1,0} M=\left\{X \in T_{\square} M \mid J X=-\sqrt{-1} X\right\}
\end{gathered}
$$

Then $\mathrm{T}^{1,0} \mathrm{M}$ is a holomorphic vector bundle of rank $n$ and $\mathrm{T}^{1,0} \mathrm{M}$ is the conjugate of $\mathrm{T}^{1,0} \mathrm{M}$, i.e., $\mathrm{T}^{1,0} \mathrm{M} \cong \overline{\mathrm{T}^{1,0} \mathrm{M}}$. We can identify $\mathrm{TM}$ with $\mathrm{T}^{1,0} \mathrm{M}_{1}$ via the correspondence

$$
\mathrm{TM} \ni \mathrm{X} \mapsto \frac{1}{2}(\mathrm{X}-\sqrt{-1 \mathrm{JX}}) \in \mathrm{T}^{1,0} \mathrm{M}
$$

Consider a local complex chart $\left(\mathrm{U},\left(z_{1}, \ldots, z_{\mathrm{n}}\right)\right)$ where $z_{j}=\mathrm{x}_{2 j-1}+\sqrt{-1} \mathrm{x}_{2 j}$. Then $\left(\frac{\partial}{\partial \mathrm{x}_{1}}, \ldots, \frac{\partial}{\partial \mathrm{x}_{2 \mathrm{n}}}\right)$ (10)

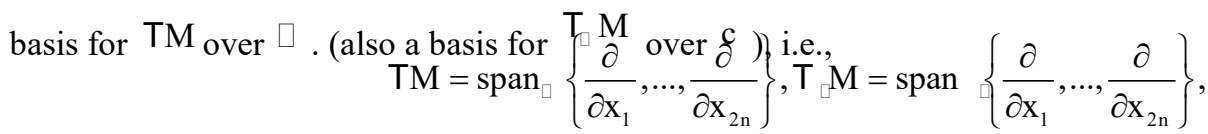

and $\left(\frac{\partial}{\partial \mathbf{z}_{1}}, \ldots, \frac{\partial}{\partial \mathbf{z}_{2 n}}\right)$ (resp. $\left(\frac{\partial}{\partial \overline{\mathbf{z}}_{1}}, \ldots, \frac{\partial}{\partial \overline{\mathbf{z}}_{2 \mathrm{n}}}\right)$ ) a basis for $\left.\mathrm{T}^{1,0} \mathrm{M}_{(\text {resp. }} \mathrm{T}^{1,0} \mathrm{M}\right)$, where $\frac{\partial}{\partial \mathbf{z}_{1}}$ and $\frac{\partial}{\partial \overline{\mathbf{z}}_{1}}$ are as in 7 , in other words,

$$
\mathrm{T}_{\square} \mathrm{M}=\operatorname{span}\left\{\frac{\partial}{\partial \mathbf{z}_{1}}, \ldots, \frac{\partial}{\partial \mathbf{z}_{\mathrm{n}}}, \frac{\partial}{\partial \overline{\mathbf{z}}_{1}}, \ldots, \frac{\partial}{\partial \overline{\mathbf{z}}_{\mathrm{n}}}\right\},
$$

and

$$
\mathrm{T}^{1,0} \mathrm{M}=\operatorname{span}_{\square}\left\{\frac{\partial}{\partial \mathbf{z}_{1}}, \ldots, \frac{\partial}{\partial \mathbf{z}_{\mathrm{n}}}\right\}, \mathrm{T}^{1,0} \mathrm{M}=\operatorname{span}\left\{\frac{\partial}{\partial \overline{\mathbf{z}}_{1}}, \ldots, \frac{\partial}{\partial \overline{\mathbf{z}}_{\mathrm{n}}}\right\}
$$

The dual of the holomorphic vector bundle $\mathrm{T}^{1,0} \mathrm{M}$ will be denoted by $\Omega_{\mathrm{M}}^{1}$. Let $\mathrm{M}$ and $\mathrm{N}$ be two complex manifolds. Recall that a $C^{\infty}$-map $\mathrm{f}: \mathrm{M} \rightarrow N$ between the underlying $C^{\infty}$ manifolds is said to be holomorphic if 


\section{BOUDJEMAA ANCHOUCHE}

$$
\psi \text { of o } \varphi^{-1}: \varphi(\mathrm{U}) \rightarrow \psi(\mathrm{V}) \text { is a holomorphic map, }
$$

for all local complex charts $(\mathrm{U}, \varphi)$ of $\mathrm{M}$ and $(\mathrm{V}, \psi)$ of $N$ such that $\mathrm{U} \subset \varphi^{-1}(\mathrm{~V})$. At each point $\mathrm{m} \in \mathrm{M}$, the differential

$$
\text { df }: T_{m} M \rightarrow T_{f(m)} N \text {, }
$$

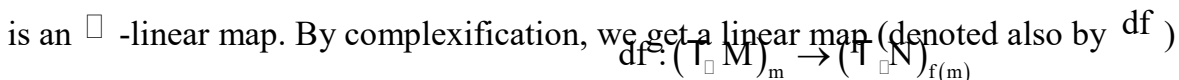

In general

$$
\text { df : }\left(\left(\mathrm{T}^{1,0} \mathrm{M}\right)_{\mathrm{m}}\right) \not \subset\left(\mathrm{T}^{1,0} \mathrm{~N}\right)_{\mathrm{f}(\mathrm{m})}
$$

It can be shown that

Theorem 92. Let $\mathrm{M}$ and $\mathrm{N}$ be two complex manifolds and $\mathrm{f}: \mathrm{M} \rightarrow \mathrm{N}{ }_{a} C^{\infty}$-map between the underlying $C^{\infty}$ -

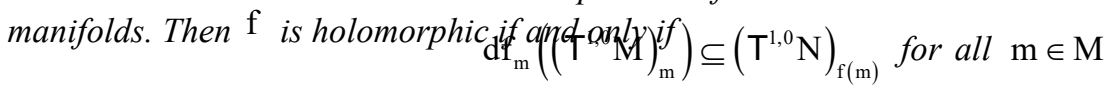

\section{Differential forms on complex manifolds}

Let $\mathrm{M}$ be a complex manifold of dimension $n, \omega$ a differential $\mathrm{p}_{\text {-form, }}(\mathrm{U}, \varphi)$ a local chart and let $\left(\mathrm{z}_{1}, \ldots, \mathrm{z}_{\mathrm{n}}\right)$ be the system of complex coordinates associated to ${ }^{\varphi}$. Put $z_{j}=x_{2 j-1}+\sqrt{-1} x_{2 j}$. Then $\left(x_{1}, \ldots, x_{n}, x_{n+1}, \ldots, x_{2 n}\right)$ are

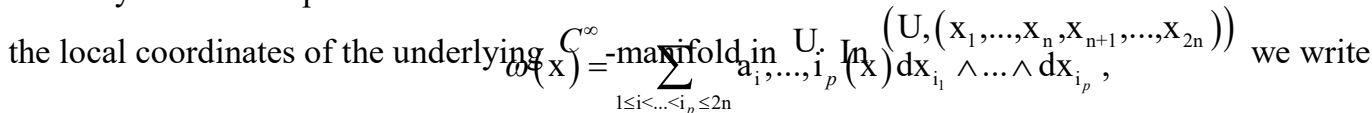

where $\mathrm{a}_{\mathrm{i}}, \ldots, \mathrm{i}_{p}$ are complex valued functions on $\mathrm{U}$. From

$$
z_{j}=z_{j}=x_{2 j-1}+\sqrt{-1} x_{2 j}, \bar{z}_{j}=x_{2 j-1}-\sqrt{-1} x_{2 j}
$$

we deduce that

$$
\mathrm{x}_{2 \mathrm{j}-1}=\frac{1}{2}\left(\mathrm{z}_{\mathrm{j}}+\overline{\mathrm{z}}_{\mathrm{j}}\right), \quad \mathrm{x}_{2 \mathrm{j}}=\frac{1}{2 \sqrt{-1}}\left(\mathrm{z}_{j}-\overline{\mathrm{z}}_{j}\right)
$$

Hence,

$$
\mathrm{dx}_{2 \mathrm{j}-1}=\frac{1}{2}\left(\mathrm{dz}_{\mathrm{j}}+\mathrm{d} \bar{z}_{\mathrm{j}}\right) \text { and } \mathrm{dx}_{2 \mathrm{j}}=\frac{1}{2 \sqrt{-1}}\left(\mathrm{dz} \mathrm{z}_{\mathrm{j}}-\mathrm{d} \bar{z}_{\mathrm{j}}\right)
$$

By substituting 12 in 11 , we $\sum_{\mathrm{r}+\mathrm{s}=\mathrm{p}} \mathrm{b}_{\mathrm{j}, \ldots \mathrm{j}_{p}, \overline{\mathrm{k}}_{1}, \ldots, \overline{\mathrm{k}}_{s}}(z) \mathrm{dz} \mathrm{z}_{\mathrm{j} 1} \wedge \ldots \wedge \mathrm{dz}_{\mathrm{j}_{r}} \wedge \mathrm{d} \overline{\mathrm{z}}_{\mathrm{k}_{1}} \wedge \ldots \wedge \mathrm{d} \overline{\mathrm{k}}_{\mathrm{k}_{s}}$.

Definition 93. A differential form $\stackrel{\sum}{=} \mathrm{b}_{\mathrm{j}_{1}, \ldots, \mathrm{j}_{r}, \mathrm{k}_{1}, \ldots, \mathrm{k}_{s}}(\mathrm{z}) \mathrm{dz}_{\mathrm{j}_{1}} \wedge \ldots \wedge \mathrm{dz} \mathrm{j}_{\mathrm{j}_{r}} \wedge \mathrm{d} \overline{\mathrm{z}}_{\mathrm{k}_{1}} \wedge \ldots \wedge \mathrm{d} \overline{\mathrm{z}}_{\mathrm{k}_{s}}$ is called a differential form of type $(\mathrm{r}, \mathrm{s})$.

Then a ${ }^{\mathrm{p}}$-form ${ }^{\theta}$ can be expressed in a unique way as 


\section{KÄHLER MANIFOLDS POSITIVE RICCI CURVATURE}

$$
\theta=\sum_{\mathrm{r}+\mathrm{s}=\mathrm{p}} \theta^{\mathrm{r}, \mathrm{s}}
$$

where $\theta^{\mathrm{r}, \mathrm{s}}$ is a form of type $(\mathrm{r}, \mathrm{s})$, It can be shown that the type of a form is independent of the choice of the local complex coordinates. For a function $\begin{aligned} & \mathrm{f} \in C^{1}(\mathrm{U}, \square) \\ & \mathrm{df}=\sum_{\mathrm{i}=1}^{\mathrm{n}} \frac{\partial \mathrm{f}}{\partial \mathrm{z}_{i}} \mathrm{~d} \mathrm{z}_{\mathrm{i}}+\sum_{\mathrm{i}=1} \frac{\partial \mathrm{f}}{\partial \bar{z}_{i}} \mathrm{~d} \overline{\mathrm{z}}_{\mathrm{i}} .\end{aligned}$

We put

$$
\partial \mathrm{f}=\sum_{\mathrm{i}=1}^{\mathrm{n}} \frac{\partial \mathrm{f}}{\partial \mathrm{z}_{i}} \mathrm{dz} \text { and } \bar{\partial} \mathrm{f}=\sum_{\mathrm{i}=1}^{\mathrm{n}} \frac{\partial \mathrm{f}}{\partial \overline{\mathrm{z}}_{i}} \mathrm{~d} \overline{\mathrm{z}}_{i}
$$

In the same way, for an $(\mathrm{r}, \mathrm{s})$ form $\theta$ as in (13) with coefficients in $C^{1}(\mathrm{U}, \square)$, we put

$$
\partial \theta=\sum\left(\partial \mathrm{b}_{\mathrm{j}_{1}, \ldots, \mathrm{j}_{r}, \overline{\mathrm{k}}_{1}, \ldots, \overline{\mathrm{k}}_{\mathrm{s}}}(\mathrm{z})\right) \wedge \mathrm{dz} \mathrm{z}_{\mathrm{j} 1} \wedge \ldots \wedge \mathrm{d} \mathrm{z}_{\mathrm{j}_{r}} \wedge \mathrm{d} \overline{\mathrm{z}}_{\mathrm{k}_{1}} \wedge \ldots \wedge \mathrm{d} \overline{\mathrm{z}}_{\mathrm{k}_{s}},
$$

and

$$
\bar{\partial} \theta=\sum\left(\bar{\partial} \mathrm{b}_{\mathrm{j}_{1}, \ldots, j_{r}, \overline{\mathrm{k}}_{1}, \ldots, \overline{\mathrm{k}}_{s}}(\mathrm{z})\right) \wedge \mathrm{dz} \mathrm{z}_{j 1} \wedge \ldots \wedge \mathrm{dz}_{j_{r}} \wedge \mathrm{d} \bar{z}_{k_{1}} \wedge \ldots \wedge \mathrm{d} \bar{z}_{k_{s}} .
$$

Theorem 72 is equivalent to

$$
H(\Omega)=\left\{\mathrm{f} \in L_{\mathrm{loc}}^{2}(\Omega) \mid \bar{\partial} \mathrm{f}=0\right\} .
$$

Definition 94. A holomoryhic $\mathrm{p}_{\text {-form is a }}(\mathrm{p}, 0)$ form $\omega_{\text {satisfying }} \bar{\partial} \omega=0$.

Remark 95. It is possible to define integration of smooth differential forms on any complex manifold, since it can be shown that every complex manifold is orientable. For a proof, see Kobayashi and Nomizu (1969).

\section{Kähler manifolds}

Definition 96. A Hermitian metric on an almost complex manifold $(\mathrm{M}, \mathrm{J})$ is a Riemannian metric $\mathrm{g}$ which is invariant under the almost complex structure i.e $\left.e_{\mathrm{Y}}\right)$ for all vector fields $\mathrm{X}$ and $\mathrm{Y}$.

Theorem 97. Every paracompact almost complex manifold $(\mathrm{M}, \mathrm{J})$ admits a Hermitian metric.

The proof goes as follows: Let $\mathrm{h}$ be a Riemannian metric on the underlying $C^{\infty}$-manifold $\mathrm{M}$ whose existence is guaranteed by Theorem 36 . Then the metric ${ }^{\mathrm{g}}$ defined by

$$
\mathrm{g}(\mathrm{X}, \mathrm{Y})=\mathrm{h}(\mathrm{X}, \mathrm{Y})+\mathrm{h}(\mathrm{JX}, \mathrm{JY}) \text {. }
$$

for all vector fields $\mathrm{X}, \mathrm{Y}$ is a Hermitian metric. The fundamental $(1,1)$-form associated to the Hermitian metric $\mathrm{g}$ is given by

$$
\omega_{\mathrm{g}}(\mathrm{X}, \mathrm{Y})=\mathrm{g}(\mathrm{X}, \mathrm{JY}) .
$$

A very important class of Hermitian manifolds is given by what we call "Kähler manifolds" .

Definition 98. A Kähler manifold is a pair $(\mathrm{M}, \mathrm{g})$, where $\mathrm{M}$ is a complex manifold and $\mathrm{g}$ is a Hermitian metric whose associated $(1,1)$ form $\omega_{\mathrm{g}}$ is closed, i.e., $\mathrm{d} \omega_{\mathrm{g}}=0$. 


\section{BOUDJEMAA ANCHOUCHE}

Let $(M, g)$ be a Hermitian manifold. Then the Hermitian inner product $g$ in $T_{m} M$ can be extended to a unique complex symmetric bilinear form in the complex tangent space $\mathrm{T}^{\square} \mathrm{M}$ of $\mathrm{M}$. If $\mathrm{X}$ and $\mathrm{Y}$ are two holomorphic $\begin{aligned} \text { vector fields written in the local chart } & \begin{array}{r}\left(U,\left(z_{1}, \ldots, Z_{n}\right)\right) \text { of } M \text { as } \\ X\end{array}=\sum_{i=1}^{n} \xi_{i} \frac{\partial}{\partial z_{i}} \text { and } Y=\sum_{i=1}^{n} \zeta_{i} \frac{\partial}{\partial z_{i}},\end{aligned}$

then

$$
\mathrm{g}(\mathrm{X}, \mathrm{Y})=\sum_{\mathrm{i}, \mathrm{j}=1}^{\mathrm{n}} \mathrm{g}_{\mathrm{i}, \mathrm{j}} \xi_{\mathrm{i}} \bar{\zeta}_{\mathrm{j}}
$$

where

$$
\mathrm{g}_{\mathrm{i}, \overline{\mathrm{j}}}(\mathrm{m})=\mathrm{g}_{\mathrm{m}}\left(\left.\frac{\partial}{\partial \mathbf{z}_{\mathrm{i} \mid}}\right|_{\mathrm{m}},\left.\frac{\partial}{\partial \overline{\mathbf{z}}_{\mathrm{j}}}\right|_{\mathrm{m}}\right) \text {. }
$$

Then the metric is usually written as

$$
g(z)=\sqrt{-1} \sum_{i, j=1}^{n} g_{i, \bar{j}}(z) d z_{i} \otimes d \bar{z}_{j}
$$

The matrix $\left(\mathrm{g}_{\mathrm{i}, \mathrm{j}}(\mathrm{z})\right)_{\substack{1 \leq \mathrm{i} \leq \mathrm{n} \\ 1 \leq \mathrm{j} \leq \mathrm{n}}}$ is a positive definite Hermitian symmetric
given by
\[ \omega_{\mathrm{g}}=\sqrt{-1} \sum_{\mathrm{i}, \mathrm{j}=1}^{\mathrm{n}} \mathrm{g}_{\mathrm{i}, \overline{\mathrm{j}}}(\mathrm{z}) \mathrm{d} \mathrm{z}_{\mathrm{i}} \wedge \mathrm{d} \overline{\mathrm{z}}_{\mathrm{j}} . \]

The length of a tangent vector

$$
\mathrm{X}=\sum_{\mathrm{i}, \mathrm{j}=1}^{\mathrm{n}} \xi_{\mathrm{i}} \frac{\partial}{\partial \mathrm{z}_{\mathrm{i}}} \in \mathrm{T}_{\mathrm{m}} \mathrm{M}
$$

is given by

$$
\|\mathrm{X}\|=\sqrt{\sum_{\mathrm{i}, \mathrm{j}=1}^{\mathrm{n}} \mathrm{g}_{\mathrm{i}, \mathrm{j}}(\mathrm{z}) \xi_{i} \bar{\xi}_{j}}
$$

Theogem $99 \mathrm{og}_{\mathrm{k}, \bar{j}}^{A}$ Hermitian manifold

$$
\frac{\mathrm{g}_{\mathrm{i}, \bar{j}}}{\partial \mathrm{z}}=\frac{\partial \mathrm{g}_{\mathrm{k}, \bar{j}}^{A}}{\partial \mathrm{z}_{i}}
$$

$(\mathrm{M}, \mathrm{g})$ is Kähler if and only if one of the following conditions is satisfied.

(3) For every $\mathrm{m} \in \mathrm{M}$, there exists an open neighborhood $\mathrm{U}$ of $\mathrm{m}$ and a differentiable real junction $\mathrm{f}$ defined in $\mathrm{U}$ such that

$$
\omega_{\mathrm{g} \mid \mathrm{U}}=\sqrt{-1} \partial \bar{\partial} \mathrm{f} \text { i.e., } \mathrm{g}_{\mathrm{i}, \overline{\mathrm{j}}}=\frac{\partial^{2} \mathrm{f}}{\partial \mathrm{z}_{\mathrm{i}} \partial \overline{\mathrm{z}}_{\mathrm{j}}}
$$

There are other equivalent characterization of Kähler manifolds which will not be given here.

Example 100. (1) Every Hermitian manifold of dimension one is necessarily Kähler.

(2) The complex Euclidean space $c^{\mathrm{n}}$ equipped with the "Euclidean" metric 


\section{KÄHLER MANIFOLDS POSITIVE RICCI CURVATURE}

$$
\mathrm{g}_{\mathrm{ec}}(\mathrm{z})=\sqrt{-1} \sum_{i=1}^{\mathrm{n}} \mathrm{d} \mathrm{z}_{i} \otimes \mathrm{d} \bar{z}_{i}\left(\text { resp. } \omega_{g_{e c}}=\sqrt{-1} \sum_{\mathrm{i}, \mathrm{j}=1}^{\mathrm{n}} \mathrm{d} \mathrm{z}_{i} \wedge \mathrm{d} \overline{\mathrm{z}}_{i}\right) .
$$

is a complete Kähler manifold with zero curvature.

(3) The unit ball

$$
\mathrm{B}^{\mathrm{n}}=\left\{\mathrm{z}=\left(\mathrm{z}_{1}, \ldots, \mathrm{z}_{\mathrm{n}}\right) \in \square^{\mathrm{n}} \mid\|\mathrm{z}\|=\sqrt{\sum_{\mathrm{i}=1}^{\mathrm{n}}\left|\mathrm{z}_{i}\right|^{2}}<1\right\},
$$

is a complex manifold which can be endowed with a complete Kähler metric, called the Bergman metric, with negative curvature.

(4) The complex torus $\square^{\mathrm{n}} / \Lambda$, is a Kähler manifold, since it can be shown that the Euclidean metric on $\square^{\mathrm{n}}$ induces a Kähler metric on $\square^{\mathrm{n}} / \Lambda$.

(5) Every complex sub manifold of a Kähler manifold is Kähler, it is enough to take the induced metric.

Example 101. The Fubini-Study metric on $\mathrm{P}^{\mathrm{n}}$.

The projective space $\mathrm{P}^{\mathrm{n}}$ carries acanonical pretric called the Fubini-Study metric and defined as follows (the notations are those of Example 75):

$$
\left[\mathrm{z}_{0}, \ldots, \mathrm{z}_{\mathrm{n}}\right] \mapsto\left(\frac{\mathrm{z}_{0}}{\mathrm{z}_{i}}, \ldots, \frac{\mathrm{z}_{\mathrm{i}-1}}{\mathrm{z}_{\mathrm{i}}}, \frac{\mathrm{z}_{\mathrm{i}+1}}{\mathrm{z}_{\mathrm{i}}}, \ldots, \frac{\mathrm{z}_{\mathrm{n}}}{\mathrm{z}_{i}}\right) .
$$

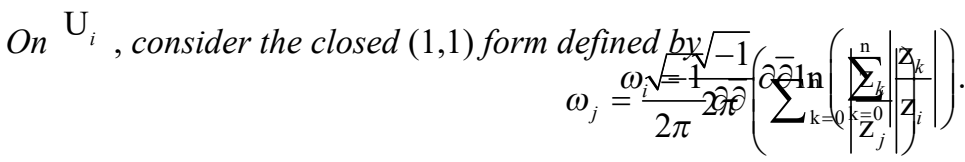

Then on $\mathrm{U}_{i}, \mathrm{U}_{j}$, we have

$$
\begin{aligned}
& =\frac{\sqrt{-1}}{2 \pi} \partial \bar{\partial} \ln \left(\left|\frac{\mathrm{z}_{i}}{\mathrm{z}_{j}}\right|^{2} \sum_{\mathrm{k}=0}^{\mathrm{n}}\left|\frac{\mathrm{z}_{k}}{\mathrm{z}_{i}}\right|\right) \\
& =\frac{\sqrt{-1}}{2 \pi} \partial \bar{\partial} \ln \left(\sum_{\mathrm{k}=0}^{\mathrm{n}}\left|\frac{\mathrm{z}_{k}}{\mathrm{z}_{i}}\right|\right) \\
& =\omega_{i}
\end{aligned}
$$

The last equality is a consequence of the fact that $\frac{\mathrm{z}_{i}}{\mathrm{z}_{j}}$ is a nonvanishing holomorphic function on $\mathrm{U}_{i} \cap \mathrm{U}_{j}$, hence In $\left|\frac{\mathrm{z}_{i}}{\mathrm{z}_{j}}\right|^{2}$ is pluriharmonic, i.e.,

$$
\sqrt{-1} \partial \bar{\partial} \ln \left|\frac{z_{i}}{z_{j}}\right|^{2}=0
$$




\section{BOUDJEMAA ANCHOUCHE}

Therefore we have a global $(1,1)$ form, denoted by $\omega_{\mathrm{FS}}$, defined by

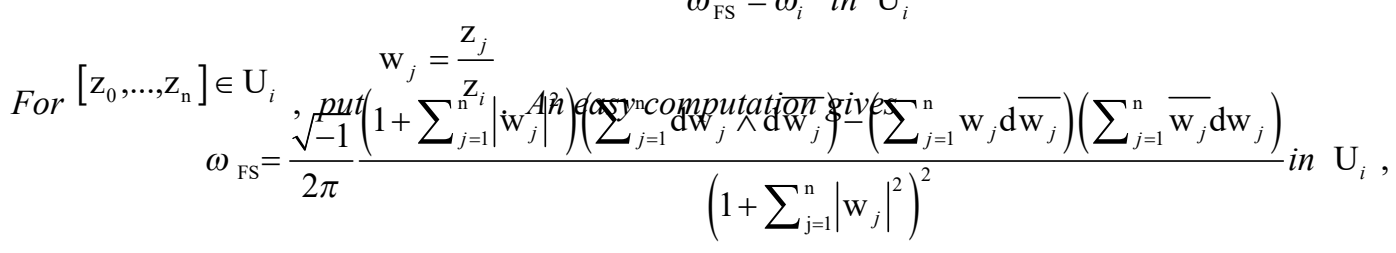

Since the unitary group $\mathrm{U}(\mathrm{n}+1)$ acts transitively on $\mathrm{P}^{\mathrm{n}}$, and since $\omega_{\mathrm{FS}}$ is invariant under $\mathrm{U}(\mathrm{n}+1)$, it is enough to check the positive definiteness of $\omega_{\mathrm{FS}}$ at the pqint ${ }_{\mathrm{n}}^{[1,0, \ldots, 0]}$. But at the point $[1,0, \ldots, 0]$, we have

$$
\omega_{\mathrm{FS}}([1,0, \ldots, 0])=\frac{\sqrt{-1}}{2 \pi} \sum_{\mathrm{j}=1}^{\mathrm{n}} \mathrm{dw}_{j} \wedge \mathrm{d} \overline{\mathrm{w}}_{j}
$$

which is positive definite. Therefore ${ }^{\left(\mathrm{P}^{\mathrm{n}}, \mathrm{g}_{\mathrm{FS}}\right)}$ is a Kähler manifold, where ${ }^{\mathrm{g}_{\mathrm{FS}}}$, called the Fubini-Study metric, is the Kähler metric whose associated $(1,1)$ form is $\omega_{\mathrm{FS}}$.

The Fubini-Study metric can also be described as the Kähler metric $\mathrm{g}_{\mathrm{FS}}$ on $\mathrm{P}^{\mathrm{n}}$ whose associated $(1,1)$ form $\omega_{\text {FS }}$ satisfies

$$
\pi^{*}\left(\omega_{\mathrm{FS}}\right)=\frac{\sqrt{-1}}{2 \pi} \partial \bar{\partial} \ln \left(\sum_{\mathrm{j}=0}^{\mathrm{n}}\left|\mathrm{z}_{j}\right|\right),
$$

where

$$
\begin{aligned}
\pi: \square^{\mathrm{n}+1} \backslash\{0\} & \rightarrow \mathrm{P}^{\mathrm{n}} \\
\left(\mathrm{z}_{0}, \ldots, \mathrm{z}_{\mathrm{n}}\right) & \mapsto\left[\mathrm{z}_{0}, \ldots, \mathrm{z}_{\mathrm{n}}\right]
\end{aligned}
$$

Some basic properties of Kähler manifolds can be summarized in the following

Theorem 102. Let $\mathrm{M}$ be a compact Kähler manifold. Then

(1) $\mathrm{b}_{2 \mathrm{k}}(\mathrm{M}) \geq 1$, where $\mathrm{b}_{2 \mathrm{k}}(\mathrm{M})$ is the $2 \mathrm{k}-$ th Betti number of $\mathrm{M}$.

(2) Every holomoryhic $\mathrm{p}_{\text {-form on }} \mathrm{M}$ is closed.

For a proof, see (Griffiths and Harris, 1978).

\section{Hodge Decomposition}

The following decomposition theorem, called the Hodge decomposition Theorem plays a fundamental role in the understanding of the structure of compact Kähler manifolds. The existence of such decomposition implies restrictions on the topology of compact Kähler manifolds. Some of its corollaries will be used to construct compact complex manifolds without Kähler structure.

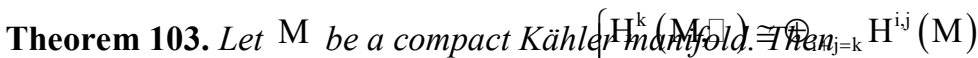

$$
\mathrm{H}^{\mathrm{i}, \mathrm{j}}(\mathrm{M})=\overline{\mathrm{H}^{\mathrm{j}, \mathrm{i}}(\mathrm{M})}
$$




\section{KÄHLER MANIFOLDS POSITIVE RICCI CURVATURE}

where

$$
\mathrm{H}^{\mathrm{i}, \mathrm{j}}(\mathrm{M}) \cong \mathrm{H}^{\mathrm{j}}\left(\mathrm{M}, \Omega_{\mathrm{M}}^{\mathrm{i}}\right)
$$

For the definitions of the spaces $\mathrm{H}^{\mathrm{i}, \mathrm{j}}(\mathrm{M})$ and a proof of Theorem 103, we suggest [21].

As a consequence of Theorem 103, we have the following

Corollary 104. Let $\mathrm{M}$ be a compact Kähler manifold. Then the odd Betti numbers 0. ( $\mathrm{M}$ are even, i.e., $\mathrm{b}_{2 \mathrm{k}+1}(\mathrm{M})$ are even.

The proof of the corollary is straightforward. From (14), we deduce that

$$
\left\{\begin{array}{c}
b_{r}(M)=\sum_{i+j=r} b^{i, j}(M) \\
b^{i, j}(M)=b^{j, i}(M)
\end{array}\right.
$$

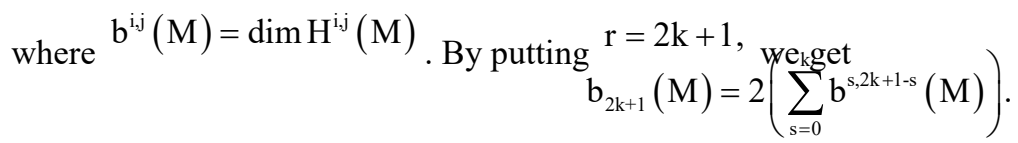

Remark 105. It is very important to mention that not every Hermitian manifold is Kähler, as is shown in the following examples.

Example 106. (1) Let $\mathrm{M} / \mathrm{G}$ be the Iwasawa manifold defined in Example 83. For $\mathrm{A} \in \mathrm{M}$, we have $\mathrm{A}^{-1} \mathrm{dA}=\left(\begin{array}{ccc}0 & 0 & \mathrm{dz}_{2} \\ 0 & 0 & 0\end{array}\right)$

The one-forms $\mathrm{dz}_{1}, \mathrm{dz}_{2}$ and $\mathrm{dz}_{3}-\mathrm{z}_{1} \mathrm{dz}_{2}$ on $\mathrm{M}$ are left invariants under $\mathrm{G}_{\text {and }}$ therefore induce holomorphic one forms on the quotient manifold $\mathrm{M} / \mathrm{G}$. Since $\mathrm{dz}_{3}-\mathrm{z}_{1} \mathrm{dz}_{2}$ is not closed, by Theorem 102 the Iwasawa manifold $\mathrm{M} / \mathrm{G}$ carries no Kähler structure.

(2) Let $\mathrm{M}_{\alpha_{1}, . ., \alpha_{\mathrm{n}}}$ be the Hopf manifold defined in Example 82 and suppose that $n \geq 2$. It can be shown that $\mathrm{M}_{\alpha_{1}, \ldots, \alpha_{\mathrm{n}}}$ is diffeomorphic to $\mathrm{S}^{2 \mathrm{n}-1} \times \mathrm{S}^{1}$. Hence $\mathrm{b}_{1}\left(\mathrm{M}_{\alpha_{1}, \ldots, \alpha_{\mathrm{n}}}\right)=1$, where $\mathrm{b}_{1}\left(\mathrm{M}_{\alpha_{1}, \ldots, \alpha_{\mathrm{n}}}\right)=1$, is the first Betti number of $\mathrm{M}_{\alpha_{1}, \ldots, \alpha_{\mathrm{n}}}$. Then, by Corollary 104, the manifold $\mathrm{M}_{\alpha_{1}, \ldots, \alpha_{\mathrm{n}}}$ carries no Kähler structure.

\section{Projective manifolds}

Definition 107. A projective manifold (or a smooth projective variety) is a closed submanifold of $\mathrm{P}^{\mathrm{n}}$ for some positive integer $n$.

We collect some of the properties of projective manifolds in the following

Theorem 108. (1) If $\mathrm{M}_{1}$ and $\mathrm{M}_{2}$ are projective, then $\mathrm{M}_{1} \times \mathrm{M}_{2}$ is projective.

(2) If $\mathrm{M}$ is projective, then $\tilde{\mathrm{M}}_{\mathrm{m}}$ is projective, where $\tilde{\mathrm{M}}_{\mathrm{m}}$ is the blow-up of $\mathrm{M}$ at $\mathrm{m} \in \mathrm{M}$. 


\section{BOUDJEMAA ANCHOUCHE}

(3) Every compact Riemann surface, i.e., compact complex manifold of dimension one, is projective.

Let $n$ be an integer $\geq 2$. A torus $\mathrm{T}^{\mathrm{n}}=\square^{\mathrm{n}} / \mathrm{G}$ is not necessarily projective (the notations are those of Example $81)$.

Theorem 109. Let $n$ be an integer $\geq 2$. A torus $\mathrm{T}^{\mathrm{n}}=\square^{\mathrm{n}} / \mathrm{G}$ is projective if and only if and only if the lattice A satisfies

$$
\left\{\begin{array}{l}
\text { 1) } \wedge^{\top} J^{-1} \wedge=0 \\
\text { 2) } \sqrt{-1} \wedge^{\top} J^{-1} \wedge>0
\end{array}\right.
$$

for some alternating $2 n \times 2 n$ integral matrix $\mathrm{J}$, where the condition 2) above means that the matrix $\sqrt{-1} \vec{\wedge}^{>} \mathrm{J}^{-1} \wedge$ is positive definite.

Definition 110. A torus $\mathrm{T}^{\mathrm{n}}$ which is a projective variety is called an Abelian variety. Readers who want to know more on Abelian varieties can consult (Birkenhake and Lang, 1992, Griffiths and Harris, 1978 or Mumford,1974) .

Remark 111. Every projective manifold $\mathrm{M}$ is necessarily Kähler, since the restriction of the Fubini-Study metric of $\mathrm{P}^{\mathrm{n}}$ to $\mathrm{M}$ is Kähler. The converse is not true, i.e., not every Kähler manifolds is projective. For example if we take any lattice $\Lambda$ not satisfying the conditions in Theorem 109 , then $\mathrm{T}^{\mathrm{n}}=\square^{\mathrm{n}} / \mathrm{G}$ is Kähler but not projective. Therefore, we have

$$
\{\text { Projective Manifolds }\} \stackrel{\subset}{\subset}\{\text { Compact Kähler Manifolds }\}
$$

Definition 112. A quasi-projective variety is $a$ an open subset (in the Zariski topology) of a projective variety. The readers who want to know more about complex algebraic geometry, can consult the following references: Demailly, ，Griffiths and harris, 1978 or Shafarevich, 1977.

\section{Part 3. Compact Kähler manifolds of positive ricci curvature (Fano Manifolds)}

Compact Kähler manifolds of positive Ricci curvature playa very important role in the classification of complex algebraic varieties. The aim of this section is to give an overview of some of the main results in this area. In all what follows, we will assume some knowledge of sheaf theory, a very nice introduction can be found for example in Kodaira, 1986 or Griffiths and Harris, 1978.

\section{Chern curvature of a hermitian line bundle}

Let $\mathrm{M}$ be a compact complex manifold and consider the following exact sequence of sheaves

$$
0 \rightarrow \square \rightarrow \mathrm{O}_{M} \rightarrow \mathrm{O}_{M}^{*} \stackrel{\exp }{\longrightarrow} 0,
$$

where $\square$ is the constant sheaf, $\mathrm{O}_{M}$ the sheaf of holomorphic functions and $\mathrm{O}_{M}^{*}$ the sheaf of nonvanishing holomorphic functions. The exact sequence (15) induces an exact sequence of cohomology groups

$$
\begin{gathered}
0 \rightarrow \mathrm{H}^{0}(\mathrm{M}, \square) \rightarrow \mathrm{H}^{0}\left(\mathrm{M}, \mathrm{O}_{M}\right) \rightarrow \mathrm{H}^{0}\left(\mathrm{M}, \mathrm{O}_{M}^{*}\right) \rightarrow \mathrm{H}^{1}(\mathrm{M}, \mathrm{)}) \rightarrow \\
\mathrm{H}^{1}\left(\mathrm{M}, \mathrm{O}_{M}\right) \rightarrow \mathrm{H}^{1}\left(\mathrm{M}, \mathrm{O}_{M}^{*}\right) \stackrel{\delta}{\longrightarrow} \mathrm{H}^{2}(\mathrm{M}, \square) \rightarrow \ldots
\end{gathered}
$$




\section{KÄHLER MANIFOLDS POSITIVE RICCI CURVATURE}

The set of holomorphic line bundles on $\mathrm{M}$ constitute a group under the tensor product called the Picard group and denoted by $\operatorname{Pic}(\mathrm{M})$.It can be proved that

Proposition 113. $\mathrm{Pic}(\mathrm{M})$ is isomorphic to $\mathrm{H}^{1}\left(\mathrm{M}, \mathrm{O}_{M}^{*}\right)$. In what follows, we will identify Pic (M) with $\mathrm{H}^{1}\left(\mathrm{M}, \mathrm{O}_{M}^{*}\right)$

Definition 114. The image $\delta(L) \in \mathrm{H}^{2}(\mathrm{M}, \square)$ of a line bundle $L \in \mathrm{H}^{1}\left(\mathrm{M}, \mathrm{O}_{M}^{*}\right)$ is called the first Chern class of $L$ and is denoted by $c_{1}(L)$.

In what follows, we will identify $c_{1}(L)$ to its image in $\mathrm{H}_{\mathrm{DR}}^{2}(\mathrm{M}) \underset{\text { de Rham Isomorphism }}{\text { using tollowing }}$

$$
c_{1}(L) \in \mathrm{H}^{2}(\mathrm{M}, \square) \subset \mathrm{H}^{2}(\mathrm{M}, \square) \stackrel{\text { de Rham Isomorphism }}{\cong} \mathrm{H}_{\mathrm{DR}}^{2}(\mathrm{M})
$$

Definition 115. Let $\mathrm{M}$ be a complex manifold of dimension $n$. The first Chern class of $\mathrm{M}$ denoted by $c_{1}(\mathrm{M})$ is defined by

$$
c_{1}(\mathrm{M}):=c_{1}\left(\mathrm{k}_{\mathrm{M}}^{-1}\right)
$$

where

$$
\mathrm{K}_{\mathrm{M}}^{-1}=\Lambda^{\mathrm{n}} \mathrm{T}^{1,0} \mathrm{M}
$$

is the anticanonicalline bundle of a complex manifold $\mathrm{M}$

Let $(L, \mathrm{~h})$ be a Hermitian line bundle over $\mathrm{M}$, and let $\left(\mathrm{U}_{i}\right)_{\mathrm{i} \in \mid}$ be an open covering of $\mathrm{M}$ such that

$$
L_{\mathrm{U}_{\mathrm{i}}} \stackrel{\tilde{\mathrm{n}} i}{\longrightarrow} \mathrm{U}_{\mathrm{i}} \times \square
$$

is an isomorphism. The point $(\mathrm{M}, \zeta) \in \mathrm{U}_{i} \times \square$ is identified with the point

$$
\tilde{\mathrm{n}}_{j} \mathrm{on}_{i}^{-1}(\mathrm{M}, \zeta)=\left(\mathrm{m}, \mathrm{g}_{j i}(\mathrm{~m}) \zeta\right) \in \mathrm{U}_{j} \times \square .
$$

The functions $\mathrm{g}_{j i}$ are nonvanishing holomorphic functions defined in $\mathrm{U}_{i} \cap \mathrm{U}_{j}$. It is very easy to check that the functions $\left(\mathrm{g}_{j i}\right)_{i, j}$, satisfy the following relation $\left\{\begin{array}{l}\mathrm{g}_{j i} \mathrm{~g}_{i j}=1 \text { in } \mathrm{U}_{i} \cap \mathrm{U}_{j} \\ \mathrm{~g}_{j i} \mathrm{~g}_{i k}=\mathrm{g}_{j k} \text { in } \mathrm{U}_{i} \cap \mathrm{U}_{j} \cap \mathrm{U}_{k}\end{array}\right.$

Conversely, given a set of nonvanishing holomorphic functions

satisfying (17), we can define a line bundle with transition functions $\left(\mathrm{g}_{j i}\right)_{i, j}$, as

follows: We put

$$
L=\left(\amalg_{\mathrm{i}}\left(\mathrm{U}_{\mathrm{i}} \times \square\right)\right) /
$$

where $\amalg$ is the disjoint union, and

$\mathrm{U}_{\mathrm{i}} \times \square \ni(\mathrm{z}, \xi) \square\left(\mathrm{z}^{\prime}, \xi^{\prime}\right) \in \mathrm{U}_{\mathrm{j}} \times \quad$ if and only if $\mathrm{z}=\mathrm{z}^{\prime}$ and $\xi^{\prime}=\mathrm{g}_{i, j}(\mathrm{z}) \xi$.

For each $\mathrm{m} \in \mathrm{M}$, and $\mathrm{v} \in L_{\mathrm{m}}$ we define the norm $\|\mathrm{v}\|_{\mathrm{h}}$ with respect to the metric $\mathrm{h}$ as follows 


\section{BOUDJEMAA ANCHOUCHE}

$$
\|\mathrm{v}\|_{\mathrm{h}}^{2}=|\zeta|^{2} e^{-\varphi_{j}(\mathrm{~m})},
$$

where $i t{ }^{\varphi_{j}}$ is $C^{\infty}$ function defined in $\mathrm{U}_{j}$, and $(\mathrm{m}, \zeta)=\tilde{\mathrm{n}}_{j}(\mathrm{v})$. The definition of ${ }^{\prime}{ }_{i}$ implies that $\varphi_{i}=\varphi_{i}+\ln \left|\mathrm{g}_{i, j}\right|$ in $\mathrm{U}_{i} \cap \mathrm{U}_{j}$.

Since $g_{i, j}$ is a non vanishing holomorphic function, it follows that $\ln \left|g_{i, j}\right|$ is pluriharmonic, i.e.,

$$
\sqrt{-1} \partial \bar{\partial} \ln \left|g_{i, j}\right|=0 \text {. }
$$

Therefore

$$
\sqrt{-1} \partial \bar{\partial}^{\prime}{ }_{i}=\sqrt{-1} \partial \bar{\partial}^{\prime} \quad \text { in } \mathrm{U}_{i} \cap \mathrm{U}_{j},
$$

and hence defines a global $(1,1)$ form on $\mathrm{M}$.

Definition 116. The Chern curvature of the Hermitian line bundle $(L, \mathrm{~h})$, is the real closed $(1,1)$ form given by

$$
\Theta_{\mathrm{h}}=\sqrt{-1} \partial \bar{\partial} \varphi_{\mathrm{i}}
$$

Remark 117. Let $\left\{\mathrm{U}_{i}\right\}_{\mathrm{i} \in \mid}$ and $\left\{g_{i, j}\right\}_{\mathrm{i}, \mathrm{j} \in \mid}$ be as above, and assume that all the intersections $\mathrm{U}_{i} \cap \mathrm{U}_{j}$ are simply connected (if nonempty). Then $L=\left[\left\{\mathrm{g}_{i, j}\right\}\right] \in \mathrm{H}^{1}\left(\mathrm{M}, \mathrm{O}_{M}^{*}\right)$. Since the holomolphic functions $g_{i, j}$ are non vanishing on $\mathrm{U}_{i} \cap \mathrm{U}_{j}$, then choose a branch of $\log g_{i, j}$, which is one valued holomolphic function, and put

$$
\sigma_{i j k}=-\frac{-1}{2 \pi}\left(\log g_{j k}-\log g_{i k}+\log g_{i j}\right)
$$

Then it can be shown that the Chern class $c_{1}(L)$ is given by

$$
c_{1}(L)=\left[\left\{\sigma_{i j k}\right\}\right] \in \mathrm{H}^{2}(\mathrm{M}, \square) .
$$

To state the next theorem we need the following definitions.

Definition 118. Let $\mathrm{M}$ be a complex manifold.

(1) A subset $\mathrm{D}$ of $\mathrm{M}$ is called a hypersurface if for every $\mathrm{m} \in \mathrm{M}$, there exists a neighborhood $\mathrm{U}$ of $\mathrm{m}$ and a nonzero holomolphic function $\mathrm{f}$ on $\mathrm{U}$ such that $\mathrm{D} \cap \mathrm{U}=\{\mathrm{x} \in \mathrm{U} \mid \mathrm{f}(\mathrm{x})=0\}$.

(2) A divisor $\mathrm{D}$ is a formal linear combination of a finite number of irreducible analytic hypersurfaces $\mathrm{D}_{i}$ with integer coefficients i.e.,

$$
\mathrm{D}=\sum_{v} v_{i} \mathrm{D}_{i}, v_{i} \in \square .
$$

(a) The divisor $\mathrm{D}$ is said to be effective if ${ }^{\nu_{i} \geq 0}$, and it is called a reduced divisor if ${ }^{\nu_{i}}=1$ for all $i$.

(b) An effective divisor $\mathrm{D}=\sum_{v} \mathrm{D}_{i}$ is called a simple normal crossing divisor if $\mathrm{D}$ is reduced, each component

$\mathrm{D}_{i}$ is smooth, and for $\mathrm{x} \in \mathrm{D}$, there exist $(\mathrm{U}, \mathrm{z}), \mathrm{x} \in \mathrm{U}$, a local complex chart, such that

$$
\mathrm{U} \cap \dot{\mathrm{D}}=\left\{\mathrm{z} \in \mathrm{U} \mid \mathrm{z}_{1} \ldots \mathrm{z}_{\mathrm{k}}=0\right\}
$$

for some $\mathrm{k} \leq \mathrm{n}$.

To each divisor $\mathrm{D}=\sum_{v} v_{i} \mathrm{D}_{i}$, we can associate a line bundle, denoted $[\mathrm{D}]$ as follows: Let $\left(\mathrm{U}_{\mathrm{j}}, \mathrm{z}\right)$ and $\mathrm{x} \in \mathrm{U}_{\mathrm{j}} \cap \mathrm{U}_{\mathrm{k}}$, be two local coordinate systems and suppose that

$$
\mathrm{U}_{\mathrm{I}} \cap \mathrm{D}_{\mathrm{i}}=\left\{\mathrm{z} \in \mathrm{U}_{\mathrm{I}} \mid \mathrm{f}_{\mathrm{i}}^{\mathrm{I}}(\mathrm{z})=0\right\} ; \mathrm{I}=\mathrm{j}, \mathrm{k},
$$




\section{KÄHLER MANIFOLDS POSITIVE RICCI CURVATURE}

where $\mathrm{f}_{i}^{\prime}$ is a holomorphic function in $\mathrm{U}_{\mathrm{I}}, \mathrm{I}=\mathrm{j}, \mathrm{k}$. Then $\mathrm{f}_{\mathrm{i}}^{\frac{\mathrm{f}_{\mathrm{i}}^{\mathrm{j}}}{\mathrm{f}^{k}}}$ is a nonvanishing function in $\mathrm{U}_{\mathrm{j}} \cap \mathrm{U}_{\mathrm{k}}$ Put

$$
\mathrm{f}_{\mathrm{j}, \mathrm{k}}(\mathrm{z})=\prod_{\mathrm{i}}\left(\frac{\mathrm{f}_{\mathrm{i}}^{j}(\mathrm{z})}{\mathrm{f}_{\mathrm{i}}^{k}(\mathrm{z})}\right)^{v_{i}}
$$

Then it is easy to see that $f_{j, k}$ satisfies the condition (17), and hence are the transition functions of a line bundle.

Definition 119. The line bundle with transition functions $\left\{\mathrm{f}_{\mathrm{j}, \mathrm{k}}\right\}$ defined in 18 is called the line bundle associated to the divisor $\mathrm{D}$ and denoted by $[\mathrm{D}]$.

Remark 120. Over projective algebraic manifolds, every line bundle $L$ is of the form $\left[\mathrm{D}_{L}\right]$ for some divisor $\mathrm{D}_{L}$, i.e.,

$$
L \cong\left[\mathrm{D}_{L}\right]
$$

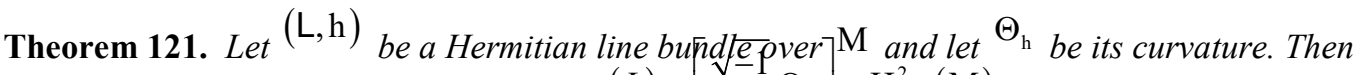

$$
\mathrm{c}_{1}(L)=\left[\frac{\sqrt{-}}{2 \pi} \Theta_{\mathrm{h}}\right] \in \mathrm{H}_{\mathrm{DR}}^{2}(\mathrm{M})
$$

where $\left[\frac{\sqrt{-1}}{2 \pi} \Theta_{\mathrm{h}}\right]_{\text {is the cohomology class of }} \frac{\sqrt{-1}}{2 \pi} \Theta_{\mathrm{h}}{ }_{\text {in }} \mathrm{H}_{\mathrm{DR}}^{2}(\mathrm{M})$. Moreover, $\left[\frac{\sqrt{-1}}{2 \pi} \Theta_{\mathrm{h}}\right]_{\text {is independent of the }}$ choice of the metric $\mathrm{h}$.

For a proof, see Griffiths and Harris (1978).

Definition 122. Let $L \rightarrow \mathrm{M}$ be a line bundle over a compact complex manifold $\mathrm{M}, \operatorname{dim}_{\square} \mathrm{M}=n$ and let $c_{1}(L) \in \mathrm{H}^{2}(\mathrm{M}, \square)$ be the first Chern class of $L$. We say that $c_{1}(L)$ is positive (resp. negative) and write $c_{1}(L)>0$ (resp. $c_{1}(L)<0$ ) if the cohomology class $c_{1}(L)$ can be represented by a $(1,1)$ closed real form $\Omega=\frac{\sqrt{-1}}{2 \pi} \sum_{\mathrm{i}, \mathrm{j}=1}^{\mathrm{k}}{ }_{\mathrm{ij}} \mathrm{dz}_{i} \wedge \mathrm{d} \bar{z}_{j}$

where the matrix $\left(\varphi_{i, \bar{j}}\right)_{\substack{1 \leq i \leq \mathrm{n} \\ 1 \leq \mathrm{j} \leq \mathrm{n}}}$ is positive definite (resp. negative definite) at each point $\mathrm{m} \in \mathrm{M}$. The line bundle $\mathrm{L}$ is said to be positive (resp. negative) if $c_{1}(L)>0$, (resp. $c_{1}(L)<0$ ).

Remark 123. It can be shown that a line bundle $L \rightarrow \mathrm{M}$ over a compact Kähler manifold $\mathrm{M}$ is positive if and only if there exists a Hermitian metric on $L$ with positive curvature.

The expression of the Ricci curvature in the Kähler case is very simple, more precisely we have

Proposition 124. Let $(\mathrm{M}, \mathrm{g})$ be a compact Kähler maxifold, where

$$
\mathrm{g}(\mathrm{z})=\sqrt{-1} \sum_{\mathrm{i}, \mathrm{j}=1} \mathrm{~g}_{\mathrm{i}, \mathrm{j}}(\mathrm{z}) \mathrm{dz}_{i} \otimes \mathrm{d} \overline{\mathrm{z}}_{j}
$$




\section{BOUDJEMAA ANCHOUCHE}

Then

$$
\operatorname{Ric}_{\mathrm{g}}=-\sqrt{-1} \partial \bar{\partial} 1 n\left[\operatorname{det}\left(\mathrm{g}_{\mathrm{i}, \mathrm{j}}\right)\right]
$$

and

$$
\left[\frac{1}{2 \pi} \operatorname{Ric}_{\mathrm{g}}\right]=\mathrm{c}_{1}(\mathrm{M}) \text {, }
$$

where $\left[\frac{1}{2 \pi} \operatorname{Ric}_{\mathrm{g}}\right]$ is the de Rham cohomology class of $\frac{1}{2 \pi} \mathrm{Ri} c_{\mathrm{g}}$

\section{Line bundles on projective spaces}

The aim of this section is to sketch a proof of the fact that the Picard group of $\operatorname{Pic}\left(\mathrm{P}^{\mathrm{n}}\right)$ is an infinite cyclic group and then construct a generator of $\operatorname{Pic}\left(\mathrm{P}^{\mathrm{n}}\right)$.

\section{Proposition 125.}

$$
\operatorname{Pic}\left(\mathrm{P}^{\mathrm{n}}\right) \stackrel{\text { isomorph }}{\cong} \square
$$

Proof. (Sketch of a proof): We start from the following well knfowin ffactd

$$
b_{r}\left(P^{n}\right)=\operatorname{dim}_{\square} H^{r}\left(P^{\mp}, \square\right)=\left\{\begin{array}{l}
1 \text { if } r \text { even }
\end{array}\right.
$$

From (103) and (19), we deduce that $\operatorname{dim}_{\square} \mathrm{H}^{\mathrm{p}}\left(\mathrm{P}^{\mathrm{n}}, \Omega_{\mathrm{p}^{\mathrm{n}}}^{q}\right)=\left\{\begin{array}{lll}0 & \text { if } & \mathrm{p} \neq \mathrm{q} \\ 1 & \text { if } & \mathrm{p}=\mathrm{q}\end{array}\right.$

In particular

$$
\operatorname{dim}_{\square} \mathrm{H}^{\mathrm{p}}\left(\mathrm{P}^{\mathrm{n}}, \mathrm{O}_{\mathrm{P}^{\mathrm{n}}}\right)=0 \text { if } \mathrm{p} \geq 1\left(\text { since } \mathrm{O}_{\mathrm{P}^{\mathrm{n}}}=\Omega_{\mathrm{P}^{\mathrm{n}}}^{0}\right) .
$$

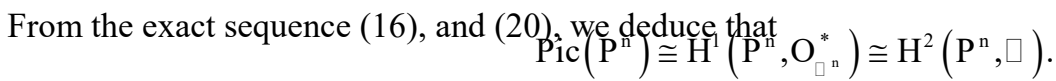

The Proposition follows from the well known fact that $\mathrm{H}^{2}\left(\mathrm{P}^{\mathrm{n}}, \square\right) \cong$

A construction of a generator of $\operatorname{Pic}\left(\mathrm{P}^{\mathrm{n}}\right)$, called the tautological line bundle, goes as follows

Definition 126. The tautological line bundle over $\mathrm{P}^{\mathrm{n}}$, denoted by $\mathrm{O}_{\mathrm{P}^{\mathrm{n}}}(-1)$, is the line subbundle of the trivial bundle $\mathrm{P}^{\mathrm{n}} \times \square^{\mathrm{n}+1}$ defined as follows: $\mathrm{O}_{\mathrm{P}^{\mathrm{n}}}(-1)=\left\{([z], \xi) \in \mathrm{P}^{\mathrm{n}} \times \square^{\mathrm{n}+1} \mid \xi \in \square \mathrm{z}\right\}$

The dual of the line bundle $\mathrm{O}_{\mathrm{p}^{\mathrm{n}}}(-1)$ will be denoted by $\mathrm{O}_{\mathrm{p}^{\mathrm{n}}}(1)$, i.e.,

$$
\mathrm{O}_{\mathrm{P}^{\mathrm{n}}}(-1)^{*}:=\mathrm{O}_{\mathrm{P}^{\mathrm{n}}}(1)
$$

For a positive integer $\mathrm{k}$, we put 


\section{KÄHLER MANIFOLDS POSITIVE RICCI CURVATURE}

$$
\begin{aligned}
& \mathrm{O}_{\mathrm{p}^{n}}(\mathrm{k})=\mathrm{O}_{\mathrm{p}^{n}}(1) \otimes \otimes^{k}=\overbrace{\mathrm{O}_{\mathrm{P}^{n}}(1) \otimes \ldots \otimes \mathrm{O}_{\mathrm{P}^{n}}(1)}^{\mathrm{k} \text {-times }} \\
& \mathrm{O}_{\mathrm{P}^{\mathrm{n}}}(-\mathrm{k})=\mathrm{O}_{\mathrm{P}^{\mathrm{n}}}(-1) \otimes k=\overbrace{\mathrm{O}_{\mathrm{P}^{n}}(-1) \otimes \ldots \otimes \mathrm{O}_{\mathrm{P}^{n}}(-1)}
\end{aligned}
$$

A definition of $\mathrm{O}_{\mathrm{p}^{\mathrm{n}}}(-1)\left(\right.$ resp. $\left.\mathrm{O}_{\mathrm{P}^{\mathrm{n}}}(1)\right)$ in terms of its transition functions is left to the reader. It can be shown that

Proposition 127. The Picard group of $\mathrm{P}^{\mathrm{n}}$ is generated by the line bundle $\mathrm{O}_{\mathrm{P}^{\mathrm{n}}}(1)$, i.e.,

$$
\operatorname{Pic}\left(\mathrm{P}^{\mathrm{n}}\right)=\left\langle\mathrm{O}_{\mathrm{P}^{\mathrm{n}}}(1)\right\rangle
$$

For a proof Proposition 127, see Kodaira (1986).

Remark 128. (1)

(2) If $\mathrm{K}_{\mathrm{P}^{\mathrm{n}}}$ is the canonical line bundle of $\mathrm{P}^{\mathrm{n}}$, then

$$
\mathrm{K}_{\mathrm{p}^{\mathrm{n}}} \cong \mathrm{O}_{\mathrm{P}^{\mathrm{n}}}(-\mathrm{n}-1)
$$
(3) If $\mathrm{D}$ is a spooth hypersurface of degree $\mathrm{d}$ in $\mathrm{P}^{\mathrm{n}}$, i.e.,

where $\mathrm{f}$ is a homogeneous polynomial of degree $\left[\mathrm{d}\right.$ then $\stackrel{[\mathrm{D}] \cong \mathrm{O}_{\mathrm{P}^{\mathrm{n}}}}{(\mathrm{d})}$

Proposition 129. The Fubini-Study $(1,1)$ form ${ }^{\omega}{ }_{\mathrm{FS}}$ on $\mathrm{P}^{\mathrm{n}}$ represents the first Chern class of the line bundle $\mathrm{O}_{\mathrm{P}^{\mathrm{n}}}(1)$, i.e.,

$$
c_{1}\left(\mathrm{O}_{\mathrm{P}^{\mathrm{n}}}(1)\right)=\left[\omega_{\mathrm{FS}}\right]
$$

Therefore, $\mathrm{O}_{\mathrm{P}^{\mathrm{n}}}(1)$ is positive.

Proof. (Sketch of the proof) We will construct a Hermitian metric on the line bundle ${ }_{\mathrm{P}^{\mathrm{n}}}(1)$, and we will show that its curvature coincides with the Fubini-Study metric. Since the fiber of the line bundle $\mathrm{O}_{\mathrm{P}^{\mathrm{n}}}(-1)$ at a point $[\mathrm{z}] \in \mathrm{P}^{\mathrm{n}}$ is given by

$$
\mathrm{O}_{\mathrm{P}^{\mathrm{n}},[\mathrm{z}]}(-1)=\square . \mathrm{z} .
$$

then, we define a Hermitian metric $\mathrm{h}$ on $\mathrm{O}_{\mathrm{P}^{\mathrm{n}}}(-1)$ as follows

$$
\left\|\left(\mathrm{z}_{0}, \ldots, \mathrm{z}_{\mathrm{n}}\right)\right\|_{\mathrm{h}}^{2}=\sum_{\mathrm{i}=0}^{\mathrm{w}}\left|\mathrm{z}_{\mathrm{i}}\right|^{2}
$$

If

$$
\begin{aligned}
s: \quad \mathrm{P}^{\mathrm{n}} \supset \mathrm{U} & \rightarrow \square^{\mathrm{n}+1} \backslash\{0\} \\
\left(\mathrm{z}_{1}, \ldots, \mathrm{Z}_{\mathrm{n}}\right) & \mapsto\left(1, \mathrm{z}_{1}, \ldots, \mathrm{z}_{\mathrm{n}}\right)
\end{aligned}
$$

is a local section, then

$$
\left\|S\left(\mathrm{z}_{0}, \ldots, \mathrm{z}_{\mathrm{n}}\right)\right\|_{\mathrm{h}}^{2}=1+\sum_{\mathrm{i}=1}^{\mathrm{n}}\left|\mathrm{z}_{\mathrm{i}}\right|^{2}
$$




\section{BOUDJEMAA ANCHOUCHE}

The curvature of the metric $\mathrm{h}$ is given by

$$
\AA_{\mathrm{h}^{*}}=-\sqrt{-1} \partial \bar{\partial} \ln \left\|_{\mathrm{s}}\left(\mathrm{s}_{\mathrm{S}}\left(\mathrm{z}_{1}, \ldots, \mathrm{Z}_{\mathrm{n}}\right) \|_{\mathrm{Z}_{1}}^{2}, \ldots, \mathrm{z}_{\mathrm{n}}^{2}\right)\right\|_{\mathrm{h}^{*}}
$$

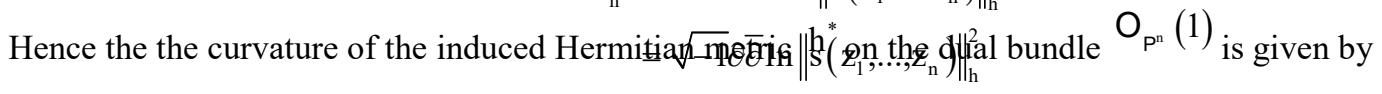

$$
=\sqrt{-1} \partial \bar{\partial} \ln \left(1+\sum_{\mathrm{i}=1}^{\mathrm{n}}\left|\mathrm{z}_{\mathrm{i}}\right|^{2}\right)
$$

It can be shown (see Griffiths and Harris, page 30) that $\ddot{A}_{h}$ (therefore $\ddot{A}_{h^{*}}$ ) is independent of the local lifting (21) .By Theorem 121, the $(1,1)$ form $\frac{\sqrt{-1}}{2 \pi} \ddot{A}_{h^{*}}$ represents the first Chern class of the line bundle $\mathrm{O}_{\mathrm{P}^{\mathrm{n}}}(1)$. Since the Fubini-Study metric $\omega_{\mathrm{FS}}$ on $\mathrm{P}^{\mathrm{n}}$ is equal to $\frac{\sqrt{-1}}{2 \pi} \ddot{\mathrm{A}}_{\mathrm{h}^{*}}$, we deduce that $\omega_{\mathrm{FS}}$ represents the first Chern class of the line bundle $\mathrm{O}_{\mathrm{P}^{\mathrm{n}}}(1)$.

\section{Kodaira embedding theorem}

As was said above, every projective manifolds is Kähler, but the converse is not true. Kodaira's embedding Theorem gives a characterization of projective manifolds among compact Kähler manifolds as those admitting positive line bundles, more precisely we have

Theorem 130. (Kodaira, 1954) (Kodaira Embdding Theorem) Let $(\mathrm{M}, \mathrm{g})$ be a compact Kähler manifold and let $L \rightarrow \mathrm{M}$ be a holomorphic line bundle. Then $L$ is positive if and only if there exists a holomorphic embedding

$$
\begin{aligned}
& \psi: \quad \mathrm{M} \rightarrow \mathrm{P}^{\mathrm{n}} \\
& \mathrm{m} \mapsto \psi(\mathrm{m}),
\end{aligned}
$$

of $\mathrm{M}$ into some projective space such that

$$
\psi^{*}\left(\mathrm{O}_{\mathrm{P}^{\mathrm{n}}}(1)\right)=L^{\otimes v}
$$

for some positive integer $v$.

Proof. (Sketch of a Proof) Suppose that such an embedding $\psi$ exists. Since $\omega_{\mathrm{FS}}$ represents

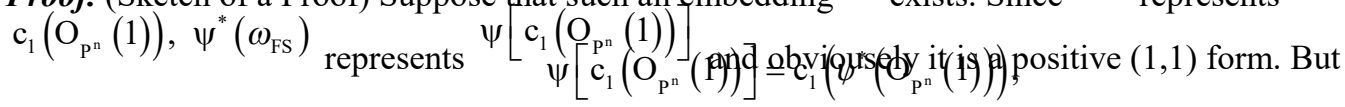

$$
=\mathrm{c}_{1}\left(L^{\otimes v}\right)=v \mathrm{c}_{1}(L) .
$$

Hence $\frac{1}{v} \psi^{*}\left(\omega_{\mathrm{FS}}\right)$ represents $\mathrm{c}_{1}(L)$, i.e., $\mathrm{L}$ is positive.

The converse is hard. For a proof, see (Kodaira, 1954), or (Griffths and Harris, 1978).

Corollary 131. A compact Kähler manifold $(\mathrm{M}, \mathrm{g})$ with positive Ricci curvature is projective.

Proof. By Proposition 124, 


\section{KÄHLER MANIFOLDS POSITIVE RICCI CURVATURE}

$$
\left[\frac{1}{2 \pi} \operatorname{Ric}_{g}\right]=\mathrm{c}_{1}(\mathrm{M})
$$

Hence $\mathrm{K}_{\mathrm{M}}^{-1}$ is positive. The corollary from the Kodaira's Embedding Theorem by taking $L=\mathrm{K}_{\mathrm{M}}^{-1}$.

Definition 132. A holomorphic line bundle $L \rightarrow \mathrm{M}$ over a compact Kähler manifold $\mathrm{M}$ is said to be ample (resp. very ample) if there exists an embedding $\mathrm{M} \stackrel{\psi}{\longrightarrow} \mathrm{P}^{\mathrm{n}}$, for some positive integer $n$ such that $L^{\otimes v}=\psi\left(\mathrm{O}_{\mathrm{p}^{\mathrm{n}}}(1)\right)$ for some positive integer $v\left(\right.$ resp. $\left.L=\psi^{*}\left(\mathrm{O}_{\mathrm{p}^{\mathrm{n}}}(1)\right)\right) \cdot \pi$

Theorem 133. A compact Kähler manifold $(\mathrm{M}, \mathrm{g})$ is projective if and only if there exists a Kähler metric $\mathrm{h}$ (not necessarily equal to ${ }^{g}$ ) such that the cohomology class $\left[\omega_{\mathrm{h}}\right]$ is rational, i.e., $\left[\omega_{\mathrm{h}}\right] \in \mathrm{H}^{2}(\mathrm{M}, \square)$, where $\omega_{\mathrm{h}}$ is the $(1,1)$ form associated to the Kähler metric $\mathrm{h}$.

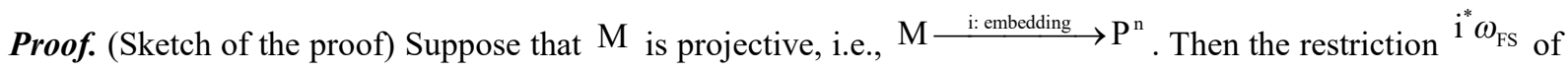
the Fubini-Study metric on $\mathrm{P}^{\mathrm{n}}$ to $\mathrm{M}$ is a Kähler metric on $\mathrm{M}$. Since the Fubini-Study metric is the first Chern class of the autological line bundle $\mathrm{O}_{\mathrm{P}^{n}}(1)$ on $\mathrm{P}^{\mathrm{n}}$, it has integral cohomology class, i.e., $\left[1 \omega_{\mathrm{FS}}\right] \in \mathrm{H}^{2}(\mathrm{M}, \square)$. For the converse, see Griffiths and Harris (1978).

As a consequence of Hodge decomposition Theorem, we have the following

Corollary 134. Let ${ }^{(\mathrm{M}, \mathrm{g})}$ be a compact Kähler manifold satisfying

$$
\mathrm{H}^{2}\left(\mathrm{M}, \mathrm{O}_{\mathrm{M}}\right)=0 \text {. }
$$

Then $\mathrm{M}$ is projective.

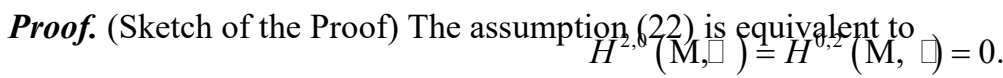

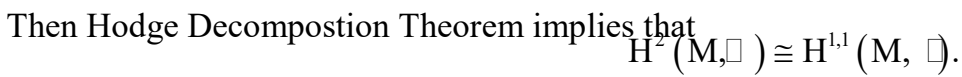

Then there exists $\mathrm{d}_{\text {-closed }}(1,1)$-forms $\theta_{1}, \ldots, \theta_{k}$ on $\mathrm{M}$ such that their cohomology classes $\left[\theta_{1}\right], \ldots,\left[\theta_{k}\right] \in H^{2}(\mathrm{M}, \square)$ and $\left\{\left[\theta_{1}\right], \ldots,\left[\theta_{k}\right]\right\}$ constitute a basis for $\mathrm{H}^{2}(\mathrm{M}, \square)$.Hence, there exists $\mathrm{k}$ real numbers $\alpha_{1}, \ldots, \alpha_{k}$ suh that

$$
\omega_{g}=\sum_{i=1}^{k} \alpha_{i}\left[\theta_{i}\right]
$$

Choose $\mathrm{k}$ rational numbers $\beta_{1}, \ldots, \beta_{k}$ suh that $\beta_{i}$ is very close to ${ }^{\alpha_{i}}$ and consider the following $(1,1)$ form $\varpi=\sum_{i=1}^{1} \beta_{i}\left[\theta_{i}\right]$.

Then $\varpi$ is $d$-closed, positive, and satisfies $[\varpi] \in \mathrm{H}^{2}(\mathrm{M}, \square)$.Theorem 133 implies that $\mathrm{M}$ is projective. 


\section{BOUDJEMAA ANCHOUCHE}

\section{Fano manifolds}

Definition 135. A projective manifold is said to be Fano if $\mathrm{K}_{\mathrm{M}}^{-1}$ is ample, where $\mathrm{K}_{\mathrm{M}}^{-1}$ is the anticanonical line bundle.

Example 136. (1) There is only one Fano manifold of dimension one, it is $\mathrm{P}^{1}$.

(2) Fano manifolds of dimension two are called Del-Pezzo surfaces and are completely classified. They are $\mathrm{P}^{1} \times \mathrm{P}^{1} \times \mathrm{P}^{2}$, and $\mathrm{P}^{2}\left(\mathrm{p}_{1}, \ldots, \mathrm{p}_{k}\right), 1 \leq \mathrm{k} \leq 8$, where $\mathrm{P}^{2}\left(\mathrm{p}_{1}, \ldots, \mathrm{p}_{k}\right)$ is obtained by blowing up $\mathrm{P}^{2}$ at $\mathrm{p}_{1}, \ldots, \mathrm{p}_{k}$ in general position.

(3) The projective space $\mathrm{P}^{\mathrm{n}}$ is a Fano manifold.

(4) Let $\mathrm{M}$ be a smooth complete intersection of $v$ hypersurfages of degree $\mathrm{d}_{1}, \ldots, \mathrm{d}_{v}$ in $\mathrm{P}^{\mathrm{n}}$. Then

$$
\mathrm{K}_{\mathrm{M}}^{-1}=\mathrm{O}_{\mathrm{P}^{\mathrm{n}}}\left(\mathrm{n}+1-\sum_{\mathrm{i}=1} \mathrm{~d}_{i}\right)
$$

In particular, $\mathrm{M}$ is Fano if and only if $\sum_{\mathrm{i}=1}^{v} \mathrm{~d}_{\mathrm{i}}<n+1$.

(5) Let $\mathrm{G}$ be a complex reductive group and $\mathrm{P}$ a parabolic subgroup of $\mathrm{G}$. Then the homogeneous space $\mathrm{M}=\mathrm{G} / \mathrm{P}$ is a Fano manifold.

From the algebro-geometric point of view, a Fano manifold $\mathrm{M}$ is a smooth projective variety with ample anticanonical bundle $\mathrm{K}_{\mathrm{M}}^{-1}$, and from the differential geo- metric point of view, a Fano manifold $\mathrm{M}$ is a compact complex manifold admitting a Kähler metric with positive Ricci curvature. The two definitions are equivalent by Yau's solution of the Calabi conjecture

Theorem 137. (Yau, 1977) A smooth projective variety $\mathrm{M}$ is Fano if and only if $\mathrm{M}$ admits a Kähler metric with positive Ricci curvature.

As was mentioned before, there is close interplay between curvature and topology of a manifold. In the case of a compact Riemannian manifold, we have seen (Theorem 46) that the fundamental group is finite. In the Kähler case we can say more.

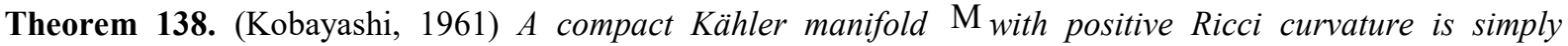
connected, i.e.,

$$
\pi_{1}(\mathrm{M})=0 .
$$

The proof uses the Riemann-Roch-Hirzubruch Theorem, Myer's Theorem, and the following result of Bochner Proposition 139. A compact Kähler manifold of positive Ricci curvature admits no non-zero holomorphic $\mathrm{p}_{\text {_ }}$ forms, for $\mathrm{p} \geq 1$..

For a proof see Kobayashi (1987).

\section{Part 4. Einstein-Kähler metrics on fano manifolds}

Definition 140. (1) A Kähler metric $\mathrm{h}$ on a compact complex manifold $\mathrm{M}$ is said to be Einstein-kähler if

where ${ }^{\mathrm{c}}$ is a constant, ${ }^{\omega_{\mathrm{h}}}$ is the closed $(1,1)$ form associated to the Kähler metric $\mathrm{h}$ and $\mathrm{Ric}_{\mathrm{h}}$ is the Ricci $(1,1)$ form associated to the Kähler metric $\mathrm{h}$.

(2) A compact Kähler manifold $\mathrm{M}$ is said to be Einstein-Kähler if it admits an Einstein-Kähler metric.

One of the main problems related to Fano manifolds and not solved yet is to decide when a compact Kähler manifolds of positive Ricci curvature has an Einstein- Kähler metric. Obstructions to the existence of Einstein- 


\section{KÄHLER MANIFOLDS POSITIVE RICCI CURVATURE}

Kähler metrics on compact Kähler manifolds of positive Ricci curvature were discovered by several mathematicians. Below, we will introduce two obstructions discovered by Matsushima and Futaki and an invariant constructed by Tian.

\section{Matsushima's obstruction}

Let $M$ be a complex manifold. An automorphism (biholomorphism) $F: M \rightarrow M$ of $M$ is a holomorphic map from $M$ to $M_{\text {such that there exists a holomorphic map } G: M \rightarrow M}$ with $G$ oF $=F o G=i d_{M}$, where ${ } d_{M}$ is the identity map of $M$. The set of automorphisms of $M$, denoted by Aut $(M)$, has a structure of a group under the composition of maps. In case the complex manifold $\mathrm{M}$ is compact, we can say more,

Theorem 141. Let $\mathrm{M}$ be a compact complex manifold. Then ${ }^{\mathrm{Aut}(\mathrm{M})}$ is a complex Lie group and its Lie algebra $\mathrm{y}(\mathrm{M})=\operatorname{Lie}(\operatorname{Aut}(\mathrm{M}))$ consists of holomorphic vector fields of $\mathrm{M}$.

For a proof, see (Kobayashi and Nomizu, 1969).

Definition 142. A complex Lie group $\mathrm{G}$ is called reductive if the Lie algebra $\mathrm{g}$ of $\mathrm{G}$ is isomorphic to the

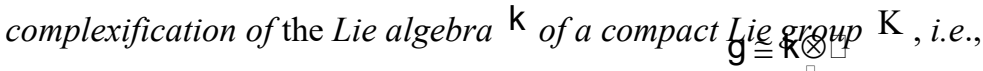

The Lie algebra $\mathrm{k}$ is called a real. form of the Lie algebm $\mathrm{g}$.

Example 143. (1) If $\mathrm{G}=\mathrm{GL}(\mathrm{n}, \square)$, then $\mathrm{G}=\mathrm{K}^{\square}$, where $\mathrm{K}=\mathrm{U}(\mathrm{n})$. Moreover $\mathrm{g}=\mathrm{gl}(\mathrm{n}, \square) \cong \mathrm{M}_{\mathrm{n}}(\square)$, and $\mathrm{k}=u(\mathrm{n})=\left\{\mathrm{A} \in \mathrm{gl}(\mathrm{n}, \square) \mid \mathrm{A}+\mathrm{A}^{*}=0\right\}$.

(2) If $\mathrm{G}=\mathrm{SO}(\mathrm{n}, \square)$, then $\mathrm{G}=\mathrm{K}^{\square}$, where $K=\mathrm{SO}(\mathrm{n})$. Moreover

$\mathrm{g}=\operatorname{so}(\mathrm{n}, \square)=\left\{\mathrm{A} \in \mathrm{gl}(\mathrm{n}, \square) \mid \mathrm{A}+\mathrm{A}^{*}=0\right\}$, and $\mathrm{k}=\left\{\mathrm{A} \in \mathrm{gl}(\mathrm{n}, \square) \mid \mathrm{A}+\mathrm{A}^{\top}=0\right\}$.

(3) If $\mathrm{G}=\mathrm{Sp}(\mathrm{n}, \square)$, then $\mathrm{G}=\mathrm{K}^{\square}$, where $\mathrm{K}=\mathrm{Sp}(\mathrm{n})$. Moreover

$\mathrm{g}=\left\{\mathrm{A} \in \mathrm{gl}(2 \mathrm{n}, \square) \stackrel{\mid}{\left.\mid \mathrm{A}^{\top} \mathrm{J}+\mathrm{JA}=0\right\} \text {, and }} \mathrm{k}=\left\{\mathrm{A} \in \mathrm{gl}(2 \mathrm{n}, \square) \mid \mathrm{A}^{\top} \mathrm{J}+\mathrm{JA}=0\right\}\right.$.

More details about Lie groups (resp. algebraic groups) can be found in (Knapp, 2001) or (Brocker, et al., 1985) (resp. (Borel, 1991) or (Humphreys, 1975).

Theorem 144. (Matsushima, 1957) The automorphism group Aut(M) of a compact Einstein-Kähler manifold of positive Ricci curvature is reductive.

At the level of Lie algebras, Matsushima's theorem says that if $\mathrm{M}$ be a compact Einstein-Kähler manifold with non zero Ricci curvature then the Lie algebra $\mathrm{I}(\mathrm{M})$ of infinitesimal isometries (or Killing vector fields) is a real form of the Lie algebra $\mathrm{h}(\mathrm{M})$ of holomorphic vector fields, i.e.,

$$
\mathrm{h}(\mathrm{M})=i(\mathrm{M}) \oplus \sqrt{-1} i(\mathrm{M}) \text {. }
$$




\section{BOUDJEMAA ANCHOUCHE}

Remark 145. If $c_{1}(\mathrm{M})<0$, then $\operatorname{Aut}(\mathrm{M})$ is finite, and consequently $\mathrm{h}(\mathrm{M})=0$. Therefore Matsushima's Theorem is not obvious only when $c_{1}(\mathrm{M})>0$.

Example 146. (Futaki, 1988$)$ Let $\tilde{\mathrm{P}}^{2}\left(\mathrm{p}_{1}, \mathrm{p}_{2}\right)$ be the projective plane $\mathrm{P}^{2}$ blown up at two points $\mathrm{p}_{1}, \mathrm{p}_{2}$. It can be shown that $\mathrm{P}^{2}\left(\mathrm{p}_{1}, \mathrm{p}_{2}\right)$ is a compact Kähler manifold with positive Ricci curvature whose automorphism group is not reductive, therefore it cannot carry an Einstein-Kähler metric.

In dimension two, the reductivity of $\mathrm{h}(\mathrm{M})$ is the only obstruction to the existence of Einstein-Kiihler metrics as shown by the following result

Theorem 147. (Tian, 1990) Any compact complex surface $M$ with positive Ricci curvature admits an EinsteinKähler metric if $\mathrm{h}(\mathrm{M})$ is reductive.

In higher dimension, there are other obstructions to the existence of Einstein-Kähler metrics besides Matsushima's obstruction.

\section{Futaki's invariant}

For the construction of Futaki's invariant, we need the following

Lemma 148. Let $\theta$ be a real $(\mathrm{p}, \mathrm{p})$ form on a compact Kähler manifold which is cohomologous to zero, i.e., $\theta=\mathrm{d} \beta$. Then there exists a $(\mathrm{p}-1, \mathrm{p}-1){ }_{\text {form }} \eta_{\text {such that }}$

$$
\theta=\sqrt{-1} \partial \bar{\partial} \eta
$$

The proof uses the Hodge Theorem for the $\bar{\partial}$ operator (see [33], Proposition 7.24, for the details).1

Let $\omega_{g}$ be a $(1,1)$ form associated to a Kähler metric $g$ and suppose that $\omega_{g} \in c_{1}(\mathrm{M})$.Then $\frac{1}{2 \pi} \mathrm{Ri} c_{\mathrm{g}}$ represents also $c_{1}(\mathrm{M})$, and by Lemma 14,8 , we have

$$
\frac{1}{2 \pi} \operatorname{Ri}_{\mathrm{g}}-\omega_{g}=\sqrt{-1} \partial \bar{\partial} \mathrm{F}_{\omega_{g}}
$$

where ${ }^{\mathrm{F}_{g}}$ is a global function on $\mathrm{L}_{\mathrm{F}}: \mathrm{M}(\mathrm{M}$ which is defined up to a constant. In (Joyce, 2000), Futaki introduced the following linear functional

$$
\mathrm{X} \mapsto \mathrm{L}_{\mathrm{F}}(\mathrm{X})=\frac{\sqrt{-1}}{2 \pi} \int_{\mathrm{M}} \mathrm{X}\left(\mathrm{F}_{\omega_{g}}\right) \omega_{\mathrm{g}}^{\mathrm{n}}
$$

Theorem 149. (Futaki, 1983) The functional $\mathrm{L}_{\mathrm{F}}$ is independent of the choice of the Kähler form $\omega \in c_{1}(\mathrm{M})$ In particular $\mathrm{L}_{\mathrm{F}}$ is invariant under the automorphism group $\operatorname{Aut}(\mathrm{M})$ of $\mathrm{M}$ and $\mathrm{L}_{\mathrm{F}}$ is a Lie algebra homomorphism. Moreover, if $\mathrm{M}$ admits an Einstein-Kähler metric, then $\mathrm{L}_{\mathrm{F}}$ vanishes identically. 


\section{KÄHLER MANIFOLDS POSITIVE RICCI CURVATURE}

The following example exhibits an example of a compact Kähler manifold $\mathrm{M}$ with positive Ricci curvature such that $\mathrm{h}(\mathrm{M})$ is reductive, but $\mathrm{L}_{\mathrm{F}}$ is not identically

zero.

Example 150. (Futaki, [18]) Let $\mathrm{r}_{\text {and }} \mathrm{S}$ be two positive integers, $\pi_{1}: \mathrm{P}^{r} \times \mathrm{P}^{s} \rightarrow \mathrm{P}^{r}$ the projection to the first factor, and $\pi_{2}: \mathrm{P}^{r} \times \mathrm{P}^{s} \rightarrow \mathrm{P}^{s}$ the projection to the second factor. Let

$$
\mathrm{E}_{\mathrm{r}, \mathrm{s}}=\pi_{1}^{*} \mathrm{O}_{\mathrm{P}^{r}}(1) \oplus \pi_{2}^{*} \mathrm{O}_{\mathrm{P}^{s}}(1) \rightarrow \mathrm{P}^{r} \times \mathrm{P}^{s}
$$

and let $\mathrm{M}_{r, s}$ be the total space of the projective bundle $\mathrm{P}\left(E_{r, s}\right)$. It can be shown that

$$
c_{1}\left(\mathrm{M}_{\mathrm{r}, \mathrm{s}}\right)>0
$$

$\mathrm{h}\left(\mathrm{M}_{\mathrm{r}, \mathrm{s}}\right)_{\text {is reductive, }}$

(3) If $\mathrm{r}=1$ and $\mathrm{s}=2$, then $\mathrm{L}_{\mathrm{F}} \neq 0$.

Therefore $\mathrm{M}_{1,2}$ is a Fano manifold which cannot carry an Einstein-Kähler metric with positive Ricci curvature.

There are other generalizations of Futaki's invariant which we will not consider in this paper.

\section{Tian's invariant}

The vanishing of the Futaki invariant is a necessary condition for the existence of a Einstein-Kähler metric but not a sufficient one. In Tian (1997), Tian constructed a compact Kähler manifold which does not admit any Einstein-Kähler metric even though $\hat{\mathrm{L}}_{\mathrm{F}}=0$.

Let us introduce Tian's invariant: let $(\mathrm{M}, \mathrm{g})$ be a compact Kähler $\sqrt{-1}$ anifold of dimension $\eta$, and let

$$
\mathrm{P}(\mathrm{M}, \mathrm{g})=\left\{\varphi \in \mathrm{C}^{2}(\mathrm{M}, \square) \mid \omega_{\varphi}=\omega_{\mathrm{g}}+\frac{\sqrt{-1}}{2 \pi} \partial \bar{\partial} \varphi>0, \sup _{\mathrm{M}} \varphi=0\right\} \text {, }
$$

where

$$
\omega_{\mathrm{g}}=\sqrt{-1} \sum_{\mathrm{i}, \mathrm{j}=1}^{\mathrm{n}} \mathrm{g}_{\mathrm{i}, \overline{\mathrm{j}}}(\mathrm{z}) \mathrm{d} \mathrm{z}_{\mathrm{i}} \wedge \mathrm{d} \bar{z}_{\mathrm{j}}
$$

is the associated $(1,1)$ form expressed in local holomorphic coordinates, and where $" \omega_{\varphi}>0 "$ means that $\omega^{\prime}$ is a positive definite $(1,1)$ form.

Proposition 151. Let $(\mathrm{M}, \mathrm{g})$ be as above. Then there exists two positive constants $\mathrm{c}$ and a such that

${ }^{c}$ and ${ }^{\alpha}$ such that

$$
\int_{M} \mathrm{e}^{-\alpha^{\prime}(\mathrm{z})} \omega_{\mathrm{g}}^{\mathrm{n}} \leq \mathrm{c},
$$

for all $\varphi \in \mathrm{P}(\mathrm{M}, \mathrm{g})$.

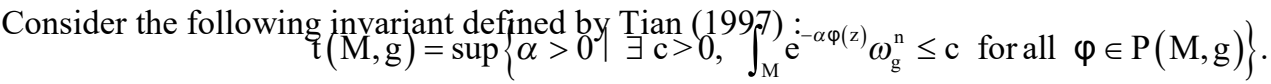




\section{BOUDJEMAA ANCHOUCHE}

Theorem 152. (Tian, 1997) Let $(\mathrm{M}, \mathrm{g})$ be a Fano manifold of dimension ${ }^{n}$, where ${ }^{\omega_{\mathrm{g}}}$ represents the first

Chern class of $\mathrm{M}$, i.e., $\left[\omega_{\mathrm{g}}\right]=c_{1}(\mathrm{M})$. If

$$
\mathrm{t}(\mathrm{M}, \mathrm{g})>\frac{\mathrm{n}}{\mathrm{n}+1},
$$

then $\mathrm{M}$ admits an Einstein-Kähler metric.

Estimates of $\mathrm{t}(\mathrm{M}, \mathrm{g})$ were used by several authors to prove the existence of Einstein-Kähler metrics on certain Fano manifolds.

\section{Uniqueness of einstenin-kähler metrics with positive ricci curvature}

Let $\mathrm{M}$ be a Fano manifold, and let $E K(\mathrm{M})$ be the set of all Einstein-Kähler metrics on $\mathrm{M}$. The automorphism $\operatorname{Aut}(\mathrm{M})$ acts on $E K(\mathrm{M})_{\text {via pull-back. Let }} \operatorname{Aut}_{0}(\mathrm{M})$ be the identity component of $\operatorname{Aut}(\mathrm{M})$.

Theorem 153. (Bando and Mabuchi, 1985) Suppose that $E K(\mathrm{M}) \neq \phi$ and let go be an Einstein-Kähler metric.

Then

$$
E K(\mathrm{M})=\operatorname{Aut}_{0}(\mathrm{M}) \cdot g_{0}
$$

i.e., any Einstein-Kähler metric $g$ is of the form $\psi^{*} \mathrm{~g}_{0}$ for some $\psi \in \mathrm{Aut}_{0}(\mathrm{M})$.

Remark 154. If $\mathrm{h}(\mathrm{M})=0$, then the Einstein-Kähler metric is unique if it exists.

\section{Part 5. Complete noncompact Kähler manifolds of positive ricci curvature}

The structure of noncompact manifolds is richer and at the same time harder to explore than the structure of compact manifolds. Complete noncompact Kähler manifolds of positive ricci curvature are less studied, and therefore less understood compared to Fano manifolds. Nonetheless, lots of partial results have bee proved although a general theory is still missing. In this part, we will survey some of these results, close to the author's interests, obtained on this topic.

\section{Construction of complete kähler metrics of positive ricci curvature}

The problem of existence of complete Kähler metrics of positive Ricci curvature on smooth quasi-projective varieties was considered by several authors, among them S. T. Yau, G. Tian, R. Kobayashi, S. K. Yeung, and others.

By solving certain complex Monge-Ampere equations, where the ideas are close to the ones introduced by Yau in his solution of the Calabi conjecture, G. Tian and S. T. Yau, proved the following Theorem 155. (Tian, Yau 1990) Suppose that $\overline{\mathrm{M}}$ is a smooth complex projective variety $\left(\left(\mathrm{K}_{\overline{\mathrm{M}}} \otimes[\mathrm{D}]\right)^{-}\right)^{\mathrm{M}}$ is a
smooth ample divisor. Let $\Omega$ be any smooth closed $(1,1)$ form in the cohomology class Then

$\overline{\mathrm{M}} \backslash \mathrm{D}$ admits a complete Kähler metric whose Ricci curvature form is equal to the restriction of $\Omega$ to $\overline{\mathrm{M}} \backslash \mathrm{D}$. As a consequence, we get 


\section{KÄHLER MANIFOLDS POSITIVE RICCI CURVATURE}

Corollary 156. Let $\overline{\mathrm{M}}$ and $\mathrm{D} \subset \overline{\mathrm{M}}$ be as above. If $\left(\mathrm{K}_{\overline{\mathrm{M}}} \otimes[\mathrm{D}]\right)^{-1}$ is ample, then $\overline{\mathrm{M}} \backslash \mathrm{D}$ admits a complete Kähler metric with positive Ricci curvature. To state the next Theorem, we need the following

Definition 157. A complete noncompact Kähler manifold $(\mathrm{M}, \mathrm{g})$ of dimension $n \geq 2$ with positive Ricci curvature is said to be of standard type if it satisfies the following three conditions

(2) there exists a constant ${ }^{c_{1}}$ such that for all $\mathrm{r}>0$,

$$
\operatorname{vol}_{g}\left(\mathrm{~B}_{\mathrm{g}}\left(\mathrm{x}_{0}, \mathrm{r}\right)\right)
$$

(3) there exists a constant $c_{2}$ such that for all $\mathrm{mect}(\mathrm{M}) \mid \leq \frac{\mathrm{c}_{2}}{(1+\mathrm{r}(\mathrm{m}))^{2}}$,

where $\operatorname{vol}_{g}\left(\mathrm{~B}_{\mathrm{g}}\left(\mathrm{x}_{0}, \mathrm{r}\right)\right)$ is the volume of the geodesic ball $\mathrm{B}_{\mathrm{g}}\left(\mathrm{x}_{0}, \mathrm{r}\right)$ with respect to the metric $\mathrm{g}$, Ric ${ }_{g}$ is the Ricci $(1,1)$ form associated to the Kähler metric $\mathrm{g}$, and ${ }^{\operatorname{sect}(\mathrm{m})}$ is the sectional curvature of $\mathrm{g}$ at the point $\mathrm{m}$.

Simultaneously with Tian and Yau, using the continuity method for the Monge-Ampere equation, Yeung obtained the following

Theorem 158. (Yeung 1990) If $\mathrm{M}$ is a smooth projective variety with $\operatorname{dim}_{\square} \overline{\mathrm{M}} \geq 2$, and $\mathrm{D}$ is a smooth hypersurface such that the associated line bundles $[\mathrm{D}]_{\text {and }}\left(\mathrm{K}_{\overline{\mathrm{M}}} \otimes[\mathrm{D}]\right)^{-1}$ are positive, then the affine variety $\overline{\mathrm{M}} \backslash \mathrm{D}$ admits a complete Kähler metric of positive Ricci curvature and of standard type.

Example 159. Let $\overline{\mathrm{M}}=\mathrm{P}^{\mathrm{n}}, n \geq 2$ and let $\mathrm{D}$ be a smooth hypersurface in $\mathrm{P}^{\mathrm{n}}$ of degree, where $1 \leq \mathrm{d} \leq n$. Since $[\mathrm{D}]=\mathrm{O}_{\mathrm{P}^{\mathrm{n}}}(\mathrm{d})$ and $\left(\mathrm{K}_{\mathrm{M}} \otimes[\mathrm{D}]\right)^{-1}=\mathrm{O}_{\mathrm{P}^{\mathrm{n}}}(\mathrm{n}+1-\mathrm{d})$ are positive, Yeung's Theorem, (Theorem 158) implies that $\mathrm{M}=\mathrm{P}^{\mathrm{n}} \backslash \mathrm{D}$ admits a complete Kähler metric of positive Ricci curvature and of standard type.

An extension of Kobayashi's result (Theorem 138) to the noncompact case was obtained by Tsuji

Theorem 160. (Tsuji,_1988) Let $\overline{\mathrm{M}}$ be a smooth projective variety and let $\mathrm{D}$ be a simple normal crossing divisor. If $\left(\mathrm{K}_{\overline{\mathrm{M}}} \otimes[\mathrm{D}]\right)$ is ample then $\overline{\mathrm{M}} \backslash \mathrm{D}$ is simply connected, i.e.,

$$
\pi_{1}(\overline{\mathrm{M}} \backslash \mathrm{D})=0
$$

\section{Compactification of complete Kähler manifolds of positive ricci curvature}

One way to approach noncompact complete Kähler manifolds of positive Ricci curvature is to try first to compactify them (if it is possible to do that), i.e., realize them as open subsets, in the Zariski topology, of some projective manifolds, via some "noncompact" version of Kodaira embedding. This was achieved by Mok (1990) for complete Kähler manifolds of positive Ricci curvature and of standard type. More precisely, Mok's result says that 


\section{BOUDJEMAA ANCHOUCHE}

Theorem 161. (Mok, 1990) Let $(\mathrm{M}, \mathrm{g})$ be a complete noncompact Kähler manifold of dimension $n \geq 2$ with positive Ricci curvature and of standard type. Then $\mathrm{M}$ is biholomoryhic to a quasi-projective variety $\overline{\mathrm{M}} \backslash \mathrm{D}$, where $\mathrm{M}$ is a smooth projective variety and $\mathrm{D}=\sum_{\mathrm{j}=0} \mathrm{D}_{\mathrm{j}}$ is a normal crossing divisor. More precisely, there exists a finite set of sections $\left\{\mathrm{s}_{\mathrm{j}}\right\}_{\mathrm{j}}^{\mathrm{n}} \subset \mathrm{H}^{0}\left(\mathrm{M}, \mathrm{K}_{\mathrm{M}}^{-\mathrm{q}}\right)$ of class $L^{2}$ for some positive integer $\mathrm{q}$, where $\mathrm{K}_{\mathrm{M}}^{-1}$ is the anticanonical line bundle, such that

$$
\begin{aligned}
\psi_{\mathrm{q}}: & \mathrm{M} \rightarrow \overline{\mathrm{M}} \subset \mathrm{P}^{\mathrm{n}} \\
\mathrm{m} & \mapsto\left[\mathrm{s}_{0}(\mathrm{~m}), \ldots, \mathrm{s}_{\mathrm{n}}(\mathrm{m})\right],
\end{aligned}
$$

is an embedding, and $\psi_{\mathrm{q}}: \quad \mathrm{M}=\overline{\mathrm{M}} \backslash \mathrm{D}$.

Mok's embedding Theorem says more or less that $\mathrm{K}_{\mathrm{M}}^{-1}$ is "ample" and can therefore be seen as a noncompact analogue of Kodaira's embedding Theorem.

Remark 162. It can be proved, under the assumption of Theorem 161, (see Borel and Serre, 1951) that
$\# \pi_{1}(\mathrm{M})=\# \pi_{1}(\mathrm{M} \backslash \mathrm{D})<+\infty$, and therefore

$$
\mathrm{H}^{0}\left(\mathrm{M}, \Omega \frac{1}{\mathrm{M}}\right)=0
$$

Remark 163. (1) The completeness of the metric in the noncompact case is crucial. All metrics are complete on compact manifolds.

(2) The constmint on the volume growth is natural, since by combining the Calabi-Yau's theorem (Theorem 58) and Bishop's Theorem (Theorem 57), on a complete Riemannian manifold with positive Ricci curvature we have

$$
\mathrm{c}_{1} \mathrm{r} \leq \operatorname{vol}_{\mathrm{g}}\left(\mathrm{B}_{\mathrm{g}}\left(\mathrm{x}_{0}, \mathrm{r}\right)\right) \leq \mathrm{c}_{2} \mathrm{r}^{2 \mathrm{~h}}
$$

(3) An extension of Mok's embedding theorem to the case of a volume growth slower than Euclidean was obtained by To (1991).

\section{Logarithmic kodaira dimension of complete Kähler manifolds of positive ricci curvature}

To introduce the logarithmic Kodaira dimension of $(\overline{\mathrm{M}}, \mathrm{D})$, we need some definitions.

Definition 164. A closed subset $\mathrm{V}$ of a complex manifold $\mathrm{M}, n=\operatorname{dim}_{\square} \mathrm{M}$, is called an analytic subvariety if for every $\mathrm{m} \in \mathrm{M}$, there exists a neighborhood $\mathrm{U}$ of $\mathrm{m}$ and a finite number of holomorphic functions $\mathrm{f}_{1}^{\mathrm{m}}, \ldots, f_{v(\mathrm{~m})}^{\mathrm{m}}$ on $\mathrm{U}$, called defining functions, such that

$$
\mathrm{V} \cap \mathrm{U}=\left\{\mathrm{x} \in \mathrm{U} \mid \mathrm{f}_{1}^{\mathrm{m}}(\mathrm{x})=\ldots=\mathrm{f}_{v(\mathrm{~m})}^{\mathrm{m}}(\mathrm{x})=0\right\} .
$$

A point $\mathrm{m} \in \mathrm{V}$ is called a smooth point, if there exists an open subset $\mathrm{U}^{\prime}$ of $\mathrm{m}$ and defining functions $\mathrm{f}_{1}^{\mathrm{m}}, \ldots, \mathrm{f}_{\mathrm{k}}^{\mathrm{m}}$ in $\mathrm{U}^{\prime}$ such that 


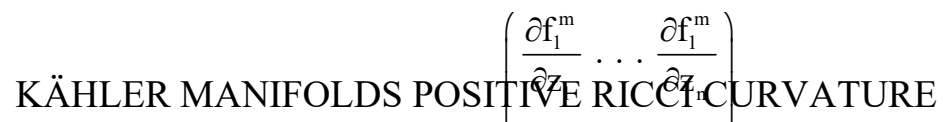

$$
\begin{aligned}
& \operatorname{rank} \frac{\partial\left(\mathrm{f}_{1}^{\mathrm{m}}, \ldots, \mathrm{f}_{\mathrm{k}}^{\mathrm{m}}\right)}{\partial\left(\mathrm{z}_{1}, \ldots, \mathrm{z}_{\mathrm{n}}\right)}=\operatorname{rank}\left(\begin{array}{ccc}
\cdot & \ldots & \cdot \\
\cdot & \ldots & \cdot \\
\cdot & \ldots & \cdot \\
\frac{\partial \mathrm{f}_{\mathrm{k}}^{\mathrm{m}}}{\partial \mathrm{z}_{1}} & \ldots & \frac{\partial \mathrm{f}_{\mathrm{k}}^{\mathrm{m}}}{\partial \mathrm{z}_{\mathrm{n}}}
\end{array}\right)=\mathrm{k} .
\end{aligned}
$$

The integer $\mathrm{k}$ is called the codimension of $\mathrm{V}$ at $\mathrm{m}$. The set of smooth points is denoted by $\mathrm{V}_{\mathrm{sm}}$. It can be proved that if $\mathrm{V}_{\mathrm{sm}}$ is connected, then it is a complex submanifold of $\mathrm{M}$ of dimension $n-\mathrm{k}$, in which case we write $\operatorname{codim}_{\square} \mathrm{V}=\mathrm{k}$.

Remark 165. The defining functions of an analytic subvariety in a neighborhood o.t a point are not unique.

Definition 166. Let $\mathrm{M}$ and $N$ be two projective algebraic manifolds.

(1) A rational map $\Psi$ from $\mathrm{M}$ to $N$, denoted by $\Psi: \mathrm{M}--->N$, is given by a holomorphic map

$$
\psi: \mathrm{M} \backslash \mathrm{V} \rightarrow \mathrm{N} \text {, }
$$

where $\mathrm{V}$ is a subvariety of $\mathrm{M}$, such that $\operatorname{codim}_{\square} \mathrm{V} \geq 2$.

(2) We say that a rational map $\Psi: \mathrm{M} \mathrm{---->N}$ is birational, if there exists a rational map $\phi: \mathrm{N}---->\mathrm{M}{ }_{\text {such }}$ that $\Psi \circ \phi$ is the identity as a rational map.

If such a birational map $\Psi: \mathrm{M}-\mathrm{N}$ exists, then we say that the algebraic manifolds $\mathrm{M}$ and ${ }^{n}$ are

birational.

Let $\phi: \mathrm{M}$---- $>\mathrm{P}^{\mathrm{n}}$ be a rational map defined by a holomorphic map $\phi: \mathrm{M} \backslash \mathrm{V}$---- $>\mathrm{P}^{\mathrm{n}}$,

where $\mathrm{V}$ is a subvariety of $\mathrm{M}$, such that $\left.{ }_{\Gamma_{\psi}}=\{(\mathrm{m}, \phi(\mathrm{m})))^{\prime} \in \mathrm{M} \backslash \mathrm{V} \times \mathrm{P}^{\mathrm{n}}\right\}$.

Denote by $\bar{\Gamma}_{\psi}$ the closure (in the Zariski topology) of $\Gamma_{\psi}$ in $\mathrm{M} \times \mathrm{P}^{\mathrm{n}}$ and by

$$
\pi_{2}: \bar{\Gamma}_{\psi} \rightarrow \mathrm{P}^{\mathrm{n}}
$$

the projection to the second factor. The image $\phi(\mathrm{M})$ of $\mathrm{M}$ is given by

$$
\phi(\mathrm{M})=\pi_{2}\left(\bar{\Gamma}_{\psi}\right) \text {. }
$$

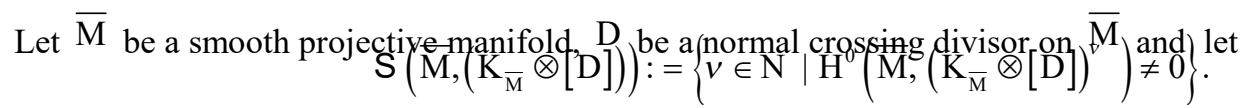

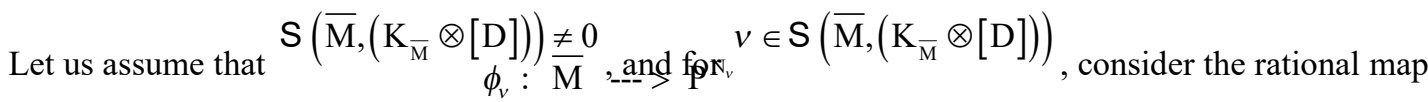

$$
\mathrm{m} \mapsto \phi_{v}(\mathrm{~m})=\left[\varphi_{0}^{v}(\mathrm{~m}), \ldots, \varphi_{\mathrm{N}_{v}}^{v}(\mathrm{~m})\right]
$$

where 


\section{BOUDJEMAA ANCHOUCHE}

$$
\mathrm{N}_{v}=\operatorname{dim}_{\square} \mathrm{H}^{0}\left(\overline{\mathrm{M}},\left(\mathrm{K}_{\overline{\mathrm{M}}} \otimes[\mathrm{D}]\right)^{v}\right)-1,
$$

and

$$
\left\{\varphi_{0}^{v}, \ldots, \varphi_{\mathrm{N}_{v}}^{v}\right\} \text { is a basis for } \mathrm{H}^{0}\left(\overline{\mathrm{M}},\left(\mathrm{K}_{\overline{\mathrm{M}}} \otimes[\mathrm{D}]\right)^{v}\right)
$$

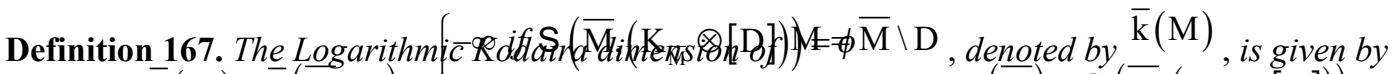

$$
\overline{\mathrm{k}}(\mathrm{M})=\overline{\mathrm{k}}(\overline{\mathrm{M} \backslash \mathrm{D})})=\left\{\begin{array}{l}
\operatorname{dim}_{\square} \phi_{v}(\overline{\mathrm{M}}) \text { if } \mathrm{S}\left(\overline{\mathrm{M}},\left(\mathrm{K}_{\overline{\mathrm{M}}} \otimes[\mathrm{D}]\right)\right) \neq \phi . \\
\left.\max \left(\mathrm{K}_{\overline{\mathrm{M}}} \otimes[\mathrm{D}]\right)\right)
\end{array} \quad\right.
$$

Remark 168. The Logarithmic Kodaira dimension has the following properties: (1) It is independent of the compactification, i.e., if

$$
\mathrm{M} \stackrel{\text { biholomorphic }}{\cong} \bar{M}_{1} \backslash \mathrm{D}_{1} \stackrel{\text { biholomorphic }}{\cong} \overline{\mathrm{M}_{2}} \backslash \mathrm{D}_{2},
$$

where $\overline{\mathrm{M}}_{1}\left(\right.$ resp. $\left.\overline{\mathrm{M}}_{2}\right)$ is a smooth projective variety and $\overline{\mathrm{D}}_{1}\left(\right.$ resp. $\left.\overline{\mathrm{D}}_{2}\right)$ is a normal crossing divisor on $\overline{\mathrm{M}}_{1}\left(\operatorname{resp} . \overline{\mathrm{M}}_{2}\right)$ and if the isomorphism

$$
\overline{\mathrm{M}}_{1} \backslash \mathrm{D}_{1} \stackrel{\text { biholomorphic }}{\cong} \overline{\mathrm{M}}_{2} \backslash \mathrm{D}_{2}
$$

extends to a birational map

$$
\overline{\mathrm{M}}_{1} \stackrel{\text { birational }}{----}>\overline{\mathrm{M}}_{2}
$$

then

$$
\overline{\mathrm{k}}\left(\overline{\mathrm{M}}_{1} \backslash \mathrm{D}_{1}\right)=\overline{\mathrm{k}}\left(\overline{\mathrm{M}}_{2} \backslash \mathrm{D}_{2}\right)
$$

For a proof of (24), see Litaka (1977).

(2) It is not a biholomorphism invariant. For a proof, see Hartshorne (1970).

Theorem 169. (Anchouche, 1998) Let $(\mathrm{M}, \mathrm{g})$ be a complete noncompact Kähler manifold $(\mathrm{M}, \mathrm{g})$ of dimension $n \geq 2$ with positive Ricci curvature and of standard type and let $(\overline{\mathrm{M}}, \mathrm{D})$ be the compactification obtained in Theorem 161. Then

$$
\overline{\mathrm{k}}(\mathrm{M})=-\infty
$$

Proof. (Sketch of the Proof) In all what follows, we identify $\mathrm{M}$ with $\overline{\mathrm{M}} \backslash \mathrm{D}$. Remark first that

$$
\mathrm{H}^{0}\left(\mathrm{M},\left(\mathrm{K}_{\overline{\mathrm{M}}} \otimes[\mathrm{D}]\right)\right) \cong \Upsilon_{v, \mathrm{D}}\left(\mathrm{M}, \mathrm{K}_{\overline{\mathrm{M}}}\right) \text {, }
$$

where $\Upsilon_{v, \mathrm{D}}\left(\overline{\mathrm{M}}, \mathrm{K}_{\overline{\mathrm{M}}}\right)$ is the set of meromorphic sections of $\mathrm{K}_{\overline{\mathrm{M}}}$ which are holomorphic in $\mathrm{M}$ and admitting poles along the divisor $D$ of order at most $v$.

Step1: We establish the following inequality 


\section{KÄHLER MANIFOLDS POSITIVE RICCI CURVATURE}

$$
\int_{\mathrm{B}_{\mathrm{g}}(\mathrm{x}, \mathrm{r})}\|\mathrm{s}\|_{\mathrm{g}}^{\frac{4}{(\mathrm{n}+3) v}} \omega_{\mathrm{g}}^{\mathrm{n}} \leq \mathrm{c}\left(\int_{\mathrm{B}_{\mathrm{g}}(\mathrm{x}, \mathrm{r})}\left(\ln \frac{1}{\Pi_{i=1}^{\mathrm{n}}\left\|\mathrm{S}_{\mathrm{D}_{i}}\right\|_{i}^{2}}\right)^{2} \omega_{\mathrm{g}}^{\mathrm{n}}\right)^{\frac{\mathrm{n}+1}{\mathrm{n}+3}},
$$

where $s \in \mathrm{H}^{0}\left(\overline{\mathrm{M}},\left(\mathrm{K}_{\overline{\mathrm{M}}} \otimes[\mathrm{D}]\right)^{v}\right)$ is the section of the line bundle $\left[\mathrm{D}_{i}\right]$ defining the divisor $\mathrm{D}_{i}$, i.e., $\mathrm{s}_{\mathrm{D}_{i}}^{-1}(0)=D_{i},\left\|\mathrm{~S}_{D_{i}}\right\|_{i}$ is the norm of the section SD, defined by a fixed Hermitian metric hi on the line bundle [Di], and 115111 is the norm of the section $\mathrm{s}$ with respect to the metric on $\mathrm{K}_{\mathrm{M}}$ induced from the metric ${ }^{g}$.

Step 2: Let

$$
\begin{array}{r}
\psi_{1}=-\ln \frac{1}{\prod_{i=1}^{\mathrm{n}}\left\|\mathrm{s}_{\mathrm{D}_{i}}\right\|_{i}^{2}}+\mathrm{c}\left(\mathrm{qu}+\ln \left(\sum_{\mathrm{i}=0}^{\mathrm{n}}\left\|\mathrm{s}_{i}\right\|\right)\right) \\
\psi_{2}=\mathrm{c}\left(\mathrm{qu}+\ln \left(\sum_{\mathrm{i}=0}^{\mathrm{n}}\left\|\mathrm{s}_{i}\right\|\right)\right)
\end{array}
$$

where $\mathrm{u}$ is a solution of the equation $\Delta_{\mathrm{g}} \mathrm{u}=\operatorname{Tr}\left(\mathrm{Ric}_{g}\right)$ (see Mok, 1984), $\Delta_{\mathrm{g}}$ is the Laplacian associated to the Kähler metric ${ }^{\mathrm{g}, \mathrm{c}}$ is chosen in such a way that $\psi_{1}$ and $\psi_{2}$ are subharmonic functions, and ${ }^{\mathrm{s}_{i}}$ are the sections of

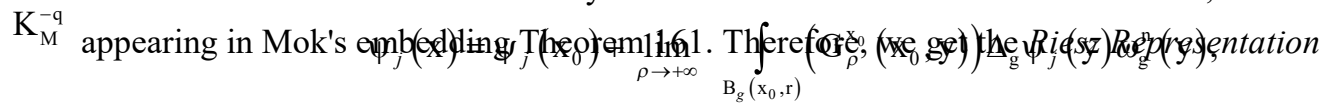

where $\mathrm{G}_{\rho}^{\mathrm{x}_{0}}(.,$.$) is the Green kernel of the geodesic ball \mathrm{B}_{g}\left(\mathrm{x}_{0}, \mathrm{r}\right)$ for the operator $\Delta_{\mathrm{g}}$.

Step 3: There exist a constant ${ }^{\mathrm{c}}{ }_{-\mathrm{cuch} \text { that }} \omega_{\overline{\mathrm{M}}} \leq \sqrt{-1} \partial \bar{\partial} \prod_{i=1}^{\mathrm{n}}\left\|\mathrm{s}_{\mathrm{D}_{\mathrm{i}}}\right\|_{\mathrm{i}}^{2} \leq \mathrm{c} \omega_{\overline{\mathrm{M}}}$,

where $\omega_{\overline{\mathrm{M}}}$ is the Fubini-Study metric on $\overline{\mathrm{M}}$.

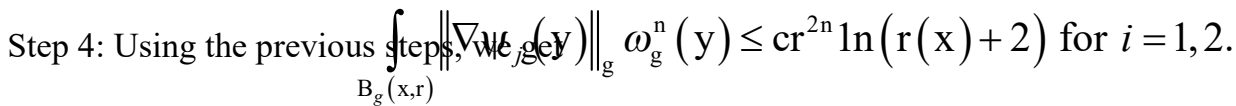

The estimate above is the hardest pat of the proof.

Step 5: Using the inequality obtained in Step 4 and following a şimilar scheme developed by John-Nirenberg, we get $\psi_{j}(\mathrm{y})-\Theta_{j, \mathrm{r}} \|_{\mathrm{g}} \omega_{\mathrm{g}}^{\mathrm{n}}(\mathrm{y}) \leq \mathrm{cr}^{2 \mathrm{n}+\mathrm{z}} \ln ^{2}(\mathrm{r}(\mathrm{x})+\mathrm{r}+2)$ for $i=1,2$.

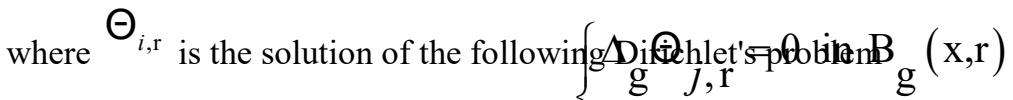

$$
\Theta_{j, \mathrm{r}} \mid \partial \mathrm{B}_{\mathrm{g}}(\mathrm{x}, \mathrm{r})=\psi_{j}
$$




\section{BOUDJEMAA ANCHOUCHE}

Step 6: using the previous steps, we get

$$
\|\mathrm{S}(\mathrm{x})\| \frac{4}{(n+3) v} \leq \mathrm{c} \frac{\left[\mathrm{r}^{2 \mathrm{n}+2}\left(\mathrm{c}_{\mathrm{x}}+\ln ^{2}(\mathrm{r}+\mathrm{r}(\mathrm{x})+2)\right)\right]^{\frac{\mathrm{n}+1}{\mathrm{n}+3}}}{\mathrm{r}^{2 \mathrm{n}}}
$$

where the constants $c$ and $c_{\mathrm{x}}$ are independent of $\mathrm{r}$. Since $\mathrm{n} \geq 2$, the theorem is obtained by letting $\mathrm{r} \rightarrow+\infty$. For more details, see Anchouche (1998).

The vanishing theorem above puts a lot of restriction on the structure of the manifold $\mathrm{M}$, for example if we assume that $\operatorname{dim}_{\mathrm{C}} \mathrm{M}=2$ then, as a consequence of Theorem 169 and Miyanishi's classification of open algebraic surfaces [40], we obtain the following

Theorem 170. (Anchquehe, 1998) Let $\mathrm{M}$ be a complete Kähler surface of positive Ricci curvature and of standard type, and let $(\mathrm{M}, \mathrm{D})$ be the compactification obtained in Theorem 161. Then

(1) $\overline{\mathrm{M}}$ is a rational surface.

(2) Each component ${ }^{\mathrm{j}}$ of $\mathrm{D}_{\text {is a smooth rational curve, i.e., }} \mathrm{D}_{\mathrm{j}}$ is isomoryhic to $\mathrm{P}^{1}$.

(3) $\mathrm{D}$ is a tree.

(4) None of the components $\mathrm{D}_{\mathrm{j}}$ is exceptional.

The Theorem above is a consequence of Theorem 169 and Miyanishi's classifi- cation of quasi projective surfaces of logarithmic Kodaira dimension $-\infty$. The fact that the Kähler manifold $M$ is of infinite volume implies part (4) of the Theorem 170.

In [2], it has been shown that the $\mathrm{L}^{2}$ sections of the line bundle $\mathrm{K}_{\mathrm{X}}^{-\mathrm{q}}$, and the volume form of the metric $g$ have no essential singularities near the divisor at infinity $\mathrm{D}$. As a consequence we obtain a comparison between the form forms of the complete Kähler metric $g$ and the Fubini-Study metric of the compactification. In the case of $\operatorname{dim}_{C} X=2$, we establish a relation petween the number of components of the divisor $D$ and the dimension of the logarithmic groups

$$
\mathrm{H}^{\mathrm{i}}\left(\underline{\mathrm{X}}, \Omega \frac{\mathrm{x}}{\mathrm{X}}(\log \mathrm{D})\right) \text {. }
$$

\section{Acknowledgement}

The author is grateful to the referees for their suggested corrections and improvements. One of them has kindly sent us a very detailed report. We take this opportunity to express our deep gratitude and appreciation to him. Last, but not least, I want to thank Profs. M. S. Narasimhan, S. Veldsman and Dr. M. Benrhouma for reading the paper and for their comments.

\section{References}

ANCHOUCHE, B. 1998. Sur la dimension logarithmique de Kodaira des varietes Kählcriennes com- pletes de courbure de Ricci positive. Math Zeit. 227: 403-421.

ANCHOUCHE, B. On the Asymptotic behavior of complete Kähler metrics of positive ricci curvature and of standard type. In preparation, 2007.

AUBIN, T. A course in differential geometry. Graduate studies in mathematics, 27. AMS, Providence, Rhode Island 2001. 


\section{KÄHLER MANIFOLDS POSITIVE RICCI CURVATURE}

BANDO, S. and MABUCHI, T. 1985. Uniqueness of einstein-Kähler metrics modulo connected group actions, Algebraic, Geometry, Sendai, Adv. Studies in Pure Math. 10 (1987).

BEAUVILLE, A. 2006. Riemannian holonomy and algebraic geometry, http://math.unice.fr/ beauvill/pubs/rha.pdf.

BERGER, M. 2000. Riemannian geometry during the second half of the twentieth century. University Lecture Series. 17. AMS.

BERGER, M. 1953. Sur les groupes d'holonomie des varieties connections et des varieties Riemanninnes. Bul. Soc. Math. Franc 83: 279-330.

BIRKENHAK, C. and LANG, H. 1992. Complex abelian varieties. Grundlehren der mathematischen wissenschaften 302. Springer Verlag.

BISHOP, R.L. and CRITTENDEN, R. 1964. Geometry of manifolds, New York, Academic Press.

BOREL, A. 1991. Linear algebraic groups. Second edition. Graduate Texts in Mathematics, 126. SpringerVerlag, New York.

BOREL, A. and SERRE, J.P. 1951. Determination des puissance reduites de Steenrod dans la cohomoloie des groups classiques, Applications, C.R. Acad. Sci. Paris 233: 680-682.

BROCKER, T. and TOM DIECK, T. 1985. Representations of compact lie groups. Graduate texts in mathematics 98, Springer Verlag.

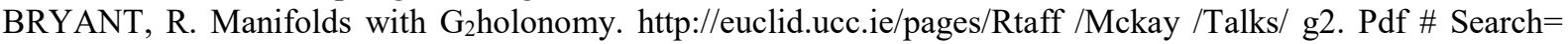
$\% 22$ bryant $\% 20$ holonomy $\% 20$ group $\% 22$.

CHAVEL, I. 1995. Riemannian geometry, A modern introduction. Cambridge University Press, 108.

DEMAILLY, J.P. Complex analytic and algebraic geometry. http://www-fourier.ujf-grenoble.fr $/ \sim$ demailly /books.html.

DE RHAM, G. 1952. Sur la reducibilite d'un espace de Riemann, Commm. Math. Helv. 26: 328-344.

FUTAKI, A. 1983. An Obstruction to the Existence of Einstein Klthler Metrics. Invent. Math.73: 437-443.

FUTAKI, A. 1988. Klthler-Einstein metrics and integral invariants. (Lect. Notes Math., vol. 1314) Berlin, Heidelberg New York: Springer.

GALlOT, S. HULIN, D. and LAFFONTAINE, J. 1990. Riemannian Geometry. Springer-Verlag, Second edition.

GREENBERG, M. 1967. Lectures on Algebraic Topology. Benjamin, New York.

GRIFFITHS, P. and HARRIS, J. 1978. Principles of algebraic geometry. John Wiley \& Son's Inc.

HARTSHORNE, R. 1970. Ample subvarieties of algebraic varieties. Lect. Notes Math., Vol 156, Springer verlag.

HELGLTSON, S. 1978. Differential geometry, lie groups, and symmetric spaces. Academic Press., Inc.

HUMPHREYS, J. 1975. Linear Algebraic Groups Springer Verlag (Graduate Texts in Mathematics).

LITAKA, S. 1977. On logarithmic Kodaira dimension of algebraic varieties. Complex anal. and Alg. Geom. A collection of papers dedicated to Kodaira. Cambridge University Press,

JOYCE, D. 2000. Compact manifolds with special holonomy. Oxford mathematical monographs series, Oxford University Press,

JOYCE, D. 1996. Compact 8-manifolds with holonomy Spin(7), Inventiones mathematicae 123: 507-552.

JOYCE, D. 1996. Compact riemannian 7-manifolds with holonomy $\mathrm{G}_{2}$. Journal of differential geometry 43: 291-328.

KNAPP, A.W. 2001. Lie groups beyond an introduction. Progress in mathematics 140. Birkhauser.

KOBAYASHI, S. 1961. On compact Kähler manifolds with positive ricci tensor, Ann. of Math. 74: 570-574.

KOBAYASHI, S. and NOMIZU, K. 1969. Foundation of differential geometry, volumes I \& II. John Wiley \& Sons.

KOBAYASHI, S. 1995. Transformation groups in differential geometry. Classics in mathematics, SpringerVerlag.

KOBAYASHI, S. 1987. Differential geometry of complex vector bundles. Iwanami Shoten Publisher and Princeton University Press. 


\section{BOUDJEMAA ANCHOUCHE}

KODAIRA, K. 1986. Complex manifolds and deformation of complex structures. Classics in mathematics. Springer Verlag.

KODAIRA, K. 1954. On Klthler varieties of restricted type. Ann. of Math. 60: 28-48.

KOLLAR, J. and MORI, S. 1998. Birational Geometry of Algebraic Varieties, Cambridge University Press.

LOHKAMP, J. 1994. Metrics of negative Ricci Curvature. Ann. of Math. (2) 140(3): 655-683.

MABNCHI, T. 1986. K-energy Maps Integrating Futaki Invariants. Tohoku Math. J., 38: 245-257.

MATSUSHIMA, Y. 1957. Sur la structure du groupe d'homeomorphismes analytiques d'une certaine variete Kählerienne. Nagoya Math. J. 11: 145-150.

MIYANISHI, M. Open algebraic surfaces. CRM monograph series. AMS, volume 12, 2001.

MOK, N. 1984. An embedding Theorem of complete Kähler manifolds of positive bisectional curvature onto affine algebraic varieties. Dull. Soc. Math. de France. 112: 197-258.

MOK, N. 1990. An embedding Theorem of complete Kähler manifolds of positive Ricci curvature onto quasiprojective varieties. Math. Ann. 286: 373-408.

MOK, N., SIU, Y.T. and YAU, S.T. 1981. Poincare-Lelong equation on complete Kähler manifolds. Compo Math. 44: 183-218.

MORGAN, J.W. and TIAN, G. 2007. Ricci flow and the poincare conjecture, Clay Mathematics Monographs. American Mathematical Society.

MUMFORD, D. 1974. Abelian varieties, Second Edition, Tata Lecture Notes, Oxford University Press, London.

MUNKRES, J.R. 1975. Topology, a first course. Prentice-Hall Inc.

MYERS, S.D. 1941. Riemannian manifolds with positive mean curvature. Duke Mat. J. 8: 401-404.

NEWLANDER, A. and NIRENBERG, L. 1957. Complex analytic coordinates in almost complex manifolds, Ann. of Math., 65: 391-404.

OHSAWA, T. 2002. Analysis of several complex variables. Translations of mathematical Monographs, volume 211.

SHAFAREVICH, I.R. 1977. Basic algebraic geometry. Springer-Verlag.

SALAMON, S. 1989. Riemannian geometry and holonomy groups. Longman Scientific \& Technical.

TIAN, G. and YAU, S.T. 1990. Complete Kähler manifolds with zero Ricci curvature. I.J. Amer. Math. Soc. 3 (3): 579-609.

TIAN, G. 1990. On Calabi's conjecture for complex surfaces with positive first Chern class. Invent. Math., 101 172.

TIAN, G.1997. Kähler Einstein manifolds with positive scalar curvature. Inv. Math. 137: 1-37.

W.K.TO, 1991. Quasi-projective embedding o noncom pact complete Kähler manifolds of positive Ricci curvature and satisfying certain topological conditions. Duke Math. J. 63: 745-789.

TSUJI, H. 1988. Logarithmic Fano Manifolds are simply connected. Tokyo J. Math 11(2): 359-362.

YAN, S.T. 1978. On the Ricci curvature of a compact Kähler manifold and the Monge-Ampere equation, $I$. Comm. Pure Appl. Math. 31(3): 339-411.

YEUNG, S.K. 1990. Complete Kähler manifolds of positive Ricci curvature. Math. Z. 204: 187-208.

WARNER, F.W. 1983. Foundations of differentiable manifolds and lie groups. Graduate Texts in Mathematics 94, Springer verlag.

Received 7 December 2006

Accepted 10 October 2007 